Review

\title{
Luminescence in Sulfides: A Rich History and a Bright Future
}

\section{Philippe F. Smet ${ }^{1, *}$, Iwan Moreels ${ }^{2}$, Zeger Hens ${ }^{2}$ and Dirk Poelman ${ }^{1}$}

1 LumiLab, Department of Solid State Sciences, Ghent University, Krijgslaan 281-S1, Gent, Belgium; E-Mail: dirk.poelman@ugent.be (D.P.)

2 Physics and Chemistry of Nanostructures, Department of Physical and Inorganic Chemistry, Ghent University, Krijgslaan 281-S3, Gent, Belgium; E-Mails: iwan.moreels@ugent.be (I.M.); zeger.hens@ugent.be (Z.H.)

* Author to whom correspondence should be addressed; E-Mail: philippe.smet @ ugent.be; Tel.: +32-9-264-4353; Fax: +32-9-264-4996.

Received: 8 April 2010 / Accepted: 18 April 2010 / Published: 21 April 2010

\begin{abstract}
Sulfide-based luminescent materials have attracted a lot of attention for a wide range of photo-, cathodo- and electroluminescent applications. Upon doping with $\mathrm{Ce}^{3+}$ and $\mathrm{Eu}^{2+}$, the luminescence can be varied over the entire visible region by appropriately choosing the composition of the sulfide host. Main application areas are flat panel displays based on thin film electroluminescence, field emission displays and ZnS-based powder electroluminescence for backlights. For these applications, special attention is given to $\mathrm{BaAl}_{2} \mathrm{~S}_{4}: \mathrm{Eu}, \mathrm{ZnS}: \mathrm{Mn}$ and $\mathrm{ZnS}: \mathrm{Cu}$. Recently, sulfide materials have regained interest due to their ability (in contrast to oxide materials) to provide a broad band, $\mathrm{Eu}^{2+}$-based red emission for use as a color conversion material in white-light emitting diodes (LEDs). The potential application of rare-earth doped binary alkaline-earth sulfides, like $\mathrm{CaS}$ and $\mathrm{SrS}$, thiogallates, thioaluminates and thiosilicates as conversion phosphors is discussed. Finally, this review concludes with the size-dependent luminescence in intrinsic colloidal quantum dots like $\mathrm{PbS}$ and $\mathrm{CdS}$, and with the luminescence in doped nanoparticles.
\end{abstract}

Keywords: sulfides; photoluminescence; electroluminescence; phosphor; rare earth; nanocrystals; quantum dots; europium; cerium; light emitting diodes; persistent luminescence; storage phosphor 
In this Review, we discuss the rich and longstanding history of sulfide phosphor materials, dating back from at least the 17th century. Progress in the understanding of the basic principles of luminescence culminated in several typical applications, uniquely based on sulfides, such as $\mathrm{ZnS}$ based powder electroluminescence and thin film electroluminescence. Turning towards the $21 \mathrm{st}$ century, sulfide-based nanoparticles and color conversion phosphors possess several characteristic properties which give them a bright future as well.

The paper is structured as follows:

1. Sulfide phosphors: A short history

2. Electroluminescent powders

3. Lamp and CRT phosphors

4. Thin film electroluminescence

5. Color conversion phosphors

6. Persistent and storage phosphors

7. Luminescent sulfide nanoparticles

8. Conclusions

\section{Sulfide phosphors: A Short History}

Luminescent phenomena have fascinated mankind since the earliest times. The light from the aurora borealis, glow worms, luminescent wood, rotting fish and meat are all examples of naturally occurring luminescence. The effect was shrouded in mystery, and described accordingly in the Middle Ages and beyond. The earliest written account of a solid state luminescent material comes from a Chinese text published in the Song dynasty (960-1279 A.D.), referring to a book (never recovered) from the period 140-88 B.C. It describes a painting of a cow grazing outside. In the dark, the cow would have been seen resting inside a barn [1,2]. Possibly, the ink used was the first man-made persistent phosphor material. Harvey [3] presents an excellent account of these early observations far beyond the scope of the present review.

The first artificial phosphor described in Western literature dates from 1603. Then, the Italian shoemaker and alchemist Vincenzo Cascariolo used the natural mineral barite $\left(\mathrm{BaSO}_{4}\right)$, found near Bologna, in an effort to create gold. After heating the ground stone under reducing condition heobviously - did not obtain gold, but a persistent luminescent material. This so-called Bolognian stone became famous and a subject of study and admiration for decades to come [3]. It is not clear which dopant or dopants were actually responsible for the persistent luminescence, but the host material [2] definitely was BaS. While not made intentionally but by serendipity, BaS thus is the first sulfide phosphor ever synthesized. The name phosphor (from the Greek 'light bearer') was already used at that time, even if the chemical element phosphorous was only isolated in 1669 (from urine) by the German alchemist Hennig Brand [1]. Phosphorous becomes luminescent under moist conditions, when it oxidizes. Thus, phosphorous is chemiluminescent and the name phosphorescence for persistent 'glow in the dark' photoluminescence is actually a bit of a misnomer [4].

In the following centuries, many scientists synthesized and investigated luminescent materials, but it was too early for a systematic study. However, the synthesis of $\mathrm{CaS}$ as a phosphor in 1700 by Friedrich Hoffmann and of SrS in 1817 by J. F. John are worth mentioning. Curiously enough, the 
luminescent properties of $\mathrm{ZnS}$, which was going to become one of the most important luminescent hosts in the 20th century, were not recognized until 1866, when the so-called Sidot blend (hexagonal $\mathrm{ZnS}$ ) was developed by Theodor Sidot [5]. In 1888, Eilhard Wiedemann was the first to classify different classes of phosphors according to the type of excitation, and is credited for introducing the terms luminescence, photoluminescence, electroluminescence, thermoluminescence, crystalloluminescence, triboluminescence and chemiluminescence [6].

\section{Electroluminescent Powders}

Already in 1907, H. J. Round published light emission from a silicon carbide junction diode, the first light emitting diode (LED) ever. Independently, Losev observed emission from $\mathrm{ZnO}$ and $\mathrm{SiC}$ diodes, as published in 1927 [7]. However, as LED's are injection electroluminescent devices and contain no phosphors, we will not deal with this kind of devices further on.

Destriau is credited for the discovery of phosphor-based high field electroluminescence in solids in 1936 [8]. The original Destriau cell consisted of a Cu-doped ZnS powder in castor oil, insulated from one of the electrodes by a mica sheet. The applied AC voltage was very high and the light emission very poor, leading to the suspicion that the actual light emission was not due to electroluminescence by excitation of the $\mathrm{ZnS}: \mathrm{Cu}$, but due to the photoluminescence of the $\mathrm{ZnS}: \mathrm{Cu}$, excited by the $\mathrm{UV}$ emission of electrical discharges in gases in the porous powders [4,9]. In the following years, planar electroluminescent devices were developed, helped by the availability of $\mathrm{SnO}_{2}$ as a transparent conductor. EL panels were incorporated for dashboard back illumination from the late 1950's, for example in the Chrysler Imperial 1960 luxury car. In an effort to reduce the size and energy consumption of displays, 7 segment electroluminescent numerical displays were used in the Apollo program DSKY (display panel and keyboard) module instead of the traditional nixie tubes. Quite luckily for the developers of EL devices, the repeated failures of a segment of this display during the Apollo 11 mission were later attributed to a faulty driving circuit [10] and not to problems with the display itself.

Many research groups were active in the research on powder EL, but especially the contributions by Thornton [11], Piper and Williams [12], and Vecht [13] should be noted. The research on powder EL has been marked by periods of intense research and success followed by periods of disillusion and discouragement. At the beginning and the middle of the 1960s, a series of books and book chapters gathered the - now largely forgotten - knowledge accumulated during the former phase [14-21].

AC powder electroluminescent devices (ACPEL devices in short) typically consist of a doped $\mathrm{ZnS}$ powder suspended in a dielectric binder, sandwiched between electrodes and supported on a substrate. The substrate can be metallic or insulating (glass or plastic). An additional white reflecting layer could provide additional electric protection and improved light output from the device.

Similar DCPEL devices require a highly conductive surface layer for current injection into the phosphor particles. Devices are prepared using $\mathrm{Cu}$ concentrations higher than the solubility limit in $\mathrm{ZnS}$. While the surface excess $\mathrm{Cu}$ is washed away in the case of ACPEL devices, it is converted into an inhomogeneous conductive layer using an electrically-assisted forming process. Several models have been proposed on the exact mechanism of this process, but there is evidence of the formation of needle-like $\mathrm{Cu}_{2-\mathrm{x}} \mathrm{S}$ phases. As $\mathrm{Cu}_{2-\mathrm{x}} \mathrm{S}$ is p-type and $\mathrm{ZnS}$ is weakly n-type, this could lead to an 
improved carrier injection in the $\mathrm{ZnS}$ particles. In addition, DCPEL phosphors require a very monodisperse and small particle size in order to limit current inhomogeneity and electric breakdown. Copper is thus essential in all DCPEL devices, acting both for current injection and as a light emitting dopant. Next to copper, manganese has been used extensively as a dopant in both AC and DC powder EL devices, improving brightness and increasing the possible color gamut.

DCPEL panels are - in principle - ideally suited for graphical displays. A few commercial applications have emerged, which are now superseded by other display technologies. There is very little recent research interest in DCEL. A detailed review on DCEL devices was written by Chadha [9].

AC powder electroluminescent devices are still used in the niche application of very thin, low light level, low cost, large area background lights on flexible substrates, such as electronic gadgets, cell phones, remote controls and car radios. A number of issues prevent their widespread use:

- The absolute brightness is quite low. As large areas can emit quite homogeneously, the total light output can be considerable, but making a sunlight readable device, requiring high surface brightness, is a problem.

- The lifetime of moderate to high luminance devices is limited. The brightness of an ACPEL device can be increased by increasing the applied voltage, but this in turn decreases the lifetime. Thus a low luminance device can last for many 1000s of hours, but this lifetime decreases drastically at increased luminance. With improvements in technology, a lifetime of about $2500 \mathrm{~h}$ (at $50 \%$ relative luminance) with an initial luminance of $100 \mathrm{~cd} / \mathrm{m}^{2}$ can now be achieved [22]. Probably, the degradation is related to diffusion of copper or blunting of the copper needles in the phosphor layer, but this is still a matter of debate. Chen et al. showed that the degradation rate increases at higher operating temperatures and almost drops to zero when operated at $-67{ }^{\circ} \mathrm{C}$, suggesting diffusion related degradation [23]. Heating of degraded devices to $200{ }^{\circ} \mathrm{C}$ leads to a partial rejuvenation [24].

- The stability, and thus the lifetime, is highly dependent on the encapsulation of the layers. As these are moisture sensitive, they should be very well shielded from the ambient. First, the layers were encapsulated as a whole, but more recently, micro-encapsulation has been performed, the particles being coated individually. Obviously, this kind of additional process increases the cost of the material.

- The overall external efficiency of ACPEL devices is very low, of the order of only a few $1 \mathrm{~m} / \mathrm{W}$, which makes the technology unsuited for general lighting applications, and certainly not a match for CFL's (compact fluorescent lamps) and LEDs.

As $\mathrm{ZnS}: \mathrm{Cu}$ is the only material for efficient powder $\mathrm{EL}$, there seems little room for drastic improvements in device performance. At best, powder EL will remain a technology for blue-green the emission color being frequency dependent - background lighting for undemanding applications. A recent review on ACPEL can be found here [25].

\section{Lamp and CRT Phosphors}

Starting before the Second World War, many new luminescent materials were developed for fluorescent lighting. In a fluorescent lamp, the ultraviolet emission of an electrical discharge of a low pressure mercury vapor is converted to visible light by phosphor materials, covering the inside of the 
lamp. Sulfide phosphors are of no use in this kind of fluorescent lamps, since they react with mercury [26].

Since the advent of high performance flat panel displays a few years ago, any treatment of CRT (cathode ray tube) phosphors is - almost by definition - of historical interest. After its discovery by Braun in 1897, the CRT has had tremendous success. One of the first CRT images (the Japanese Katakana character "i") was shown in 1926 by Takayanagi. First screens were black and white, later full color displays were taken into production, thanks to the development of a large number of highly optimized possible phosphor materials [2,26]. For blue cathodoluminescence, ZnS:Ag has been the material of preference since the beginning. It has a very efficient emission due to a donor acceptor transition: the donor level being due to an aluminum or chlorine co-dopant and the acceptor level due to silver [26]. This kind of process implies that the emission wavelength is not determined by the nature of the dopants, but by the band gap of the host. By making a solid solution of $\mathrm{ZnS}$ and $\mathrm{CdS}$, the spectrum of $\mathrm{Zn}_{1-\mathrm{x}} \mathrm{Cd}_{\mathrm{x}} \mathrm{S}$ :Ag could be tuned from a peak wavelength of 450 to $620 \mathrm{~nm}$ [4]. Thus, both green and red emitting phosphors could be made using this technique. Nowadays, such Cd-containing compounds have become unacceptable for environmental reasons. For the green phosphor, $\mathrm{ZnS}: \mathrm{Cu}$ (codoped with $\mathrm{Al}$ or $\mathrm{Cl}$ ) is routinely used. For the red one, the line emission from $\mathrm{Eu}^{3+}$ was found to be an ideal compromise between optimum color coordinates and eye sensitivity [26]. The host of choice for red emission is $\mathrm{Y}_{2} \mathrm{O}_{2} \mathrm{~S}$. Many other cathodoluminescent phosphors were developed for specific applications, like projection displays (high excitation current), field emission displays (FED) (low voltage, high current) and flying spot equipment (fast decay times). Their study and description is outside the scope of this review. A recently compiled list of CRT and FED phosphors can be found here $[27,28]$.

\section{Thin Film Electroluminescence}

\subsection{Working principle}

In parallel with the development of powder EL, a new type of device, using a thin film phosphor, was presented by Vlasenko and Popkov in 1960 [29]. The device used ZnS:Mn as the active layer and was much brighter than an equivalent powder EL lamp. However, stability was a problem due to the very high electric fields, needed to drive the device. This problem was largely solved by Russ and Kennedy in 1967, who proposed a double-insulated structure, protecting the active layer from destructive dielectric breakdown [30]. The resulting device structure, which is still used to date, is shown schematically in Figure 1.

When a voltage is applied over the electrodes, it is capacitively divided between the two insulators and the central active layer. As both insulating layers and active layer have a large band gap, there are a negligible number of free electrons and holes available and no current is flowing. However, there are a number of allowed energy levels at the insulator-active layer interfaces (appropriately called interface states). To a certain extent, these are filled with electrons. When the electric field is high enough, of the order of $1-2.10^{8} \mathrm{~V} / \mathrm{m}$, the energy bands are tilted and Fowler-Nordheim tunneling of the electrons at the cathodic interface into the conduction band of the active layer becomes possible. These electrons are then accelerated to high energies by the high electric field, and can impact/excite the activator ions in the central layer. When the activator ion returns into the ground state, light is 
emitted. The active layer thus acts as a 'leaky' capacitor in these high fields, and electrons are transported from the cathodic to the anodic insulator-active layer interface. This charge transfer creates an additional electric field opposite to the applied field, therefore the tunneling, charge transfer and light emission stop after some time, usually after some microseconds. Quasi continuous light emission is obtained by AC driving of the device: a short light pulse is emitted at each polarity switch of the applied voltage. A much more detailed discussion of the physics of these ACTFEL (AC thin film electroluminescent) devices was given by Mach and Mueller [31-33] and Rack and Holloway [34].

Figure 1. M(etal)-I(nsulator)-S(emiconductor)-I(nsulator)-M(etal) structure used for thin film electroluminescence displays (color online).

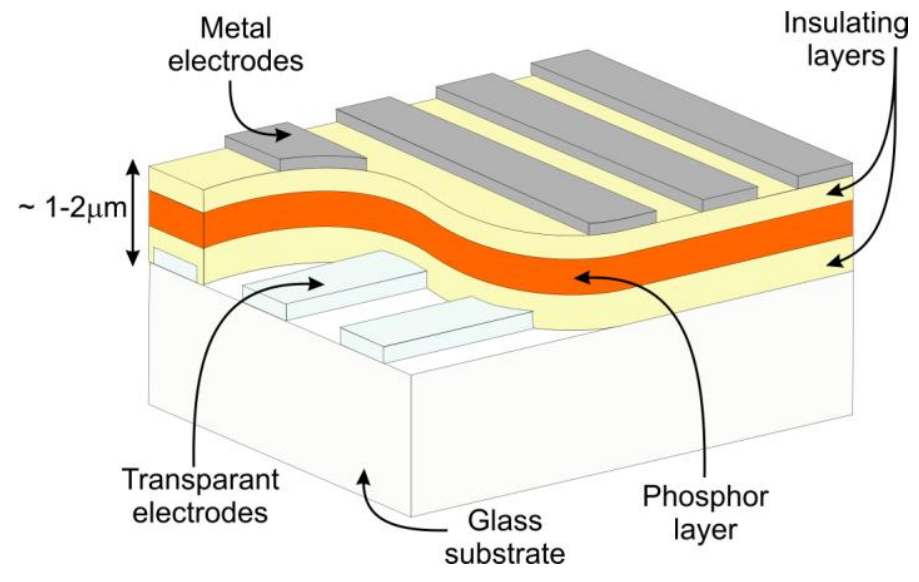

Curiously enough, it lasted until 1974 before an ACTFEL display using the device structure of Russ and Kennedy was presented [35]. In the following years, several companies started producing monochrome orange emitting displays based on $\mathrm{ZnS}: \mathrm{Mn}$, some of which are still being made. While this kind of display cannot offer the visual performance and display size of other modern flat panel display technologies, it does serve a niche market where its unique properties are needed:

- ACTFEL displays can have an unsurpassed lifetime of the order of 50.000 hours.

- As this is a fully solid state display, it can be made very rugged to withstand harsh environments, in industrial, medical, military or aviation applications.

- The tunneling mechanism, which is the cornerstone of the device operation, is essentially independent of temperature. Therefore, these displays can be made to work at extremely low and high temperatures, the temperature range of the drive electronics being the main limiting factor. An EL device has been reported to work down to $15 \mathrm{~K}$ [36].

- ACTFEL is an emissive display technology; therefore, the viewing angle can be very large, of the order of $170^{\circ}$, both horizontally and vertically.

- If transparent conductors are used for both top and bottom electrodes in Figure 1, the entire display can be made transparent [37].

- The active layer is very thin - of the order of $500 \mathrm{~nm}$ - therefore the display resolution can be high. A microdisplay with a pixel pitch of $24 \mu \mathrm{m}$ was presented by Planar Systems [38]. 
The main drawback of ZnS:Mn ACTFEL displays was the lack of full color capability. Multicolor displays can be made by filtering the wide orange wavelength distribution of the $\mathrm{ZnS}$ :Mn emission to green and red [39], but RGB full color is impossible (Figure 2).

Figure 2. Emission spectrum of (a) $\mathrm{BaAl}_{2} \mathrm{~S}_{4}: \mathrm{Eu}$ [40], (b) $\mathrm{SrS}: \mathrm{Ce}, \mathrm{Cl}$ and (c) $\mathrm{ZnS}: \mathrm{Mn}$ [41].

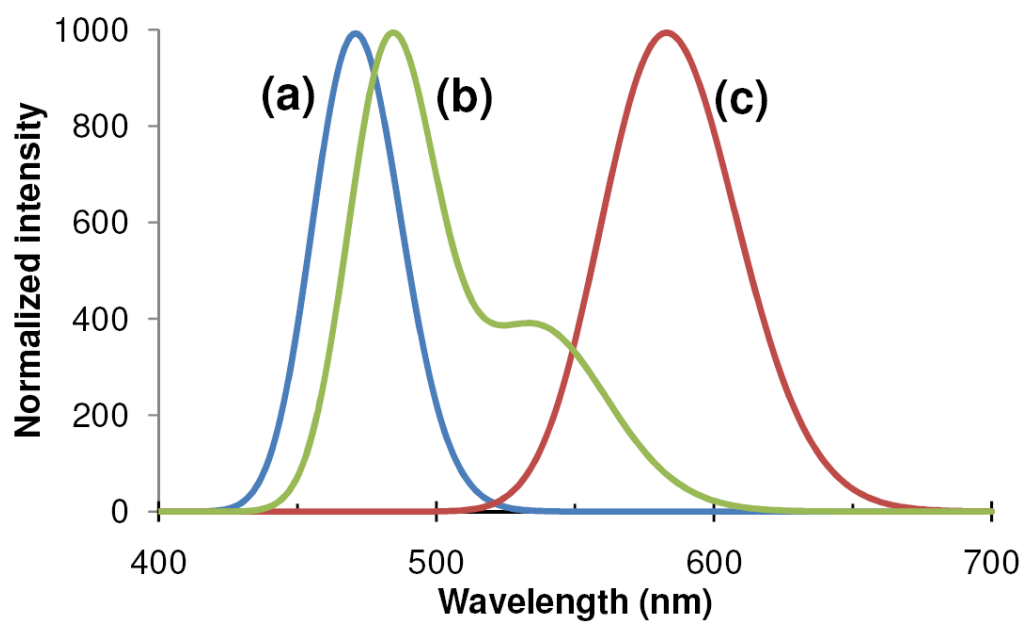

\subsection{Towards full-color EL}

In a first effort to obtain different emission colors, the $\mathrm{Mn}$ dopant in $\mathrm{ZnS}$ was replaced by trivalent rare earth luminescent centers [42-44], notably Tb, Er, Dy, Sm, Nd, Tm, Ho and Pr. The emission from these ions is due to well shielded $4 \mathrm{f}-4 \mathrm{f}$ transitions, giving rise to sharp emission peaks. As the size of the trivalent rare earth ions typically is much larger than that of the $\mathrm{Zn}$ cation in $\mathrm{ZnS}$, it is not easy to incorporate these ions substitutionally, although higher dopant concentrations can be obtained in thin films compared to single crystals or bulk powders. For most of the rare earth ions, a rather weak emission was observed. Only ZnS:Tb (efficient green emission) [45,46], ZnS:Sm (weak red emission) [47] and ZnS:Ho (white) [48] have received some interest in later years. For ZnS:Tb, the efficiency was increased by codoping with fluorine [42] and it was shown that actually TbOF centers were formed [49], thus conserving charge neutrality.

Alternative hosts for luminescent dopants were found by returning to the well known sulfide phosphors from the 19th century. Indeed, the basic requirements for the active layer in an ACTFEL device are [50-52]:

- A wide band gap semiconductor is needed, as it has to be transparent to the emitted light. However, the band gap should not be too high, allowing avalanche multiplication processes.

- The dopant chosen should show an efficient emission under high electric fields, which excludes donor-acceptor based emission. Therefore ions with internal transitions are preferred, such as encountered in $\mathrm{Mn}^{2+}$ and the rare earth ions (both $4 \mathrm{f}-4 \mathrm{f}$ and $5 \mathrm{~d}-4 \mathrm{f}$ emittors).

- The host's cation size should match the size of the dopant ions to facilitate the substitutional incorporation in the host lattice. In addition, its oxidation state should preferably be the same as that of the dopant, although charge compensating co-dopants can be used. The ideal concentration of the dopants depends on the type of dopant, but is typically in the order of $1 \%$. At higher concentration, 
non-radiative decay becomes more important because of an increased energy transfer between dopant ions. Also, high dopant concentrations can distort the host lattice thus lowering the excitation efficiency. This will especially be important for dopant ions with deviating valence state and/or ionic radius compared to the substituted ion.

- A very important parameter, which precludes the use of almost all oxides, is the need for a crystalline layer. In the applied electric field, electrons should be accelerated ballistically [53]. If the layer is amorphous, electrons are scattered at numerous grain boundaries and thus cannot gain sufficient energy to impact/excite the activator ions. While sulfides quite easily crystallize at moderate temperatures (around $500{ }^{\circ} \mathrm{C}$ ), very high processing temperatures are typically needed for crystallizing oxide materials. Another effect favors the use of sulfide materials. At high electric fields (in the order of $\mathrm{MV} / \mathrm{cm}$ ), electron-phonon interaction is the main scattering mechanism. Hence, host compounds having low optical-phonon energies are favored. Benalloul et al. compared phonon energies of sulfides and oxides and observed significantly lower values for sulfides compared to oxides [54]. The optical-phonon energy for $\mathrm{ZnS}(44 \mathrm{meV})$ is similar to the one in $\mathrm{BaAl}_{2} \mathrm{~S}_{4}$ (30-40meV) [55], both being efficient EL hosts.

In the middle of the 1980s it became clear that rare earth doping of $\mathrm{ZnS}$ would not lead to sufficiently bright EL materials. As a result, several new activator-host combinations were tested and found to yield bright emission, CaS:Ce (green) [56], SrS:Ce (blue-green) [57], CaS:Eu (red) [58] and $\mathrm{SrS}: \mathrm{Eu}$ (orange) [59] being the most successful combinations. In these phosphors, the luminescent ions are $\mathrm{Eu}^{2+}$ and $\mathrm{Ce}^{3+}$. Within the range of rare earth ions, they are exceptional in the sense that the luminescent electronic transition is due to a $5 \mathrm{~d}-4 \mathrm{f}$ transition, which is not well shielded from the crystal field of the host lattice. This has two effects: first of all, the emission has a broadband spectrum and secondly, the emission spectrum can be influenced by changing the host. Since several of the sulfides form solid solutions in all compositions, without any phase change, it became possible to tune the color coordinates of the emission by changing the ratio of the components in the solid solution. This fact was employed successfully in $\mathrm{Ca}_{1-\mathrm{x}} \mathrm{Sr}_{\mathrm{x}} \mathrm{S}: \mathrm{Eu}$ (orange to red) $[60,61], \mathrm{CaS}_{1-\mathrm{x}} \mathrm{Se}_{\mathrm{x}}$ :Eu (orange to red) [62,63] and $\mathrm{SrS}_{1-\mathrm{x}} \mathrm{Se}_{\mathrm{x}}$ :Ce (blue to blue-green) [64-66]. The research on the latter two hosts was, however, abandoned due to the high toxicity of $\mathrm{H}_{2} \mathrm{Se}$ [67], which is liberated upon exposure of the material to moisture.

The subsequent research into improving material quality led to a prototype of a full color computer monitor type display by Planar in 1993 [68]. The way in which this display was constructed, shows the state of the art and the remaining problems at that time: The red and green pixels of the display used filtered ZnS:Mn emission, and the blue phosphor was filtered SrS:Ce. A major drawback of SrS:Ce for display applications is indeed the broad emission spectrum from $\mathrm{Ce}^{3+}:$ the effective emission spectrum is blue-green, and the green component has to be filtered out to obtain saturated blue (Figure 2). In the prototype display in 1993, not only the size of the SrS:Ce pixels was larger than that of the ZnS:Mn pixels, but also the drive frequency of the SrS:Ce pixels was higher, both tricks meant to obtain a sufficiently intense blue emission.

In the following years, most research on ACTFEL phosphors was devoted to improving the intensity, color purity and stability of the blue component. As most sulfide phosphors are hygroscopic [69], reactions with the ambient and with the insulating layers had to be prevented. Secondly, due to 
the low sticking coefficient of sulfur, films prepared by PVD (physical vapor deposition) methods were sulfur deficient. This fact was usually overcome by co-evaporation of sulfur or reactive deposition in an $\mathrm{H}_{2} \mathrm{~S}$ atmosphere. Thirdly, films deposited at low temperature by PVD processes were amorphous. In order to obtain polycrystalline layers, high substrate temperatures or post-deposition annealing treatments [70] had to be used. Finally, while the most straightforward PVD technique for sulfide films is electron beam evaporation, alternative techniques such as magnetron sputtering [71] and ALD (atomic layer deposition) [72,73] were also employed, allowing a better control of the thin film properties.

In the early 1990s, when it was realized that the (filtered) blue emission intensity in SrS:Ce remained low, research efforts were directed towards ternary sulfide hosts. The ternary thiogallates $\mathrm{CaGa}_{2} \mathrm{~S}_{4}$ and $\mathrm{SrGa}_{2} \mathrm{~S}_{4}$ were proposed as a new class of promising TFEL phosphors, doped with Ce or $\mathrm{Eu}[74,75]$. However, these materials did not provide a real breakthrough of ACTFEL technology due to the difficulty to prepare high quality thin films that allowed sufficient electron acceleration.

In 1997, SrS:Cu and SrS:Cu,Ag were investigated for the first time as blue-emitting ACTFELphosphors $[36,66,76,77]$. In contrast to the situation of $\mathrm{Cu}$ as a dopant in $\mathrm{ZnS}$, where a donor-acceptor transition is taking place, the emission was found to result from an internal transition of the $\mathrm{Cu}$-ion. Unfortunately, the luminescence in $\mathrm{SrS}: \mathrm{Cu},(\mathrm{Ag})$ suffered from severe thermal quenching and dependence of the emission spectrum on the exact preparation conditions of the phosphors [66]. Indeed, in the years following 1997, several papers on the same material were published, consistently showing entirely different results.

Also in the 1990s, CaS:Pb was briefly considered as one of the best candidates for blue thin film EL [73,81-84]. Problems with clustering of the $\mathrm{Pb}$ ions, leading to a red shift of the emission and problems with crystallinity, prevented this phosphor becoming popular. CaS:Bi, a phosphor which had been marketed already in 1870 as Balmain's paint, the first well-recognized commercial luminescent pigment [3], was also tested, but revealed similar problems as $\mathrm{CaS}: \mathrm{Pb}$ [85].

1999 turned out to be a very important year for ACTFEL as the new blue phosphor $\mathrm{BaAl}_{2} \mathrm{~S}_{4}$ :Eu was presented by N. Miura from Meiji University, Japan [86,87], with properties that were far superior to any previously investigated material. As this is a phosphor of current interest, it will be treated in more detail in the following paragraphs. The most important thin film EL phosphors studied in the 20th century are listed in Table 1. 
Table 1. Overview of proposed thin film electroluminescent materials with their emission color and dominant wavelength $\left(\lambda_{\mathrm{d}}\right)$.

\begin{tabular}{|c|c|c|c|}
\hline Material & Color & $\lambda_{d}(\mathrm{~nm})$ & Refs. \\
\hline $\mathrm{ZnS}: \mathrm{Mn}$ & Amber & 585 & [29] \\
\hline $\mathrm{ZnS}: \mathrm{Tb}$ & Green & 545 & {$[46,78,79]$} \\
\hline $\mathrm{ZnS}: \mathrm{Ho}$ & White & 550 & {$[44,48]$} \\
\hline $\mathrm{ZnS}: \mathrm{Sm}$ & Red & 651 & [47] \\
\hline $\mathrm{CaS}: \mathrm{Ce}$ & Green & 505 & {$[56]$} \\
\hline $\mathrm{SrS}: \mathrm{Ce}$ & Blue-green & 480 & {$[57]$} \\
\hline CaS:Eu & Red & 660 & {$[58]$} \\
\hline $\mathrm{SrS}: \mathrm{Eu}$ & Orange & 610 & [59] \\
\hline $\mathrm{SrS}_{1-\mathrm{x}} \mathrm{Se}_{\mathrm{x}}: \mathrm{Ce}$ & Blue & 465 & [64] \\
\hline $\mathrm{CaS}_{1-\mathrm{x}} \mathrm{Se}_{\mathrm{x}}: \mathrm{Eu}$ & Orange-red & 630 & {$[62,63,80]$} \\
\hline $\mathrm{CaSr}_{1-\mathrm{x}} \mathrm{S}_{\mathrm{x}}: \mathrm{Eu}$ & Orange-red & 640 & {$[61]$} \\
\hline $\mathrm{CaS}: \mathrm{Pb}$ & Blue & 450 & {$[73,81-84]$} \\
\hline $\mathrm{CaS}: \mathrm{Bi}$ & Blue & 450 & [85] \\
\hline $\mathrm{BaAl}_{2} \mathrm{~S}_{4}: \mathrm{Eu}$ & Blue & 475 & [86-89] \\
\hline $\mathrm{CaGa}_{2} \mathrm{~S}_{4}: \mathrm{Ce}$ & Blue & 460 & [90] \\
\hline $\mathrm{CaGa}_{2} \mathrm{~S}_{4}: \mathrm{Eu}$ & Yellow & 565 & {$[91]$} \\
\hline $\mathrm{SrGa}_{2} \mathrm{~S}_{4}: \mathrm{Ce}$ & Blue & 445 & {$[90,92-94]$} \\
\hline $\mathrm{SrGa}_{2} \mathrm{~S}_{4}: \mathrm{Eu}$ & Green & 532 & {$[71,75,94,95]$} \\
\hline $\mathrm{SrS}: \mathrm{Cu}$ & Blue-green & 480 & {$[36,77]$} \\
\hline $\mathrm{SrS}: \mathrm{Cu}, \mathrm{Ag}$ & Blue & 440 & {$[36,76,77]$} \\
\hline $\mathrm{CaS}: \mathrm{Cu}, \mathrm{Ag}$ & Blue & 450 & [96] \\
\hline
\end{tabular}

\section{3. $\mathrm{BaAl}_{2} \mathrm{~S}_{4}: \mathrm{Eu}$ and color-by-blue}

The research into $\mathrm{SrGa}_{2} \mathrm{~S}_{4}$ :Ce as blue emitting phosphor was followed by the introduction of $\mathrm{BaAl}_{2} \mathrm{~S}_{4}: \mathrm{Eu}$ as an efficient blue emitter, with a relatively narrow emission band centered around $470 \mathrm{~nm}$ [97]. Although briefly mentioned by Benalloul et al. in 1998 as a promising but difficult to synthesize material in thin film form [54], the breakthrough came in 1999 with the announcement by Miura et al. of 'High-luminance blue-emitting $\mathrm{BaAl}_{2} \mathrm{~S}_{4}$ :Eu thin film electroluminescent devices' [86]. 


\subsubsection{Deposition techniques}

Using a dual-source pulsed e-beam evaporation of $\mathrm{BaS}: \mathrm{Eu}$ and $\mathrm{Al}_{2} \mathrm{~S}_{3}$, followed by a thermal annealing at $900{ }^{\circ} \mathrm{C}$ in argon, a luminance of $65 \mathrm{~cd} / \mathrm{m}^{2}$ at $50 \mathrm{~Hz}$ was obtained at approximately $80 \mathrm{~V}$ above threshold. With CIE color coordinates of $(0.12,0.10)$, this phosphor was close to the requirements for the blue component in television displays. The dual-source pulsed evaporation is based on the electron beam being rapidly switched (duty cycle of $10 \mathrm{~ms}$ ) between both sources (Figure 3), with the evaporation rate of both materials and thus the stoichiometry being determined by the electron flux ratio to both sources, which is considerably more reproducible and reliable than using thickness monitors [98].

This dual-source technique overcomes the non-stoichiometric evaporation when trying to evaporate $\mathrm{BaAl}_{2} \mathrm{~S}_{4}: \mathrm{Eu}$ powder directly by an electron-beam. To improve the compositional and thickness homogeneity of the deposited thin films over large areas, substrates were mounted on a rotating dome with specific positioning of two BaS:Eu and two $\mathrm{Al}_{2} \mathrm{~S}_{3}$ sources (Figure 3). In this way, five 17', displays could be simultaneously covered [98].

Figure 3. (left) Dual source electron beam deposition for $\mathrm{BaAl}_{2} \mathrm{~S}_{4}: \mathrm{Eu}$ thin films, (middle) evaporation of both sources is obtained by rapidly switching the single electron beam (with constant current). Stoichiometry is achieved by tuning the time ratio between both sources, (right) multi-source modification for improved stoichiometry over large areas. (adapted from $[86,104])$.
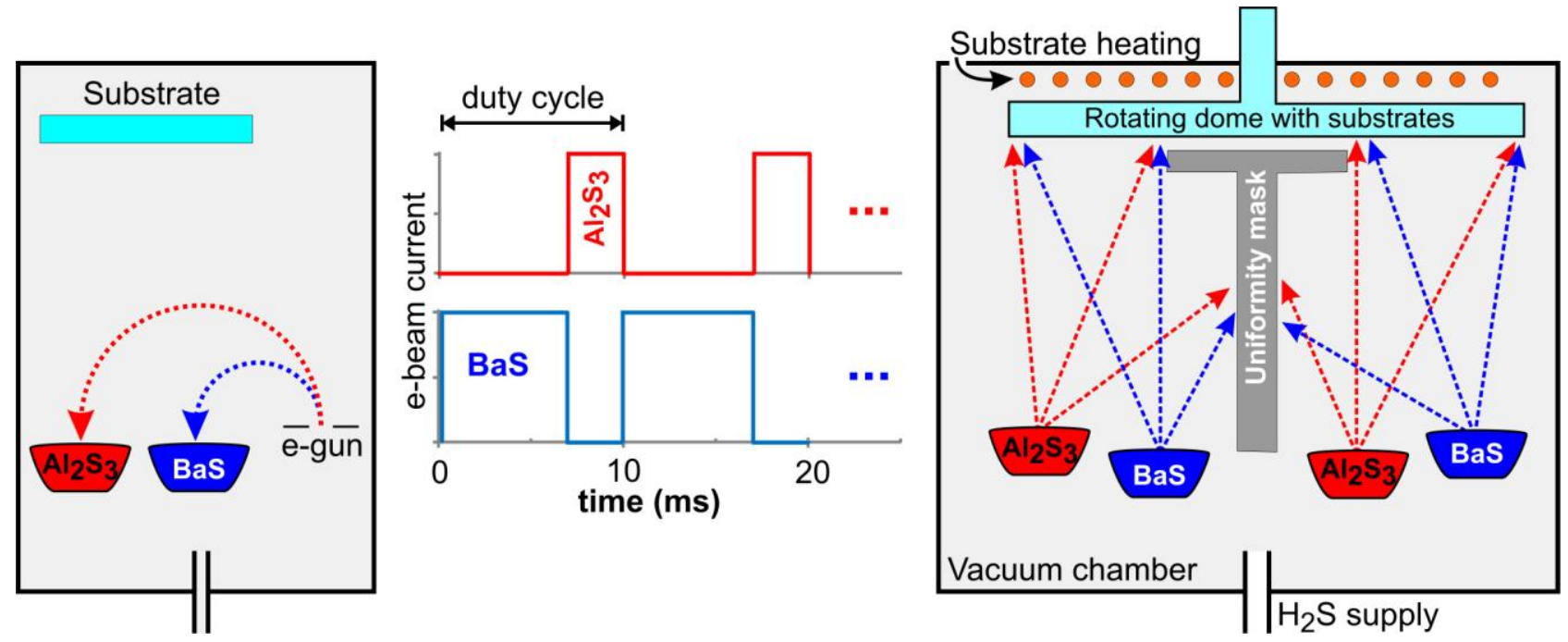

Initially, high annealing temperatures were required to obtain devices with high luminance (typically $900{ }^{\circ} \mathrm{C}$ ), putting severe constraints on the substrate and the bottom electrodes and insulators. An increase of the substrate temperature from $150{ }^{\circ} \mathrm{C}$ [86] to $650{ }^{\circ} \mathrm{C}$ [99] was proposed to lower or eliminate the need for post-deposition annealing. Furthermore, a modified $\mathrm{BaAl}_{2} \mathrm{~S}_{4}$ :Eu phosphor with a partial substitution of $\mathrm{Ba}$ by $\mathrm{Mg}$ also eased the temperature requirements [100], as well as the using of fluxing agents, such as fluorides [101].

Based on research on $\mathrm{BaAl}_{2} \mathrm{~S}_{4}(: \mathrm{Eu})$ powders and thin films [89,102], a second crystallographic phase was identified besides the well-known, cubic phase which is obtained at high temperatures 
[97,103]. Upon sintering a mixture of $\mathrm{BaS}$ and $\mathrm{Al}_{2} \mathrm{~S}_{3}$ powders in a flow of $\mathrm{H}_{2} \mathrm{~S}$, the orthorhombic

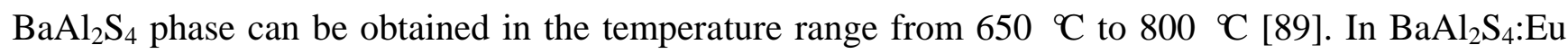
thin films prepared by a $\mathrm{BaS}: \mathrm{Eu} \mid \mathrm{Al}_{2} \mathrm{~S}_{3}$ multi-layered deposition, the formation temperature of the orthorhombic phase is lowered by about $100{ }^{\circ} \mathrm{C}$, probably due to the more intimate mixing compared to powder mixtures [40,89]. Stiles and Kamkar evaluated the performance of both phases in EL devices, and concluded that thin films consisting primarily of the cubic phase showed a higher light output, with a maximum for the films with an almost equal amount of the cubic and orthorhombic phases [102]. A clear explanation as to whether this was related to the intrinsic efficiency of both phases could not be provided. Other effects such as increased light outcoupling could also have played a role [102].

An interesting research topic is the role of oxygen in $\mathrm{BaAl}_{2} \mathrm{~S}_{4}: \mathrm{Eu}$ thin films. In the early days, a significant fraction of oxygen was unintentionally incorporated in the thin films [105], which could accumulate during annealing at the interface with the $\mathrm{ZnS}$ buffer layers. It was reported that the oxygen contamination at least partially originated from the $\mathrm{Al}_{2} \mathrm{~S}_{3}$ evaporation [40] and the reactivity of $\mathrm{Al}_{2} \mathrm{~S}_{3}$. Furthermore, interaction with other (oxygen-containing) layers in the thin film structure and with the substrate was suggested [106]. Shifting to other deposition techniques, such as sputtering from a BaS:Eu-Al target, allowed a better control of the oxygen content. Surprisingly, the stability of $\mathrm{BaAl}_{2} \mathrm{~S}_{4}$ :Eu layers was improved upon post-deposition annealing in an oxygen atmosphere [102,107], which was related to reduction of unsaturated bonds in the as-deposited devices or to the formation of a protective oxide layer [107].

\subsubsection{TDEL and CBB}

Two main (technological) improvements, in parallel to the development of the $\mathrm{BaAl}_{2} \mathrm{~S}_{4}: \mathrm{Eu}$ phosphor itself, allowed a better reproducibility and enhanced performance considerably, namely the use of thick dielectrics (TDEL) and the color-by-blue (CBB) pixel scheme.

The original EL structures, as used in the 20th century, consisted of thin film insulator layers with a thickness of only a few hundred nanometers. Two main disadvantages are associated to this concept [108]: the thin films are prone to destructive dielectric breakdown due to the high electric fields involved and should therefore be pinhole and defect free. Secondly, the use of a plane parallel thin film structure results in - mostly unwanted - optical interference effects. This leads to changes of the emission spectrum with viewing angle and with time and a dependence of the spectrum on the exact thickness of the different films [109]. Even more severely, a large fraction of the light is trapped inside the thin film structure by total internal reflections and most of the light is emitted laterally [110].

The development of a TDEL structure, in which the thin film insulator is replaced by a thick $(\sim 10-20 \mu \mathrm{m})$ dielectric, allowed operation of the device at higher voltages, improved the temperature resistance and significantly increased the light output due to diffuse outcoupling [108]. The advantages of thick dielectrics had already been shown in the early 1990s by Minami et al., where the use of $\mathrm{BaTiO}_{3}$ ceramic sheets allowed high annealing temperatures, required to crystallize oxide phosphors [111,112]. Furthermore, a thick dielectric insulator, which is more tolerant towards defects, could be deposited with cheap and easily scalable screen-printing techniques [113]. More details on contrast 
enhancement (to counteract the reduced contrast due to the increased diffuse outcoupling) can be found in the review of (TD)EL technology by Heikenfeld and Steckl [108].

The performance of $\mathrm{BaAl}_{2} \mathrm{~S}_{4}: \mathrm{Eu}$ as a blue phosphor for EL, in combination with the TDEL approach, turned out to be so good that a new device structure, based on only one emitting material, could be introduced. Instead of using two or three different electroluminescent phosphor materials for the production of full-color EL displays, a color-by-blue (CBB) approach was developed [102,113]. In this way all three (RGB) sub-pixels are based on the EL emission in $\mathrm{BaAl}_{2} \mathrm{~S}_{4}: \mathrm{Eu}$, with photoluminescent layers (outside the electrically active structure) converting the blue emission to red and green (Figure 4). This down-conversion concept was already shown in the 1990's by using an UVemitting EL phosphor $\left(\mathrm{ZnF}_{2}: \mathrm{Gd}\right)$ in combination with one or more photoluminescent materials [114-116]. The CBB concept eliminates the effects of color shifts caused by differential ageing of different EL phosphor materials during the lifetime of the device. Furthermore, no subsequent patterning and deposition of the phosphor layers is required [102]. On top of the non-converted subpixels, a color correcting filter can be deposited to improve the color saturation [108]. To reduce the color blur, caused by the excitation of the conversion material by light from neighboring blue subpixels, screen-printing black stripes in between the subpixels was proposed [117]. It is interesting to compare the CBB approach to earlier attempts to use a color-by-white approach (Figure 4) [50]. In this case, a single white phosphor [118] or a stack of multi-color phosphors [119] is used to produce white light emission for every sub-pixel. Then color filters are used to filter out saturated $\mathrm{R}, \mathrm{G}$ and $\mathrm{B}$ colors. This has the advantage, compared to an RGB-phosphor approach, that no consecutive etching and deposition of the phosphor layer is required. A disadvantage is a relatively large loss in efficiency by filtering, which occurs for all sub-pixels. In CBB, the advantage of a single emissive material for all sub-pixels is combined with high efficiency, apart from the (Stokes) conversion losses in the $\mathrm{G}$ and $\mathrm{R}$ sub-pixels.

Figure 4. Pixel layout for thin film electroluminescence displays, with RGB subpixels (upper left), colour-by-white (upper right) and by using a color-by-blue approach (bottom). (color online)

$\underline{\mathrm{RGB}}$

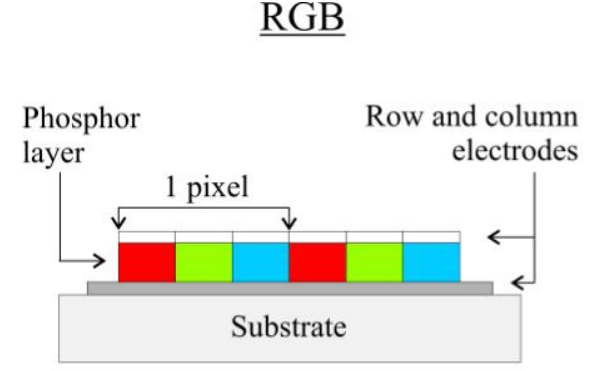

\section{Colour-by-white}

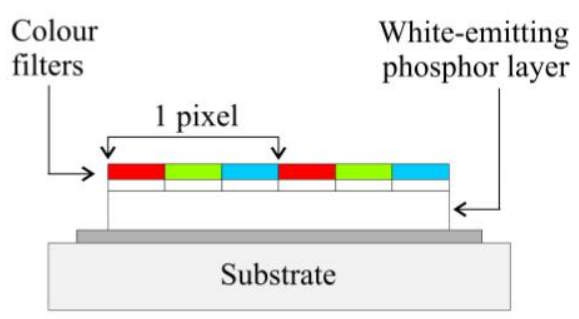

Colour-by-blue

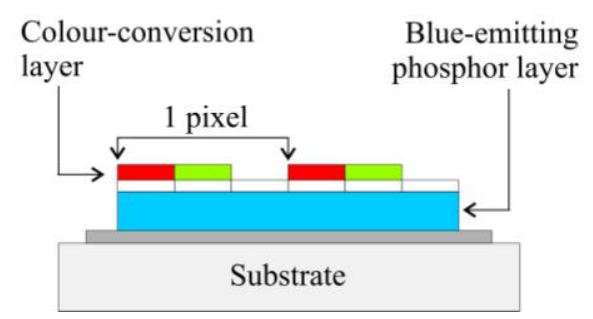


The state-of-the art in inorganic electroluminescence displays was recently described by Hamada $e t$ al. $[117,120]$. The sputtered blue $\mathrm{BaAl}_{2} \mathrm{~S}_{4}:$ Eu phosphor layer shows a high luminance and efficiency of $2300 \mathrm{~cd} / \mathrm{m}^{2}$ and $2.5 \mathrm{lum} / \mathrm{W}$ respectively, when measured at $120 \mathrm{~Hz}$ and $60 \mathrm{~V}$ above threshold. After applying color conversion materials and a color filter, a full-color device with a peak luminance of $350 \mathrm{~cd} / \mathrm{m}^{2}\left(400 \mathrm{~cd} / \mathrm{m}^{2}\right)$ could be obtained for an NTSC color gamut of $100 \%$ (95\%), in combination with a wide viewing angle.

\subsubsection{Current research activities.}

(Academic) research has diminished in recent years in the field of inorganic electroluminescence in general, but also on the $\mathrm{BaAl}_{2} \mathrm{~S}_{4}$ :Eu-based phosphor in thin film form. However, several groups have worked on $\mathrm{BaAl}_{2} \mathrm{~S}_{4}: \mathrm{Eu}$ powders. As these powders cannot be used as source material for the deposition of thin films, it merely serves to improve knowledge about the material itself.

Although $\mathrm{BaAl}_{2} \mathrm{~S}_{4}$ powder can be prepared from a mixture of $\mathrm{BaS}$ and $\mathrm{Al}_{2} \mathrm{~S}_{3}$ under a flowing $\mathrm{H}_{2} \mathrm{~S}$ atmosphere [89], the undesired formation of $\mathrm{Al}_{2} \mathrm{O}_{3}$ should be suppressed by using vacuum sealed silica tubes [121]. The orthorhombic or cubic phase can be obtained by variation of the synthesis temperature [89,121]. Several other synthesis techniques were proposed, such as using Al instead of the hygroscopic $\mathrm{Al}_{2} \mathrm{~S}_{3}$ [55]. During the synthesis, the $\mathrm{Al}$ precursor liquefies and lowers the synthesis temperature of the cubic $\mathrm{BaAl}_{2} \mathrm{~S}_{4}$ phase to $660{ }^{\circ} \mathrm{C}$ [122]. Adding a $\mathrm{H}_{3} \mathrm{BO}_{3}$ flux, this formation temperature can be further lowered to $600{ }^{\circ} \mathrm{C}$ [122]. Other methods for the synthesis of $\mathrm{BaAl}_{2} \mathrm{~S}_{4}: \mathrm{Eu}$ rely on a solution based approach for the synthesis of the BaS:Eu precursor [123], or on a sulfurization in a $\mathrm{CS}_{2}$ atmosphere of a $\mathrm{Ba}-\mathrm{Al}-\mathrm{Eu}$ oxide precursor prepared by a polymerizable complex method [124].

The radiative properties of (cubic) $\mathrm{BaAl}_{2} \mathrm{~S}_{4}$ :Eu powder were studied in detail by Barthou et al. [55], regarding the $5 \mathrm{~d}$ energy level structure and the temperature dependency of the decay and the shape of the emission spectrum (via the phonon energy). The emission spectrum and decay profile for the cubic and the orthorhombic phase are very similar [89,102]. Main differences can be noticed in the excitation spectrum and a small variation in the optical band gap $[89,125]$.

It is interesting to note that the thermal quenching of the cubic phase is still relatively limited at $500 \mathrm{~K}$ (i.e. the emission intensity has dropped by $35 \%$ compared to the low temperature intensity [55]). Taking this into account, its use as LED conversion phosphor was highlighted [126]. Nevertheless, it appears that better alternatives for the difficult to synthesize and unstable $\mathrm{BaAl}_{2} \mathrm{~S}_{4}: \mathrm{Eu}$ powder are already available, as obtaining blue emission from $\mathrm{Eu}^{2+}$ is relatively common in stable, oxide hosts [127].

\subsection{Other hosts and approaches}

Several other thin film electroluminescent materials were proposed in the past decade. $\mathrm{Ba}_{2} \mathrm{SiS}_{4}: \mathrm{Ce}$ shows a deep blue emission, but the luminance is low [128]. Furthermore, the emission efficiency and solubility of $\mathrm{Ce}^{3+}$ in thiosilicate materials appears much less than that of $\mathrm{Eu}^{2+}$ [129], although $\mathrm{Al}^{3+}$ codoping might be beneficial for the incorporation of elevated concentrations of $\mathrm{Ce}^{3+}[130]$.

$\mathrm{CaAl}_{2} \mathrm{~S}_{4}: \mathrm{Eu}, \mathrm{Gd}$ was reported as an efficient green TFEL phosphor, with a luminance of $3000 \mathrm{~cd} / \mathrm{m}^{2}$ at $1 \mathrm{kHz}$ and was prepared with a dual source e-beam technique [131]. With this phosphor, a wider 
color gamut can be obtained in comparison to $\mathrm{SrGa}_{2} \mathrm{~S}_{4}: \mathrm{Eu}$ [132]. $\mathrm{SrY}_{2} \mathrm{~S}_{4}: \mathrm{Eu}, \mathrm{Ca}(\mathrm{In}, \mathrm{Al})_{2} \mathrm{~S}_{4}: \mathrm{Eu}$ and $\mathrm{CuAlS}_{2}: \mathrm{Mn}$ were investigated as red phosphor [132].

In spite of considerable advances in the deposition techniques for $\mathrm{BaAl}_{2} \mathrm{~S}_{4}$ :Eu thin films, a relatively high temperature step is still required to obtain sufficiently crystalline materials, either during deposition or during annealing. Hence, flexible substrates cannot be used under these conditions. If flexible, inorganic EL displays could be realized, this would give the technology a unique selling point over LCD and plasma displays. A sphere supported TFEL approach was proposed to obtain flexible displays, based on the deposition of the EL active layer on small dielectric $\mathrm{BaTiO}_{3}$ spheres (at elevated temperature), which are then transferred onto a flexible substrate and electrically contacted [133].

\subsection{Future of $i E L$.}

After several decades of iEL research, a good blue phosphor with reasonable efficiency is finally available. In combination with an improved (TDEL) device structure and contrast enhancement, $\mathrm{iEL}$ displays as presented by iFire are now state-of-the-art [117]. In 2003, Heikenfeld and Steckl labeled the iEL displays as being 'at the crossroads', where they would either remain a niche application or finally go for large-scale commercialization and wide market penetration [108]. Seven years later, one has to conclude that iEL did not follow the second road. LCDs have conquered the market of large displays (>30'), initially targeted by iFire with its 34" pilot plant [113]. They have combined an almost continuous dropping consumer price with an increasing performance. Power consumption is reduced and contrast increased by the emerging LED backlight technology.

Given that the cost of an iEL display is for a large fraction determined by the temperature demands for the substrate and the expensive electronic circuitry, there are no prospects for (near) future market penetration, certainly because $\mathrm{iEL}$ still has to be considered as an invasive technology [108]. Niche applications, where the full potential of iEL devices is appreciated (such as wide temperature operating range, ruggedness and long lifetime) remain of course possible.

\section{Color Conversion Phosphors}

As described in the previous Section, several sulfide materials have been intensively investigated as thin film electroluminescent phosphors. Recently, the search for efficient color conversion phosphors for white light emitting diodes (w-LEDs) has sparked renewed interest in the photoluminescence behavior of (mainly rare-earth) doped sulfides.

w-LEDs are expected to replace incandescent light bulbs and even fluorescent lamps on a relatively short time scale. First of all, w-LEDs have many advantages, such as a high efficiency (and thus low energy consumption), small size, long lifetime (50.000h) and the absence of mercury. Incandescent light bulbs have a luminous efficacy of only 10-15 lumen per watt of electrical input power, while compact fluorescent lamps reach 40-50 lum/W. Currently, LEDs with efficiencies of over $100 \mathrm{lum} / \mathrm{W}$ have been reported, and the theoretical limit seems to be situated well above $200 \mathrm{lum} / \mathrm{W}$, provided suitable phosphor materials can be developed. As a consequence, huge power savings (and associated reductions in fossil fuel consumption and carbon dioxide emissions) can be obtained [134]. 


\subsection{Requirements for LED phosphors.}

wLEDs are composed of a near-UV (or blue) LED, in combination with one or more phosphor materials which fully (or partially) convert the LED emission to longer wavelengths (Figure 5). An appropriate choice of the phosphor composition then results in white light emission, ideally with a high color rendering and the desired color temperature [135].

Figure 5. (center) 5mm white LED, (left) Schematic structure of the LED's cross-section along the plane perpendicular to the (center) image and indicated by the white arrows, (right) Elemental mapping of selected elements using EDX (energy-dispersive x-ray analysis), with the maps for $\mathrm{Y}, \mathrm{Al}$ and $\mathrm{Ga}$ indicating the $\mathrm{Y}_{3} \mathrm{Al}_{5} \mathrm{O}_{12}$ :Ce phosphor powder, the sapphire substrate and the $(\mathrm{Ga}, \mathrm{In}) \mathrm{N}$ diode, respectively.
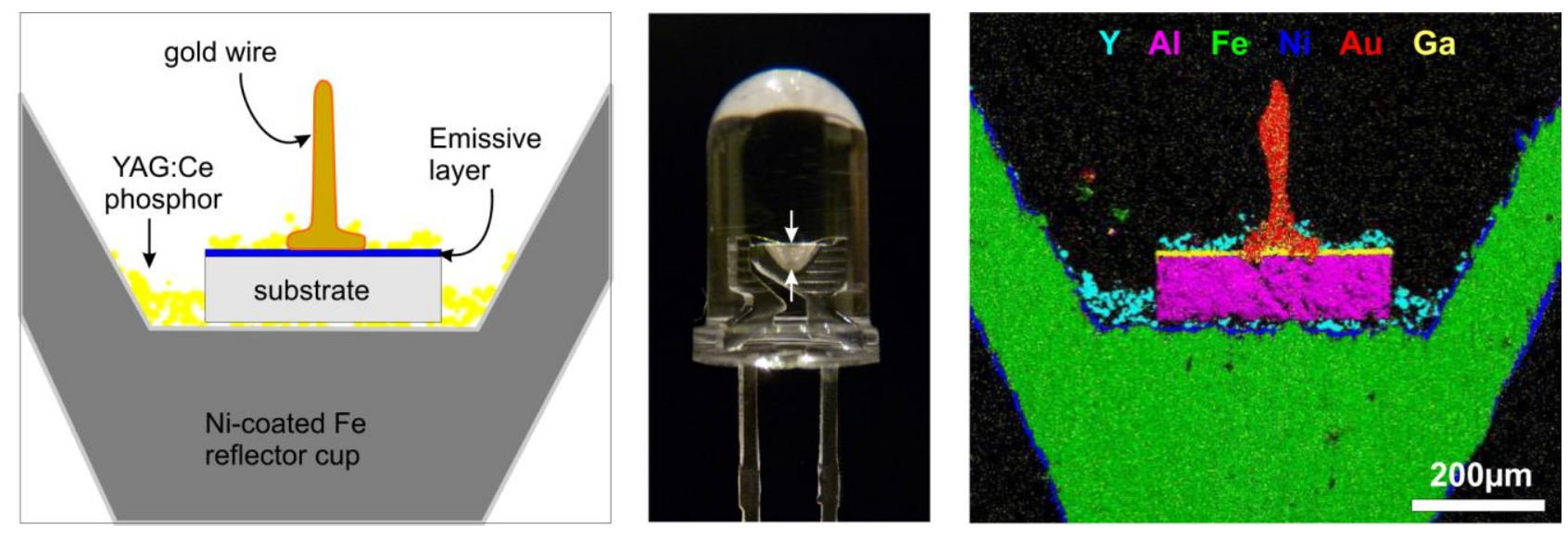

Currently, most wLEDs are based on yellow-emitting $\mathrm{Y}_{3} \mathrm{Al}_{5} \mathrm{O}_{12}: \mathrm{Ce}^{3+}$ (YAG:Ce) as color conversion material. Although its emission is relatively broad, it lacks a significant output in the long wavelength range of the visible spectrum, thus hampering the development of wLEDs with high color rendering and/or low color temperature. The main requirements for a color conversion material are:

1. An appropriate emission spectrum to achieve a true white emission when mixed with the remaining (visible) LED emission and possible other phosphors. To achieve a high color rendering index (CRI) for high-quality illumination applications (typically 90 or higher), broad band emission is required.

2. High quantum efficiency for the conversion process. YAG:Ce can be considered as a benchmark, with a quantum efficiency exceeding $90 \%$ [136].

3. The excitation spectrum should show sufficient overlap with the LED's emission spectrum. As the LED's emission spectrum can significantly change as a function of temperature and/or driving current, a broad excitation band overlapping the LED's emission is preferred to avoid color shifts of the LED-phosphor combination.

4. A relatively short decay time, to prevent saturation in high flux devices.

5. A high thermal quenching temperature, as LED chips can reach relatively high temperatures of $450 \mathrm{~K}$ [137] during operation. 
6. Good stability during the full lifetime of an LED (typically over 50,000 hours)

The overall efficiency for a wLED is mainly determined by the electrical-to-optical conversion efficiency of the pumping LED, the Stokes losses associated with the color conversion, the light extraction efficiency and the quantum efficiency of the phosphor. As the overall efficiency is the product of all partial efficiencies, it is of utmost importance to carefully select and optimize phosphors for a quantum efficiency as close to unity as possible, also at elevated operating temperatures.

Requirements 1, 3 and 4 favor the broad band emitting rare earth ions $\mathrm{Ce}^{3+}$ and $\mathrm{Eu}^{2+}$ over most lineemitting rare earth ions (including $\left.\mathrm{Eu}^{3+}\right), \mathrm{Mn}^{2+}$ and transition elements. The decay times of $\mathrm{Ce}^{3+}$ (typically 60ns or less, [138]) and $\mathrm{Eu}^{2+}$ (typically $1 \mu$ s or less, [139]) are sufficiently short to avoid saturation. Furthermore, these ions present a relatively small Stokes shift, which allows pumping by a blue LED which reduces conversion losses over UV LEDs, even if the quantum efficiency is close to unity. Nevertheless, the excitation band width in most compounds is sufficiently broad to allow nearUV excitation as well.

As there are several sulfide materials which can yield orange-to-red emission, these materials were recently investigated as conversion phosphor. This ability stands in contrast to oxide hosts, where red $\mathrm{Eu}^{2+}$ emission is relatively rare [127]. In general, the main criteria for the evaluation of rare-earth doped sulfides are requirements 5 and 6. Depending on the host's composition, the band gap in sulfides is relatively low, typically in the range from 3 to $5 \mathrm{eV}$. This implies an increased chance of interaction of the $\mathrm{Eu}^{2+} 5 \mathrm{~d}$ orbitals with the conduction band states, thus leading to anomalous emission [140] or a relatively low quenching temperature. Furthermore, the stability of sulfides is often a matter of concern as well. In the following discussion, several host materials are discussed in the framework of the above mentioned requirements. This Section concludes with a comparison to other host compositions, such as the nitride and oxynitrides.

\subsection{Binary sulfides}

The luminescence of impurity doped binary, alkaline earth sulfides like $\mathrm{MgS}, \mathrm{CaS}, \mathrm{SrS}$ and $\mathrm{BaS}$ has been extensively studied in the past century. For instance, the rare earths ions (broad band d-f emitters like $\mathrm{Eu}^{2+}$ and $\mathrm{Ce}^{3+}$, as well as narrow line $\mathrm{f}$-f emitters), transition metals $\left(\mathrm{Cu}^{+}, \mathrm{Ag}^{+}, \mathrm{Mn}^{2+}, \mathrm{Au}^{+}, \mathrm{Cd}^{2+}\right)$ and $\mathrm{s}^{2}$ ions $\left(\mathrm{Bi}^{3+}, \mathrm{Pb}^{2+}, \mathrm{Sb}^{3+}, \mathrm{Sn}^{2+}\right)$ are all known to luminesce in one or more of the above mentioned hosts [141]. Several of these host-dopant combinations were studied as thin film EL phosphor (Table 1). Interestingly, undoped $\mathrm{CaS}$ and $\mathrm{SrS}$ are reported to luminesce as well, although the intensity is far too low for (LED) applications. The emission wavelength strongly depends on the synthesis conditions, suggesting the presence of multiple, optically active centers [142,143].

The emission properties of the abovementioned transition metals (except $\mathrm{Mn}^{2+}$ ) and the $\mathrm{s}^{2}$ ions are not very useful for LED color conversion purposes, as they often show considerable thermal quenching, in combination with a strong temperature dependent spectrum. The latter effect is due to formation of different emission centers, depending on the dopant concentration and the synthesis conditions [76,144].

In Table 2, luminescence of alkaline earth sulfides doped with some typical dopants is given. Especially the data on $\mathrm{Eu}^{2+}$ and $\mathrm{Ce}^{3+}$ doping are interesting as this is valuable information when considering the emission of these ions in ternary sulfides. 
Table 2. Peak emission wavelength (nm) for $\mathrm{Eu}^{2+}, \mathrm{Ce}^{3+}, \mathrm{Cu}^{+}$and $\mathrm{Sb}^{3+}$ doped alkaline earth sulfides, at room temperature and for low dopant concentration.

\begin{tabular}{|c|c|c|c|c|c|c|c|c|}
\hline HostlDopant & $\mathbf{E u}^{2+}$ & & $\mathrm{Ce}^{3+}$ & & $\mathrm{Cu}^{+}$ & & $\mathbf{S b}^{3+}$ & \\
\hline MgS & 591 & {$[145]$} & 521 & [146] & 472 & [147] & 539 & [148] \\
\hline CaS & $\begin{array}{l}652 \\
663 \\
\end{array}$ & $\begin{array}{l}{[145]} \\
{[149,150]}\end{array}$ & $\begin{array}{l}509 \\
520 \\
\end{array}$ & $\begin{array}{l}{[151]} \\
{[146]}\end{array}$ & 413 & [147] & 549 & [148] \\
\hline SrS & 620 & [145] & $\begin{array}{l}483 \\
503\end{array}$ & $\begin{array}{l}{[151]} \\
{[146]}\end{array}$ & 478 & [147] & 600 & [148] \\
\hline BaS & 878 & {$[152]$} & 480 & [146] & 585 & [147] & & \\
\hline
\end{tabular}

In general, the emission of sulfides shifts to longer wavelength when the cation is changed from $\mathrm{Ba}$ over $\mathrm{Sr}$ to $\mathrm{Ca}$, as is the case for thioaluminates, thiosilicates and thiogallates (hereafter called the ternary sulfides). However, this observation only partially applies to the case of the alkaline earth sulfides, as can be observed in Table 2. The peak emission of SrS:Eu $(620 \mathrm{~nm})$ is indeed blue-shifted compared to CaS:Eu (655 nm) [152]. Although the emission of BaS:Eu was reported at $572 \mathrm{~nm}$ [146], this observation could not be confirmed later on [152,153]. BaS:Eu shows a broad emission band, peaking at about $878 \mathrm{~nm}$, with a much longer lifetime than expected for $\mathrm{Eu}^{2+}$. Interaction between the $5 \mathrm{~d}$ excited state of $\mathrm{Eu}^{2+}$ and the conduction band levels leads to anomalous emission [140,152]. The emission in $\mathrm{MgS}$ :Eu peaks at $615 \mathrm{~nm}$, which is blue-shifted compared to CaS:Eu. As $\mathrm{Ca}_{1-\mathrm{x}} \mathrm{Mg}_{\mathrm{x}} \mathrm{S}: \mathrm{Eu}$ indeed shows an increasing red-shift upon increasing the compositional parameter $\mathrm{x}$ from 0 to 0.5 , it was concluded that the substitutional incorporation of the $\mathrm{Eu}^{2+}$ on the much smaller $\mathrm{Mg}^{2+}$ lattice led to a stress-related blue-shift in $\mathrm{MgS}: \mathrm{Eu}$ [146]. Upon doping with $\mathrm{Ce}^{3+}$, the emission is bluish-green in $\mathrm{SrS}$ and green in $\mathrm{CaS}$ [154].

$\mathrm{CaS}: \mathrm{Eu}, \mathrm{SrS}: \mathrm{Eu}$ and the solid solutions $\mathrm{Ca}_{1-\mathrm{x}} \mathrm{Sr}_{\mathrm{x}} \mathrm{S}: \mathrm{Eu}$ have been in the picture as the red color conversion material in LEDs [150,154-157], due to their excitation and emission behavior, i.e. the emission spectrum of a blue LED perfectly overlaps with the excitation to the lowest $5 \mathrm{~d}$ state and the emission is situated at longer wavelengths than YAG:Ce. Xia et al. recently determined the quantum efficiency of $\mathrm{CaS}: \mathrm{Eu}$ at $53 \%$ under excitation centered at $460 \mathrm{~nm}$ [150]. The emission of $\mathrm{CaS}: \mathrm{Eu}$ is saturated red $(\mathrm{CIE}(\mathrm{x}, \mathrm{y})=(0.69,0.30))$, which can be useful for improving the color rendering and achieving low color temperatures. However, a low photopic luminous efficacy (PLE) of only $75 \mathrm{lum} / \mathrm{W}$ is a serious trade-off, as the eye sensitivity is low in this part of the visible spectrum [60]. The emission of SrS:Eu is blue-shifted, resulting in a luminous efficacy of $217 \mathrm{lum} / \mathrm{W}$. This effect is partially counteracted by the lower quantum efficiency of SrS:Eu (31\%) [150]. The emission color can be tuned, by making solid solutions of $\mathrm{CaS}: \mathrm{Eu}$ and $\mathrm{SrS}: \mathrm{Eu}$, although the emission wavelength does not shift linearly on the composition, as was reported by several groups $[60,146,150,155]$. By adding $\mathrm{Ce}^{3+}$ to $\mathrm{CaS}: \mathrm{Eu}$ or $\mathrm{SrS}: \mathrm{Eu}$, the excitation efficiency of the $\mathrm{Eu}^{2+}$ emission is enhanced, although it does not change the emission spectrum, due to an efficient energy transfer from $\mathrm{Ce}^{3+}$ to $\mathrm{Eu}^{2+}[154]$.

In contrast to the europium-doped ternary sulfides (where the optimum dopant concentration is typically around 5 mole \%), concentration quenching is relatively strong in the alkaline earth sulfides, with optimum dopant concentration below $0.5 \%$ [61,158]. On the one hand this can be explained by the larger number of available cation sites within a distance of 0.4 to $0.5 \mathrm{~nm}$ in the alkaline earth sulfides, compared to the case of the ternary sulfides. On the other hand, this is somewhat surprising 
given that $\mathrm{Eu}$ is easily incorporated in $\mathrm{CaS}$ and $\mathrm{SrS}$, as no charge compensation is required and as the ionic radii of $\mathrm{Eu}^{2+}$ and $\mathrm{Sr}^{2+}$ (and to a somewhat lesser extent $\mathrm{Ca}^{2+}$ ) are very similar. Although higher dopant concentrations are favorable for efficient absorption of the excitation light, it negatively affects the thermal quenching behavior. In thin films, clustering of Eu dopant ions has been reported [61], thus increasing the local concentration.

Xia reported a reduction of the emission intensity by about $40 \%$ at room temperature, compared to the intensity at $20 \mathrm{~K}$, for a dopant concentration of 0.3 mole $\%$ in $\mathrm{Ca}_{0.8} \mathrm{Sr}_{0.2} \mathrm{~S}: \mathrm{Eu}$ [150]. Nevertheless, the emission was only quenched to $50 \%$ at $420 \mathrm{~K}$, in comparison to the low temperature case. This observation, typical for $\mathrm{Ca}_{1-\mathrm{x}} \mathrm{Sr}_{\mathrm{x}} \mathrm{S}$ :Eu, shows that the thermal quenching profile deviates from the profile observed in most ternary compounds where the thermal quenching manifests itself in a rather narrow temperature region. Given that the $\mathrm{T}_{0.5}$ (i.e. the temperature when the emission intensity is halved compared to the low temperature case) has been reported at $475 \mathrm{~K}$ for CaS:Eu and $320 \mathrm{~K}$ for $\mathrm{SrS}: \mathrm{Eu}$ [159], it is questionable whether $\mathrm{Ca}_{1-\mathrm{x}} \mathrm{Sr}_{\mathrm{x}} \mathrm{S}: \mathrm{Eu}$ phosphors with higher Sr concentrations are ideal for use in LEDs.

The stability of the alkaline earth sulfides $\mathrm{CaS}$ and $\mathrm{SrS}$ is reasonable, although slow decomposition in moist air is observed. In the case of $\mathrm{MgS}: \mathrm{Eu}$, Kasano et al. reported its stability to be much better when the powder was fully sulfurized [146]. Besides the reduction in light output, Shin et al. reported another detrimental effect of the decomposition of $\mathrm{CaS}$ :Eu upon application in LEDs, namely a chemical reaction of the released $\mathrm{H}_{2} \mathrm{~S}$ with the $\mathrm{Ag}$ pad under the LED chip, thus reducing the reflectivity [160]. Several encapsulation methods have been recently proposed, all reducing the decomposition rate under accelerated ageing conditions (high temperature and high humidity). These methods include coating with $\mathrm{Al}_{2} \mathrm{O}_{3}$ using atomic layer deposition [161], an organic-SiO${ }_{2}$ nanocomposite [162,163] or a thin BN sheet [164].

\subsection{Thiogallates.}

In the early 1970's, the luminescence of several europium-doped thiogallates was described (Table 3 , with the peak emission wavelength red-shifting when going from $\mathrm{BaGa}_{2} \mathrm{~S}_{4}: \mathrm{Eu}$ (490 nm) over $\mathrm{SrGa}_{2} \mathrm{~S}_{4}: \mathrm{Eu}(538 \mathrm{~nm})$ to $\mathrm{CaGa}_{2} \mathrm{~S}_{4}: \mathrm{Eu}(560 \mathrm{~nm})[165,166]$. Some luminescent thiogallate phosphors with deviating 1:2:4 stoichiometry can also be synthesized, such as $\mathrm{Sr}_{2} \mathrm{Ga}_{2} \mathrm{~S}_{5}: \mathrm{Eu}$ and $\mathrm{BaGa}_{4} \mathrm{~S}_{7}: \mathrm{Eu}$, while other compositions are thermally quenched at room temperature (e.g. $\mathrm{Ba}_{3} \mathrm{Ga}_{2} \mathrm{~S}_{6}: \mathrm{Eu}$ and $\left.\mathrm{Ba}_{4} \mathrm{Ga}_{2} \mathrm{~S}_{7}: \mathrm{Eu}\right)$ [167]. 
Table 3. Emission properties of $\mathrm{Eu}^{2+}$ and $\mathrm{Ce}^{3+}$ doped thiogallate phosphors. $x \%$ quenching indicates the fraction of the emission intensity at room temperature compared to the low temperature intensity. $x \mathrm{~K}$ is the temperature for which the emission intensity is half that at low temperature.

\begin{tabular}{|c|c|c|c|c|c|}
\hline Host & Dopant & $\lambda_{\max }(\mathrm{nm})$ & Quenching & Remarks & Ref. \\
\hline $\mathrm{MgGa}_{2} \mathrm{~S}_{4}$ & $\mathrm{Eu}^{2+}$ & 660 & & & {$[168]$} \\
\hline $\mathrm{CaGa}_{2} \mathrm{~S}_{4}$ & $\begin{array}{l}\mathrm{Eu}^{2+} \\
\mathrm{Ce}^{3+}\end{array}$ & $\begin{array}{l}565 \\
459 \\
\end{array}$ & $410 \mathrm{~K}$ & & $\begin{array}{l}91] \\
{[169]}\end{array}$ \\
\hline $\mathrm{SrGa}_{2} \mathrm{~S}_{4}$ & $\begin{array}{l}\mathrm{Eu}^{2+} \\
\mathrm{Ce}^{3+}\end{array}$ & $\begin{array}{l}534 \\
445 \\
\end{array}$ & $470 \mathrm{~K}$ & & $\begin{array}{l}{[95]} \\
{[170]}\end{array}$ \\
\hline $\mathrm{Sr}_{2} \mathrm{Ga}_{2} \mathrm{~S}_{5}$ & $\mathrm{Eu}^{2+}$ & $553(90 \mathrm{~K})$ & $280 \mathrm{~K}$ & & {$[166]$} \\
\hline $\mathrm{BaGa}_{4} \mathrm{~S}_{7}$ & $\mathrm{Eu}^{2+}$ & $482(90 \mathrm{~K})$ & $70 \%$ & & {$[166]$} \\
\hline $\mathrm{BaGa}_{2} \mathrm{~S}_{4}$ & $\begin{array}{l}\mathrm{Eu}^{2+} \\
\mathrm{Ce}^{3+}\end{array}$ & $\begin{array}{l}493 \\
448 \\
\end{array}$ & $420 \mathrm{~K}$ & & $\begin{array}{l}{[171]} \\
{[170]}\end{array}$ \\
\hline $\mathrm{Ba}_{2} \mathrm{Ga}_{2} \mathrm{~S}_{5}$ & $\mathrm{Eu}^{2+}$ & - & & $\begin{array}{l}\text { No emission at } 90 \\
\mathrm{~K}\end{array}$ & [167] \\
\hline $\mathrm{Ba}_{3} \mathrm{Ga}_{2} \mathrm{~S}_{6}$ & $\mathrm{Eu}^{2+}$ & $538(90 \mathrm{~K})$ & $140 \mathrm{~K}$ & & [167] \\
\hline $\mathrm{Ba}_{4} \mathrm{Ga}_{2} \mathrm{~S}_{7}$ & $\mathrm{Eu}^{2+}$ & $654(90 \mathrm{~K})$ & $110 \mathrm{~K}$ & & {$[167]$} \\
\hline $\mathrm{Ba}_{5} \mathrm{Ga}_{2} \mathrm{~S}_{8}$ & $\mathrm{Eu}^{2+}$ & - & & $\begin{array}{l}\text { No emission at } 90 \\
\mathrm{~K}\end{array}$ & [167] \\
\hline $\mathrm{EuGa}_{2} \mathrm{~S}_{4}$ & $\mathrm{Eu}^{2+}$ & 546 & $+/-150 \mathrm{~K}$ & & {$[166,172]$} \\
\hline $\mathrm{ZnGa}_{2} \mathrm{~S}_{4}$ & $\mathrm{Eu}^{2+}$ & 540 & & & [173] \\
\hline
\end{tabular}

As the quantum efficiency of $\mathrm{CaGa}_{2} \mathrm{~S}_{4}: \mathrm{Eu}$ and $\mathrm{Sr}_{2} \mathrm{Ga}_{2} \mathrm{~S}_{5}: \mathrm{Eu}$ was reported to be similar to that of YAG:Ce [174], the thiogallates recently attracted attention as color conversion phosphor as well [174-179]. The emission band width is considerably smaller than in YAG:Ce, which necessitates the use of at least a second, red-emitting phosphor to produce white light starting from a blue LED. Several authors reported the combination of $\mathrm{CaS}: \mathrm{Eu}$ and $\mathrm{CaGa}_{2} \mathrm{~S}_{4}: \mathrm{Eu}[175,177,179]$, even with a 'one pot synthesis' based on the observation that a $\mathrm{CaS}: \mathrm{Ga}_{2} \mathrm{~S}_{3}$ starting ratio higher than 1:1 leads to a mixture of $\mathrm{CaS}: \mathrm{Eu}$ and $\mathrm{CaGa}_{2} \mathrm{~S}_{4}: \mathrm{Eu}$. Taking into account that $\mathrm{CaS}: \mathrm{Eu}$ has a much more severe concentration quenching behavior compared to $\mathrm{CaGa}_{2} \mathrm{~S}_{4}: \mathrm{Eu}$, it is questionable whether this synthesis approach is optimal in terms of overall quantum efficiency of the mixture.

$\mathrm{Yu}$ et al. described the structural and luminescent properties of $\mathrm{Ca}_{1-\mathrm{x}} \mathrm{Sr}_{\mathrm{x}}\left(\mathrm{Ga}_{1-\mathrm{y}} \mathrm{Al}_{\mathrm{y}}\right)_{2} \mathrm{~S}_{4}: \mathrm{Eu}^{2+}$ phosphors [174]. Changing the values of $\mathrm{x}$ and $\mathrm{y}$, a single crystallographic phase is obtained over the entire range. The luminescence shifts almost linearly on the composition, which allows continuous tuning of the peak emission wavelength from $496 \mathrm{~nm}\left(\mathrm{SrAl}_{2} \mathrm{~S}_{4}: \mathrm{Eu}\right)$ to $556 \mathrm{~nm}\left(\mathrm{CaGa}_{2} \mathrm{~S}_{4}: \mathrm{Eu}\right)$, while keeping a narrow emission band, indicated by a FWHM of about $40 \mathrm{~nm}$.

In view of LED applications, the thermal quenching behavior is reasonable for the $\mathrm{MGa}_{2} \mathrm{~S}_{4}: \mathrm{Eu}$ compounds $\left(\mathrm{T}_{0.5}=420 \mathrm{~K}\right.$ for $\mathrm{BaGa}_{2} \mathrm{~S}_{4}: \mathrm{Eu}$ [171], $470 \mathrm{~K}$ for $\mathrm{SrGa}_{2} \mathrm{~S}_{4}: \mathrm{Eu}$ [95] and $400 \mathrm{~K}$ for $\mathrm{CaGa}_{2} \mathrm{~S}_{4}: \mathrm{Eu}$ [180]) allowing remote phosphor approaches, while it is worse for thiogallates with different alkaline earth to gallium ratio [167]. 


\subsection{Thioaluminates and thioindates.}

When $\mathrm{BaAl}_{2} \mathrm{~S}_{4}: \mathrm{Eu}$ came in the picture as thin film electroluminescent material (Section 4), it also sparked interest in the other thioaluminates, which finally led to investigations as color conversion phosphor [126]. The pure green emission from $\mathrm{CaAl}_{2} \mathrm{~S}_{4}: \mathrm{Eu}$ (peaking at $516 \mathrm{~nm}$ ) makes it an interesting phosphor (Table 4). In powder from, it can be synthesized from $\mathrm{CaS}$ and $\mathrm{Al}_{2} \mathrm{~S}_{3}$ under $\mathrm{H}_{2} \mathrm{~S}$, however this leads to the undesired formation of $\mathrm{Al}_{2} \mathrm{O}_{3}$ and unreacted $\mathrm{CaS}$ remains [181,182]. Starting from stable $\mathrm{Al}$ and $\mathrm{S}$ powder, in combination with the use of vacuum sealed silica tubes, $\mathrm{Al}_{2} \mathrm{O}_{3}$ formation can be suppressed. $\mathrm{CaAl}_{2} \mathrm{~S}_{4}$ :Eu shows a broad excitation spectrum in combination with a small Stokes shift, allowing overlap with both blue and near-UV pump LEDs. Upon doping $\mathrm{CaAl}_{2} \mathrm{~S}_{4}$ with $\mathrm{Ce}^{3+}$, two spin-orbit split emission bands at 436 and $477 \mathrm{~nm}$ are observed. The emission of $\mathrm{CaAl}_{2} \mathrm{~S}_{4}: \mathrm{Ce}^{3+}$ was however much weaker than $\mathrm{CaAl}_{2} \mathrm{~S}_{4}: \mathrm{Eu}$ [182]. $\mathrm{SrAl}_{2} \mathrm{~S}_{4}: \mathrm{Eu}$ shows bluish-green color with emission peaking at $495 \mathrm{~nm}[97,126]$.

Table 4. Emission properties of $\mathrm{Eu}^{2+}$ and $\mathrm{Ce}^{3+}$ doped thioaluminate and thioindate phosphors. $x \%$ quenching indicates the fraction of the emission intensity at room temperature compared to the low temperature intensity. $x \mathrm{~K}$ is the temperature for which the emission intensity is half that at low temperature.

\begin{tabular}{|l|l|l|l|l|l|}
\hline Host & Dopant & $\lambda_{\max }(\mathbf{n m})$ & Quenching & Remarks & Ref. \\
\hline $\mathrm{MgAl}_{2} \mathrm{~S}_{4}$ & $\mathrm{Eu}^{2+}$ & 499 & & & {$[131]$} \\
\hline $\mathrm{CaAl}_{2} \mathrm{~S}_{4}$ & $\mathrm{Eu}^{2+}$ & 516 & $93-98 \%$ & & {$[97,181]$} \\
& $\mathrm{Ce}^{3+}$ & 436 & & & {$[126]$} \\
\hline $\mathrm{SrAl}_{2} \mathrm{~S}_{4}$ & $\mathrm{Eu}^{2+}$ & 495 & $90 \%$ & & {$[97]$} \\
\hline $\mathrm{Sr}_{2} \mathrm{Al}_{2} \mathrm{~S}_{5}$ & $\mathrm{Eu}^{2+}$ & 521 & & & {$[97]$} \\
\hline $\mathrm{BaAl}_{4} \mathrm{~S}_{7}$ & $\mathrm{Eu}^{2+}$ & 470 & $490 \mathrm{~K}$ & & {$[97]$} \\
\hline $\mathrm{BaAl}_{2} \mathrm{~S}_{4}$ & $\mathrm{Eu}^{2+}$ & $467-473$ & $>550 \mathrm{~K}$ & $\begin{array}{l}\text { Cubic } \\
\text { Orthorhombic }\end{array}$ & $\begin{array}{l}{[55,89,97]} \\
{[89]}\end{array}$ \\
\hline $\mathrm{Ba}_{2} \mathrm{Al}_{2} \mathrm{~S}_{5}$ & $\mathrm{Eu}^{2+}$ & 487 & & & {$[97]$} \\
\hline $\mathrm{Ba}_{4} \mathrm{Al}_{2} \mathrm{~S}_{7}$ & $\mathrm{Eu}^{2+}$ & 534 & $330 \mathrm{~K}$ & & {$[97]$} \\
\hline $\mathrm{Ba}_{5} \mathrm{Al}_{2} \mathrm{~S}_{8}$ & $\mathrm{Eu}^{2+}$ & 540 & & & {$[97]$} \\
\hline $\mathrm{EuAl}_{2} \mathrm{~S}_{4}$ & $\mathrm{Eu}^{2+}$ & 508 & & & {$[166]$} \\
\hline $\mathrm{CaIn}_{2} \mathrm{~S}_{4}$ & $\mathrm{Eu}^{2+}$ & 731 & strong & $95 \mathrm{~nm} \mathrm{FWHM}$ & {$[183]$} \\
\hline $\mathrm{SrIn}_{2} \mathrm{~S}_{4}$ & $\mathrm{Eu}^{2+}$ & $640(80 \mathrm{~K})$ & strong & & {$[166]$} \\
& & 614 & & & {$[183]$} \\
\hline $\mathrm{BaIn}_{2} \mathrm{~S}_{4}$ & $\mathrm{Eu}^{2+}$ & $680(80 \mathrm{~K})$ & strong & & {$[166]$} \\
& & 663 & & 145 & FWHM \\
\hline
\end{tabular}

The preparation requirements and the intrinsic instability of the phosphor against moisture make handling difficult and potentially reduce the lifetime upon improper encapsulation. In combination with the reported moderate quantum efficiencies [97,124,181], make the class of the thioaluminates less suited for LED color conversion, in spite of the excellent thermal quenching behavior of for instance $\mathrm{BaAl}_{2} \mathrm{~S}_{4}: \mathrm{Eu}[55]$ (Table 4). 
Upon consideration of the interesting properties of the alkaline earth thioaluminate and thiogallate phosphors, one might also consider the thioindate phosphors, for which a red-shifted emission can be anticipated. However, the relatively small bandgap of these materials compared to the thioaluminates and thiogallates [184], leads to anomalous emission and/or strong thermal quenching due to the increased interaction of the $5 \mathrm{~d}$ excited states of $\mathrm{Eu}^{2+}$ and the conduction band states [159]. For instance $\mathrm{BaIn}_{2} \mathrm{~S}_{4}$ and $\mathrm{CaIn}_{2} \mathrm{~S}_{4}$, both show a strongly broadened and weak emission at room temperature [166,183].

\subsection{Thiosilicates and thiogermanates.}

The emission of thiosilicate hosts upon doping with $\mathrm{Ce}^{3+}$ and $\mathrm{Eu}^{2+}$ covers the entire range from deep-blue $\left(\mathrm{Ba}_{2} \mathrm{SiS}_{4}: \mathrm{Ce}^{3+}\right)$ to saturated red $\left(\mathrm{Ca}_{2} \mathrm{SiS}_{4}: \mathrm{Eu}^{2+}\right)[129,168]$. Figure 6 gives an overview of the emission colors that can be obtained. In general, $\mathrm{Ce}^{3+}$ doping is less efficient and the optimal dopant concentration is fairly low. Adding $\mathrm{Al}^{3+}$ as a co-dopant to $\mathrm{Ba}_{2} \mathrm{SiS}_{4}: \mathrm{Ce}^{3+}$ improves the crystallinity, the luminescence intensity and the dopant incorporation [130]. An internal quantum efficiency of 36\% was reported.

$\mathrm{Ca}_{2} \mathrm{SiS}_{4}: \mathrm{Eu}^{2+}$ shows two emission bands, at $565 \mathrm{~nm}$ and $660 \mathrm{~nm}$ [186], with the ratio between both bands depending on the europium concentration (Table 5). The solubility of $\mathrm{Eu}^{2+}$ in the orthorhombic $\mathrm{Ca}_{2} \mathrm{SiS}_{4}$ host is limited to about $10 \%$. For higher concentrations, a second, monoclinic phase similar to $\mathrm{Eu}_{2} \mathrm{SiS}_{4}$ is formed [189]. The fully substituted compound $\mathrm{Eu}_{2} \mathrm{SiS}_{4}$ is still luminescent, although the emission efficiency is considerably quenched [186,190]. Moreover, the practical application of such a fully substituted phosphor would be limited due to the prohibitively high cost of europium. It is interesting to note that also $\mathrm{EuGa}_{2} \mathrm{~S}_{4}$ and $\mathrm{EuAl}_{2} \mathrm{~S}_{4}$ show luminescence at room temperature, while EuS does not $[166,191,192]$.

Figure 6. Emission colors of europium and cerium doped thiosilicates. Dopant concentration is $1 \mathrm{~mol} \%$, unless otherwise specified [129,186,188].

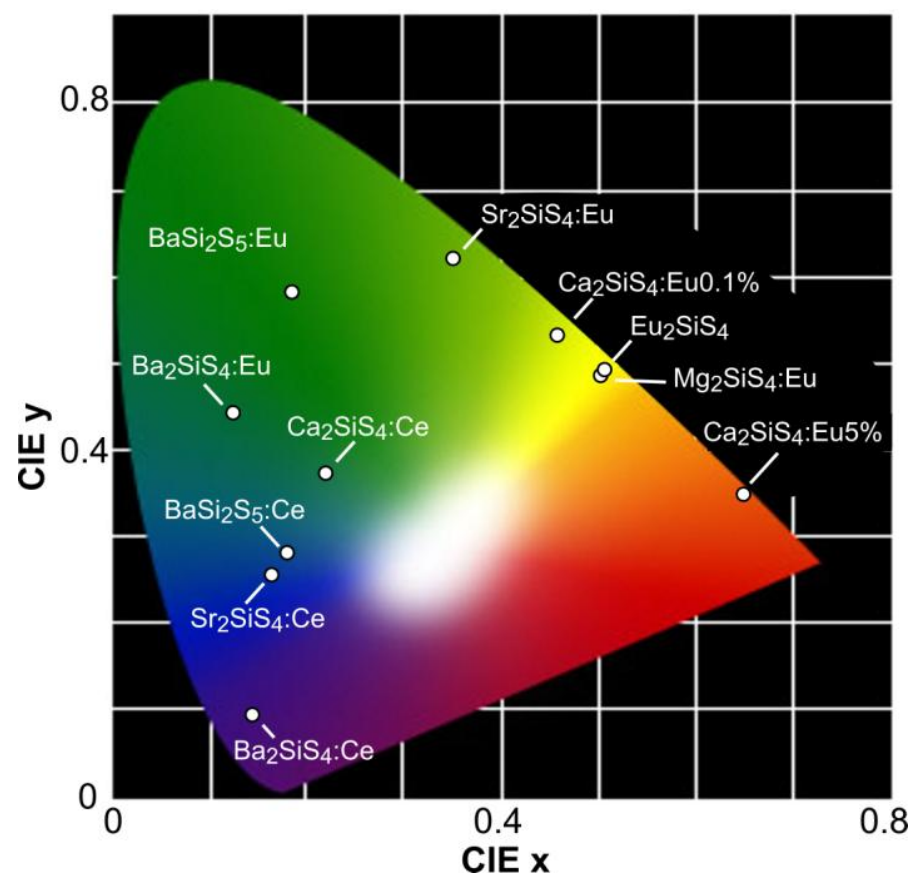


Table 5. Emission properties of $\mathrm{Eu}^{2+}$ and $\mathrm{Ce}^{3+}$ doped thiosilicate and thiogermanate phosphors. $x \%$ quenching indicates the fraction of the emission intensity at room temperature compared to the low temperature intensity. $x \mathrm{~K}$ is the temperature for which the emission intensity is half that at low temperature.

\begin{tabular}{|l|l|l|l|l|l|}
\hline Host & Dopant & $\lambda_{\max }(\mathbf{n m})$ & Quenching & Remarks & Ref. \\
\hline $\mathrm{Na}_{2} \mathrm{Si}_{2} \mathrm{~S}_{5}$ & $\mathrm{Eu}^{2+}$ & 488 & & Weak emission & {$[185]$} \\
\hline $\mathrm{Na}_{4} \mathrm{SiS}_{4}$ & $\mathrm{Eu}^{2+}$ & 460 & & & {$[185]$} \\
& $\mathrm{Ce}^{3+}$ & 436 & & & \\
\hline $\mathrm{Mg}_{2} \mathrm{SiS}_{4}$ & $\mathrm{Eu}^{2+}$ & 660 & & & {$[168]$} \\
\hline $\mathrm{Ca}_{2} \mathrm{SiS}_{4}$ & $\mathrm{Eu}^{2+}$ & 565 & $445 \mathrm{~K}$ & {$[\mathrm{Eu}]<1 \mathrm{~mol} \%$} & {$[186,187]$} \\
& $\mathrm{Eu}^{2+}$ & 660 & $470 \mathrm{~K}$ & {$[\mathrm{Eu}]>1 \mathrm{~mol} \%$} & {$[186,187]$} \\
& $\mathrm{Ce}^{3+}$ & 475 & & & {$[129]$} \\
\hline $\mathrm{CaEuSiS}_{4}$ & $\mathrm{Eu}^{2+}$ & 614 & & & {$[186]$} \\
\hline $\mathrm{Sr}_{2} \mathrm{SiS}_{4}$ & $\mathrm{Eu}^{2+}$ & 545 & $380 \mathrm{~K}$ & & {$[168,188]$} \\
& $\mathrm{Ce}^{3+}$ & 466 & & & {$[168]$} \\
\hline $\mathrm{SrSi}_{2} \mathrm{~S}_{5}$ & $\mathrm{Eu}^{2+}$ & 490 & & & {$[185]$} \\
\hline $\mathrm{Ba}_{2} \mathrm{SiS}_{4}$ & $\mathrm{Eu}^{2+}$ & 495 & & & {$[129,185]$} \\
& $\mathrm{Ce}^{3+}$ & 435 & & & {$[129,185]$} \\
\hline $\mathrm{BaSi}_{2} \mathrm{~S}_{5}$ & $\mathrm{Eu}^{2+}$ & 505 & & & {$[129,185]$} \\
& $\mathrm{Ce}^{3+}$ & 508 & & & {$[129,185]$} \\
\hline $\mathrm{Ba}_{3} \mathrm{SiS}_{5}$ & $\mathrm{Eu}^{2+}$ & - & & No emission at RT & {$[128]$} \\
\hline $\mathrm{Eu}_{2} \mathrm{SiS}_{4}$ & & 577 & & & {$[186]$} \\
\hline $\mathrm{Sr}_{2} \mathrm{GeS}_{4}$ & $\mathrm{Eu}^{2+}$ & - & & No emission at RT & {$[185]$} \\
\hline $\mathrm{Ba}_{2} \mathrm{GeS}_{4}$ & $\mathrm{Eu}^{2+}$ & - & & No emission at RT & {$[185]$} \\
\hline
\end{tabular}

The stability of the thiosilicates upon contact with moisture depends on the composition. It is significantly better than the thioaluminates, and comparable to that of $\mathrm{CaS}$ and SrS. Several thiosilicates show two emission bands with the ratio depending on the europium concentration, often leading to relatively broad emission. This might be favorable for use as LED phosphor, where one can tune the emission color by changing both the composition of the host lattice and the dopant concentration. $\mathrm{Ca}_{2} \mathrm{SiS}_{4}$ and $\mathrm{Sr}_{2} \mathrm{SiS}_{4}$ show only a partial miscibility, due to a different crystal lattice [188]. The thermal quenching is limited for $\mathrm{Ca}_{2} \mathrm{SiS}_{4}: \mathrm{Eu}\left(\mathrm{T}_{0.5}=470 \mathrm{~K}\right)$ [187], but appears worse for other compounds like $\mathrm{Sr}_{2} \mathrm{SiS}_{4}: \mathrm{Eu}\left(\mathrm{T}_{0.5}=380 \mathrm{~K}\right)$ [188]. At $425 \mathrm{~K}, \mathrm{Ba}_{2} \mathrm{SiS}_{4}: \mathrm{Ce}^{3+}$ keeps $80 \%$ of its room temperature emission intensity [130].

Only a few reports on the luminescence of the thiogermanates are available. $\mathrm{Ba}_{2} \mathrm{GeS}_{4}: \mathrm{Eu}^{2+}$ and $\mathrm{Sr}_{2} \mathrm{GeS}_{4}: \mathrm{Eu}^{2+}$ are not luminescent at room temperature [185]. A much smaller optical band gap can be anticipated for the thiogermanates in comparison to the thiosilicates. This would lead to a strong interaction (if not overlap) between the $5 \mathrm{~d}$ excited states and the conduction band states and consequently to a strong thermal, if not full, quenching of the luminescence. 


\subsection{Future}

The past years were characterized by a strong research interest in color conversion phosphors for LEDs. The lack of phosphors with sufficient emission intensity in the red part of the visible spectrum can be overcome with certain $\left(\mathrm{Eu}^{2+}\right.$-doped) sulfide phosphors. As discussed above, several sulfide phosphors are well suited as color conversion material, provided that their thermal quenching behavior and quantum efficiency are meticulously studied. Currently, these aspects are often lacking in recently published work on (sulfide) conversion phosphors. When compared to other recently proposed hosts, such as the nitrides $[135,193,194]$ and oxynitrides $[195,196]$, the sulfides have the disadvantage of a much lower stability, although this could be improved upon proper encapsulation, which can both be achieved at the level of a single phosphor particle or by incorporation in an impermeable matrix. Of course, when considering the expected lifetime of an LED being in the range of 10-50 khours, one would rather use the most stable phosphor host available.

\section{Persistent Luminescence and Storage Phosphors}

Persistent phosphors are materials which can emit light up to hours after the (optical) excitation has ceased. Since more than a decade, green-emitting $\mathrm{SrAl}_{2} \mathrm{O}_{4}: \mathrm{Eu}$,Dy has replaced $\mathrm{ZnS}: \mathrm{Cu}$,Co, due to its better stability and longer afterglow [197]. Several other efficient materials were developed, especially in the short wavelength range of the visible spectrum, such as $\mathrm{CaAl}_{2} \mathrm{O}_{4}: \mathrm{Eu}, \mathrm{Nd}$ (violet, [198]) and $\mathrm{Sr}_{2} \mathrm{MgSi}_{2} \mathrm{O}_{7}$ :Eu,Dy (blue, [199]). A review of the reported persistent phosphors and the different models which have been proposed can be found in this 'Special Issue' [200]. Yellow and red persistent phosphors with high initial brightness are relatively scarce, which is partially due to the reduced eye sensitivity at low light intensity levels and the limited number of host materials for $\mathrm{Eu}^{2+}$ yielding red emission [201]. Moreover, a new standard was proposed to accurately describe persistent phosphors when light levels are below $1 \mathrm{~cd} / \mathrm{m}^{2}$ [201,202]. The development of bright red persistent phosphors would open a new range of applications, for instance in emergency signage.

To obtain persistent luminescence in the long wavelength range of the visible spectrum, one could either look at $\mathrm{Eu}^{3+}$ based materials or specific $\mathrm{Eu}^{2+}$ activated sulfides. $\mathrm{Y}_{2} \mathrm{O}_{2} \mathrm{~S}: \mathrm{Eu}^{3+}$ codoped with $\mathrm{Ti}$ and $\mathrm{Mg}$ is one of the few red persistent phosphors, but it cannot efficiently be excited by visible light and the afterglow is relatively short [203].

As $\mathrm{CaS}: \mathrm{Eu}^{2+}$ and $\mathrm{SrS}: \mathrm{Eu}^{2+}$ are able to yield red and orange emission respectively, they have attracted some attention as persistent phosphor as well. $\mathrm{SrS}: \mathrm{Eu}^{2+}$ often shows some afterglow even without (intentional) co-doping [204], which is possibly related to synthesis conditions promoting sulfur deficiency. The addition of $\mathrm{Dy}^{3+}$ somewhat enhances the afterglow, although it remains short and relatively weak [205,206].

The addition of $\mathrm{Cl}^{-}$to $\mathrm{CaS}$ :Eu yields an afterglow in the deep-red region with slightly red-shifted emission compared to CaS:Eu [207]. Addition of trivalent ions such as $\mathrm{Y}^{3+}, \mathrm{Al}^{3+}$ and $\mathrm{Tm}^{3+}$ to $\mathrm{CaS}: \mathrm{Eu}$ gives moderate (Y, Al) to bright afterglow (Tm) [208,209], while adding $\mathrm{Na}^{+}$to CaS:Eu,Tm reduces it, suggesting a significant role for the charge compensating defects.

Upon adding $\mathrm{Sm}^{3+}$ to $\mathrm{CaS}: \mathrm{Eu}$ [210], a photo stimulable phosphor (rather than a persistent phosphor) is obtained as the trap levels introduced by $\mathrm{Sm}^{3+}$ are too deep to be thermally emptied. However, upon illumination of the material with infrared excitation, visible emission can be obtained (provided the 
powder has previously been excited by UV or visible light, x-rays..., which discriminates it from an up conversion phosphor). The exact defect structure caused by the introduction of the rare earth ions and its influence on the energy level scheme has not been fully established yet $[211,212]$. Furthermore, the phosphor's behavior strongly depends on the concentrations of the Sm and Eu dopants [213]. Jia et al. also reported that the addition of $\mathrm{Tm}^{3+}$ to $\mathrm{Ca}_{0.9} \mathrm{Sr}_{0.1} \mathrm{~S}_{\mathrm{Bi}^{3+}}$ prolongs and intensifies the (blue) afterglow in this material [214]. A relatively short and weak afterglow could be obtained upon co-doping of $\mathrm{CaGa}_{2} \mathrm{~S}_{4}$ :Eu, with the best result for $\mathrm{Ho}^{3+}[101,215]$.

Recently, persistent luminescence in $\mathrm{Ca}_{2} \mathrm{SiS}_{4}: \mathrm{Eu}, \mathrm{Nd}$ was reported, with the main emission band peaking at $660 \mathrm{~nm}$ [187]. Practical usage seems limited, as excitation below $360 \mathrm{~nm}$ is required to induce the persistent luminescence. In addition, the perceived emission intensity is relatively low, due to the eye sensitivity which drops rapidly at decreasing light levels at this long wavelength [201]. Nevertheless, it could be interesting from a fundamental point of view, as it was shown that transfer of charge carriers via the conduction band must be limited and that the $\mathrm{Nd}^{3+}$ codopants (and associated charge compensating defects) most probably reside in the proximity of the $\mathrm{Eu}^{2+}$ ions [187].

Most of the time, persistent phosphors are applied as luminous paint, for instance in emergency exit indicators. Hence they are required to have long lifetimes in often relatively harsh environments. Even with adequate encapsulation, the intrinsic instability of phosphor hosts like $\mathrm{CaS}, \mathrm{SrS}$ or $\mathrm{Ca}_{2} \mathrm{SiS}_{4}$ appears unfavorable for persistent luminescence applications.

\section{Luminescent Sulfide Nanoparticles}

\subsection{Undoped nanoparticles}

\subsubsection{Introduction}

Colloidal semiconductor nanocrystals or quantum dots (Qdots) offer an interesting alternative to $\mathrm{Ce}^{3+}$ - or $\mathrm{Eu}^{2+}$ - doped bulk sulfide materials. When their radius $R$ is smaller than the bulk exciton Bohr radius $R_{B}$, their electronic properties, most importantly the Qdot band gap, become size-dependent [216]. In this regime, termed the strong quantum confinement regime, the Qdot eigenstates form a discrete set instead of the quasi-continuum of states found in bulk semiconductors. To illustrate this, let us first assume that a Qdot can be regarded as an infinite spherical quantum well. The eigenenergies $E_{l k}$ of a particle with mass $m_{0}$ in this infinite well are given by:

$$
E_{l k}=\frac{\hbar^{2} u_{l k}^{2}}{2 m_{0} R^{2}}
$$

$u_{l k}$ denotes the $k$-th zero of the BesselJ-function of order $l$. Clearly, every energy level $E_{l k}$ increase with the inverse of the square of the particle radius $R$. A more rigorous calculation of the Qdot eigenstates accounts for a shielded Coulomb attraction between the electron and hole which constitute the exciton formed after excitation. This correction scales with $R^{-1}$, and we obtain following sizedependence for the Qdot band gap $E_{0}$ (Brus-equation, [216] $E_{g}$ : bulk band gap; $m_{e}$ : electron effective mass; $m_{h}$ : hole effective mass, $\varepsilon$ dielectric constant): 


$$
E_{0}=E_{g}+\frac{\hbar^{2} \pi^{2}}{2 R^{2}}\left(\frac{1}{m_{e}}+\frac{1}{m_{h}}\right)-\frac{1.8 e^{2}}{\varepsilon R}
$$

Conveniently, the blue shift of the band gap with decreasing Qdot size allows covering a large part of the electromagnetic spectrum by a single material. Taking the cadmium salt Qdots as an example: $\mathrm{CdS}$ emits violet to blue light, CdSe emits from blue to red and the CdTe emission can be tuned from green to deep red [217], [218].

Most semiconductor Qdot materials can be synthesized with a high photoluminescence quantum yield, which is often accomplished by coating the Qdot core with an inorganic shell [219]. This shell, typically consisting of $\mathrm{ZnS}$, has a larger band gap than the Qdot core and thus prohibits a penetration of the exciton wavefunction into the shell (type-I core-shell Qdots, both carriers localized in the Qdot core). It effectively shields the exciton from the surface; hence, possible surface states no longer lead to a quenching of the Qdot luminescence and Qdots with a high quantum yield are obtained. For instance, quantum yield values of up to $60 \%$ have been reported for $\mathrm{CdSe} / \mathrm{ZnS}$ and $\mathrm{InP} / \mathrm{ZnS}$ core-shell Qdots [219].

Coating procedures can also be used to further engineer the Qdot band gap. Instead of using a high band gap shell material (such as $\mathrm{ZnS}$ ), two materials with a large bulk band offset can be combined. In this case, the staggered band alignment leads to a spatially separated exciton, where the electron for instance remains in the Qdot core while the hole is transferred to the shell (type-II core-shell Qdots). An indirect band gap is formed which may be, depending on the core size and shell thickness, narrower than the bulk band gap of both constituents. CdS/ZnSe for instance can be synthesized with an absorption onset down to $650 \mathrm{~nm}$, while both bulk materials have an absorption onset of $515 \mathrm{~nm}$ and $460 \mathrm{~nm}$, respectively [219].

The versatile band gap tuning and high photoluminescence quantum yield has lead to a diverse range of applications based on colloidal Qdots; they are currently used as luminescent biomarkers [220,221] and in light-emitting diodes [222-225] and lasers [226-228]. Clearly, colloidal semiconductor Qdots have a large potential, however covering the broad range of materials and applications is beyond the scope of this review. We refer to the review by Bera et al. [229] for a more detailed discussion. Here, we will limit ourselves to sulfide Qdots, in casu $\mathrm{CdS}$ and $\mathrm{PbS}$, and the applications realized with these materials.

\subsubsection{Brief historic overview of sulfide Qdots}

During the pioneering years of research on quantum dots (Qdots), now thirty years ago, metal sulfide nanocrystals were among the first materials to be synthesized. Following the groundbreaking theoretical work of Brus [216] and Efros and Efros [230], who calculated that quantum confinement induces a discretization of the electronic band structure and a blue shift of the band gap in small semiconductor nanocrystals, several research groups indeed succeeded in the synthesis of metal sulfide Qdots, more specifically CdS and PbS, either in solution [231-234], in polymers [235,236] or in a glass host [237-240]. As a result of the small nanocrystal size, typically a few nanometer (Figure 7), the Qdot band gap was clearly shifted to higher energies and pronounced absorption peaks, due to transitions between the discrete Qdot energy levels, appeared in the spectrum (Figure 8). 
However, the typical Qdot photoluminescence yield in these materials was low, and the Qdots often suffered from trap emission due to the high surface-to-volume ratio. Although Henglein [232] successfully increased this yield to $50 \%$ by a coating of $\mathrm{CdS}$ particles with $\mathrm{Cd}(\mathrm{OH})_{2}$, this problem was remedied more efficiently by the development of a high temperature organic phase synthesis, described by Murray et al. in 1993 [241]. High-quality colloidal CdX (X = S, Se, Te) Qdots of uniform size were prepared by their method. Furthermore, a proper passivation of the surface by organic ligands ensured a high photoluminescence yield. Consequently, this paper sparked a strong interest in colloidal Qdots.

Figure 7. Transmission electron microscopy image of a single $\mathrm{PbS}$ nanocrystal (Reprinted with permission from [231]. Copyright 1985 American Institute of Physics).

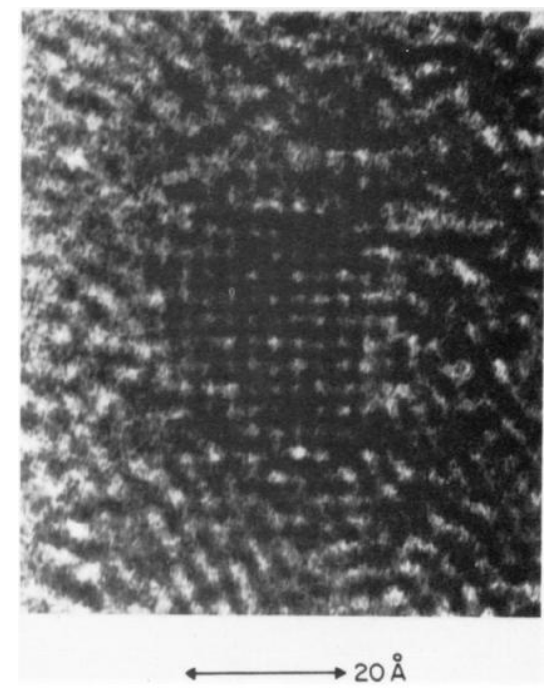

Figure 8. (left) Absorbance spectra of CdS Qdots of radius $32 \mathrm{~nm}(1), 2.3 \mathrm{~nm}(2), 1.5 \mathrm{~nm}$ (3) and $1.2 \mathrm{~nm}$ (4), (right) absorbance spectra of $31 \mathrm{~nm}(1), 2.9 \mathrm{~nm}$ (2) and $2.0 \mathrm{~nm}$ (3) $\mathrm{CuCl}$ Qdots (Reprinted from [237] with permission from Elsevier).

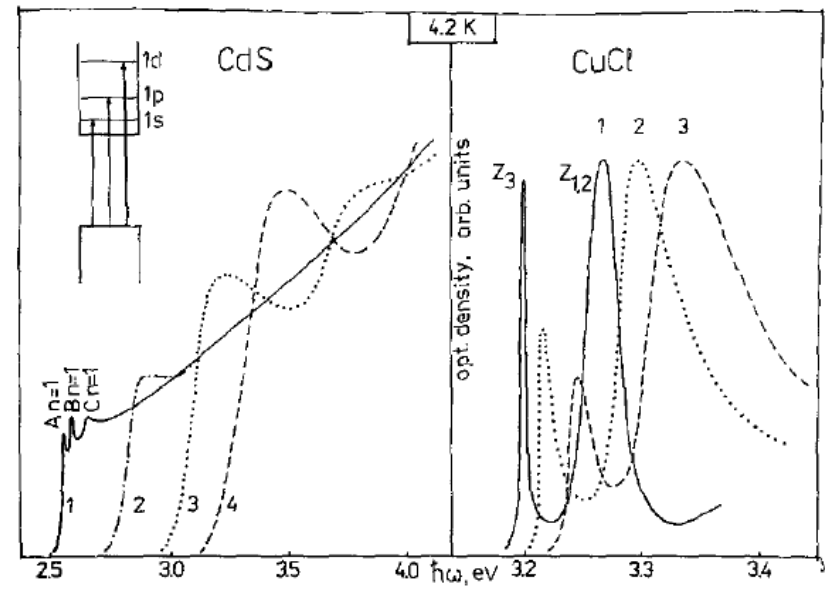




\subsubsection{State-of-the-art}

Currently, both $\mathrm{CdS}$ and $\mathrm{PbS}$ Qdots are widely investigated, especially since the development of high quality synthesis routes employing greener chemicals. For the production of CdS Qdots, Peng et al. replaced the dimethyl cadmium employed by Murray et al. [241] with Cd-phosphonate or Cdcarboxylate complexes, which were prepared by reacting $\mathrm{CdO}$ with the respective long-chained acid [217,218]. As the bulk band gap for CdS equals $2.41 \mathrm{eV}$ [242], these synthesis schemes usually yield Qdots with an emission tunable from the blue to the near UV (Figure 9). Reported quantum efficiencies for CdS Qdots produced by similar methods typically vary between 3 and 12\% [243,244], although it can be increased to $30-40 \%$ by coating the Qdots with a protective ZnS shell [244,245]. Similarly, encapsulating them with 2-mercaptopropionic acid increases the luminescence yield to ca. $50 \%$ [246].

Figure 9. Series of absorbance (full lines) and luminescence spectra (dotted lines) of CdS Qdots of varying size. (Reprinted from [217] with permission. Copyright Wiley-VCH Verlag GmbH \& Co. KGaA.).

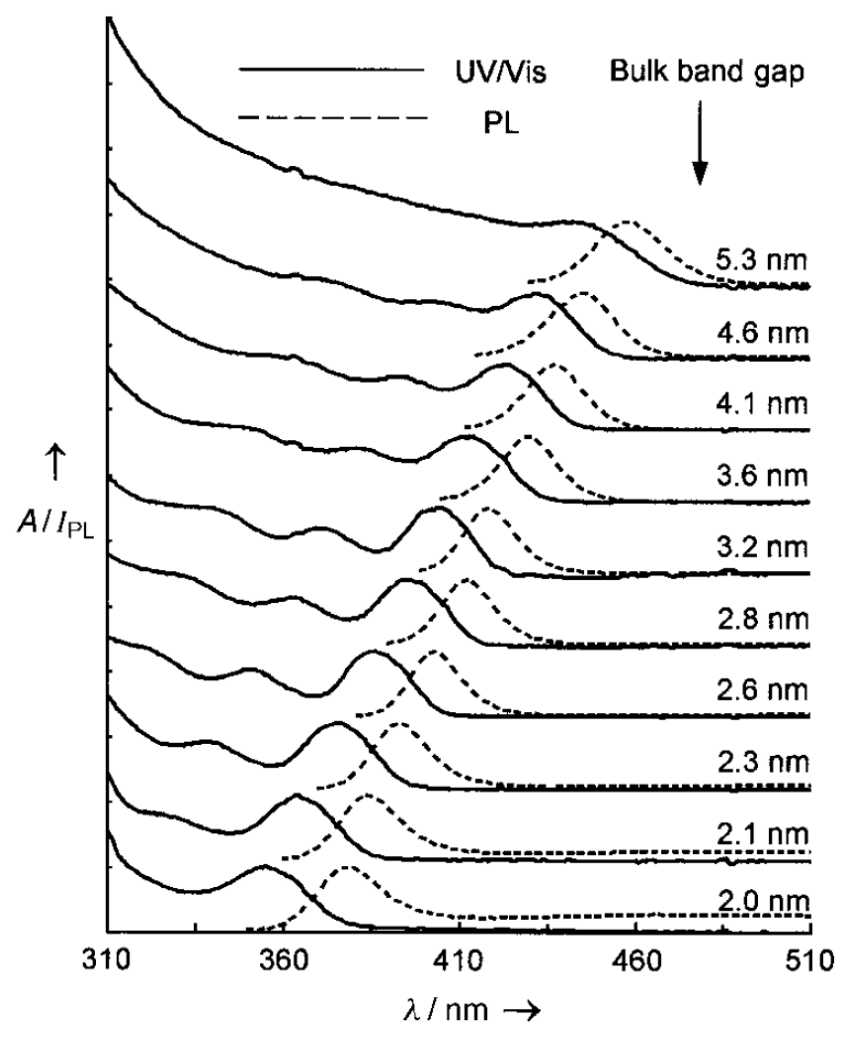

With a bulk band gap of $0.41 \mathrm{eV}, \mathrm{PbS}$ Qdots are an ideal material for NIR imaging [248], photodetectors and photovoltaics [249-253] and telecom applications [227,254]. In 2003, two important colloidal synthesis routes for $\mathrm{PbS}$ Qdots were proposed. They differ significantly, the method of Hines et al. [255] being based on leadoleate and bis(trimethylsilyl)sulfide, while Joo et al. [256] (and later Cademartiri et al. [247]) start from $\mathrm{PbCl}_{2}$ and elemental sulphur dissolved in oleylamine. However, both lead to monodisperse $\mathrm{PbS}$ Qdot suspensions, indicated by the sharp absorption and luminescence features of the Qdots (Figure 10). They possess a strong band gap 
luminescence in the NIR (Figure 10), with quantum yields ranging between 20 and $80 \%$ [247,255,257]. Interestingly, the luminescence decay time in these materials is quite long (typically a few $\mu$ s) [258], comparable to PbSe Qdots [259], but much longer than CdX materials, which have a decay time of the order of 10-50 ns [246,260,261]. Recent results have shown that a strong local field effect in PbS Qdots [262] leads to this long decay time, although the different band structure may also play a role here.

Figure 10. Series of luminescence (a) and absorbance spectra (b) of PbS Qdots of varying size. (Reprinted with permission from [247]. Copyright 2006 American Chemical Society).

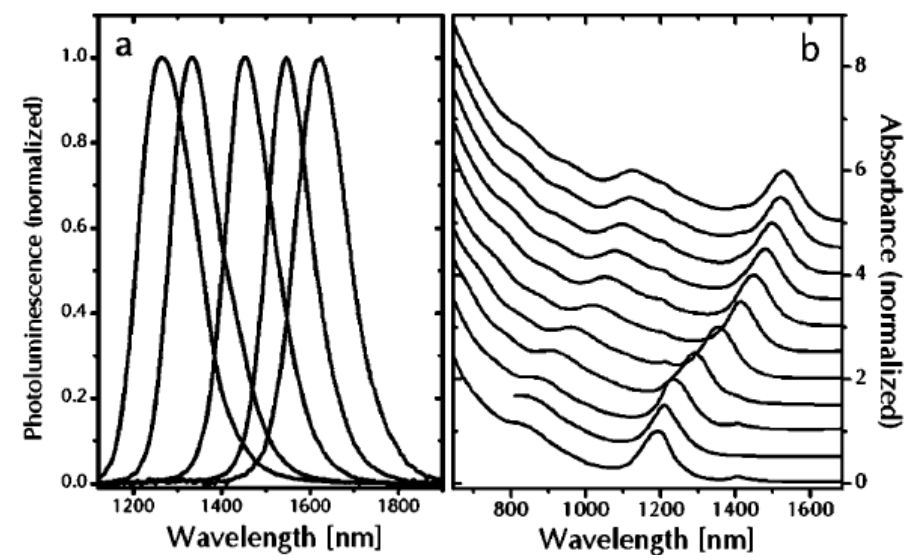

\subsubsection{Applications of luminescent metal sulfide Qdots}

Due to their bright luminescence, both $\mathrm{CdS}$ and $\mathrm{PbS}$ Qdots are interesting materials for photonic devices based on light emission. Hence, the observation of amplified spontaneous emission and gain in visible [260,263,264] and NIR [265-267] Qdot materials rapidly led to the development of Qdot lasers. For instance, using CdS Qdots, an optically pumped blue laser was recently demonstrated [228]. The Qdot emission was coupled to the whispering gallery modes of a glass microsphere, and above a threshold of $\sim 60 \mu \mathrm{W}$ (corresponding to a fluence of $3.7 \mathrm{~mJ} / \mathrm{cm}^{2}$ ), lasing was observed. Similarly, $\mathrm{PbS}$ Qdots have been used by Hoogland et al. [227] to produce a laser operating at telecom wavelengths (1.53 $\mu \mathrm{m}$ in this case). By coating the inner walls of a glass microcapillary tube, the emission was again coupled to the whispering gallery modes of the cavity, leading to efficient lasing above a threshold fluence of $177 \mu \mathrm{J} / \mathrm{cm}^{2}$ (Figure 11). 
Figure 11. (a) Absorption spectrum (full line) and below-threshold photoluminescence spectrum at room temperature (dashed line) and $80 \mathrm{~K}$ (dotted line) of $\mathrm{PbS}$ Qdots. The sharp peak corresponds to the emission spectrum of the Qdot microcapillary laser when pumped above threshold. (b) Pump fluence dependence of the Qdot emission. The threshold behavior and representative emission spectra (insets) clearly demonstrate lasing. (permission requested, adapted from [227]).
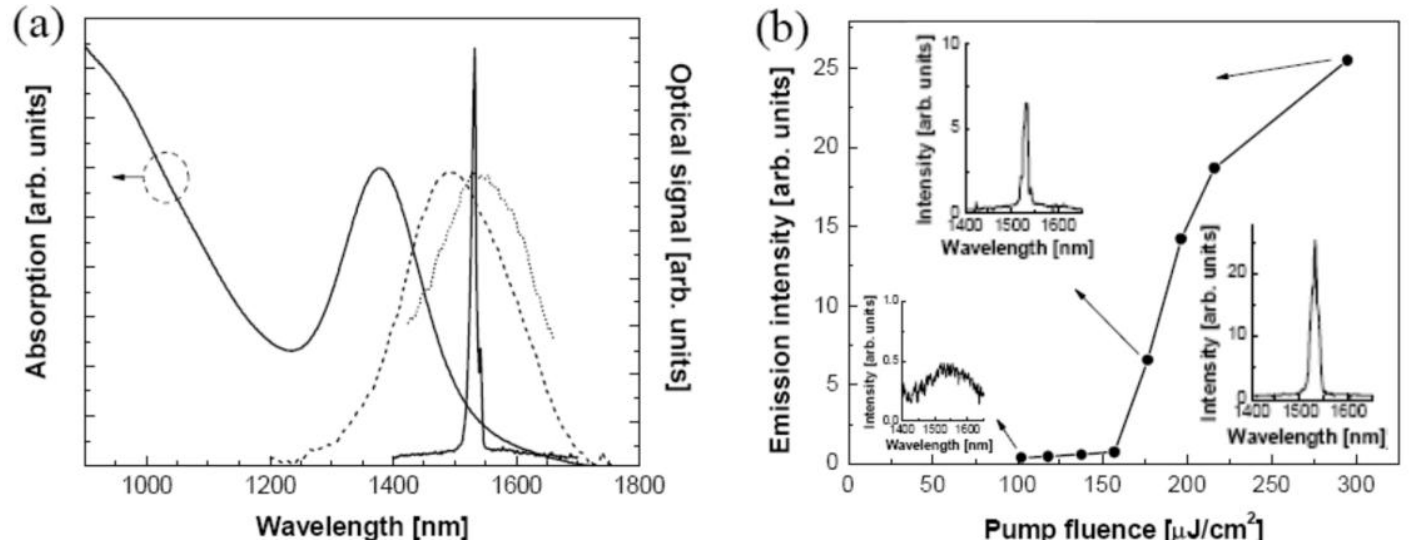

Next to emission due to photoexcitation, colloidal Qdots can also be excited by electrical pumping. The demonstration of electroluminescence [268-270] was therefore an important step forward in the fabrication of light-emitting devices (LEDs). Following these early experiments, Qdot LEDs based on $\mathrm{CdS}$ (Figure 12) [222] and PbS [223] Qdots have been reported. While PbS Qdots offer the unique possibility of having efficient NIR LEDs over a wide spectral range, unfortunately, in the case of CdS, we are restricted to the blue part of the electromagnetic spectrum. Other $\mathrm{CdX}$ materials and compositions are needed to enable LED fabrication over the remaining visible spectrum [224,225]. However, as reported by Anikeeva et al., in the blue spectral region important challenges remain, as the external quantum efficiency is low [224]. A value of only $0.4 \%$ was obtained for a blue LED employing ZnCdS Qdots coated with a ZnS shell, compared to an efficiency of $2.6 \%$ for a green LED. This implies that there is still plenty of room for optimization, either through device fabrication or an improvement of the active material.

Figure 12. Electroluminescence spectrum of a CdS Qdot LED, measured at a bias of 5.5 V. Inset: images of the LED. (Reprinted with permission from [222]. Copyright 2007 American Chemical Society.).

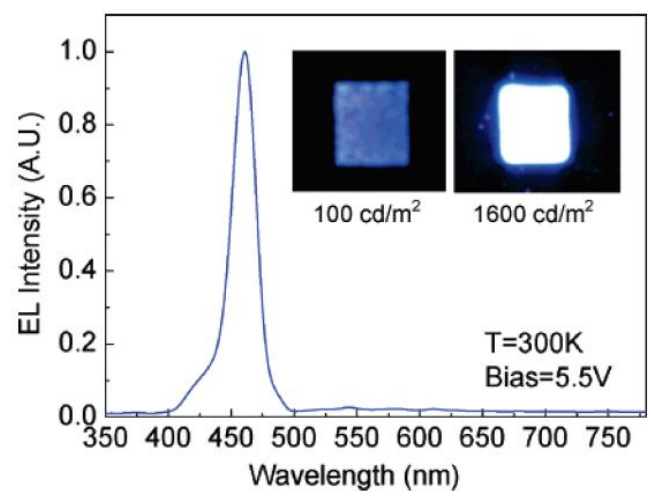




\subsection{Doped nanoparticles}

During the past decade, the strong research effort in semiconductor quantum dots also sparked interest into doped quantum dots, being the nano-sized counterpart of the well-studied rare earth and transition metal doped bulk phosphors. Regardless of the exact composition of these nano-materials, it is not a priori clear whether reducing the particle's size is favorable for the luminescence properties of the dopants (having localized transitions). The increase in band gap which follows the decrease in size might be favorable for the thermal quenching behavior, while the increased surface-to-volume ratio offers additional non-radiative decay routes. The main obstacle, however, is the effective incorporation of the dopant ions into the nanoparticles, rather than simply decorating the particles' surface. As hardly any work has been reported on ternary sulfides, except for some top-down approaches, where particle size is reduced by ball-milling [271], we will focus on doped 'simple sulfides' like ZnS, CaS and SrS.

$\mathrm{ZnS}: \mathrm{Mn}$ is probably the most studied doped sulfide in nano-sized form, due to the chemical similarity between $\mathrm{Zn}^{2+}$ and $\mathrm{Mn}^{2+}$, facilitating the incorporation of the dopant ion. Nevertheless, the incorporated concentration is consistently lower than the intended dopant concentration [272] and part of the $\mathrm{Mn}^{2+}$ ions reside near the surface of the nanoparticle. The work by Bol et al. showed that the lifetime of $\mathrm{Mn}^{2+}$ in $\mathrm{ZnS}: \mathrm{Mn}^{2+}$ quantum dots is very similar to the bulk lifetime [273,274], in spite of earlier work stating a considerable shortening of the lifetime [275]. Also the emission spectrum itself is almost size-independent [272,274]. Hence, growing an inorganic ( $\mathrm{ZnS}$ ) shell around $\mathrm{ZnS}: \mathrm{Mn}$ effectively reduces non-radiative decay paths and enhances the luminescence [276], more efficiently than organic passivation of the surface [272]. Synthesis techniques, luminescence properties and possible applications of $\mathrm{ZnS}: \mathrm{Mn}$ nanoparticles can be found in the Reviews by Chen et al. [277] and Yang et al. [272].

For the solvothermal synthesis of $\mathrm{ZnS}$, Biswas and Kar investigated the influence of precursors, solvents and temperature on the crystallographic phase formation (cubic and hexagonal), morphology (particles, rods and sheets) and size (few nm to micron size) [278]. Some reports are available on the luminescence of nano-sized $\mathrm{ZnS}: \mathrm{Eu}$, although the results are diverging, with the presence of both $\mathrm{Eu}^{3+}$ and (assumed) $\mathrm{Eu}^{2+}$ emission [279-281]. Bulk $\mathrm{ZnS}: \mathrm{Eu}$ is not luminescent and it was supposed that increasing the band gap of the host would allow the 5d-4f transition in $\mathrm{Eu}^{2+}$. Incorporation of Eu in the first place appears difficult in $\mathrm{ZnS}$, due to the strongly different ionic radius of $\mathrm{Zn}^{2+}$ and $\mathrm{Eu}^{2+}$ [282].

$\mathrm{AC}$ electroluminescence was reported using $\mathrm{ZnSe} / \mathrm{ZnS}: \mathrm{Mn} / \mathrm{ZnS}$ core/shell nanoparticles with a high photoluminescent quantum efficiency of 65\% [283]. The semiconductor part of the ACTFEL devices consisted of a multi-layer of spin-casted nanoparticles layers (thickness of $30 \mathrm{~nm}$ ) and sputtered (undoped) $\mathrm{ZnS}$ layers $(12 \mathrm{~nm}$ ). The typical orange $\mathrm{ZnS}: \mathrm{Mn}$ emission was obtained for these structures, with a brightness of $2 \mathrm{~cd} / \mathrm{m}^{2}$ at $30 \mathrm{kHz}$, while devices without the sputtered $\mathrm{ZnS}$ layers didn't show EL emission. Toyama et al. did obtain EL in a $150 \mathrm{~nm}$ thick printed layer of ZnS:Mn nanoparticles. At 5 $\mathrm{kHz}$, and $45 \mathrm{~V}$ above threshold, a luminance of $1 \mathrm{~cd} / \mathrm{m}^{2}$ could be obtained for the smallest particles (3 nm) [284].

The doped 'simple sulfides', like CaS and SrS, have recently attracted some attention in their nanosized form. Several synthesis methods have been proposed for the synthesis of $\mathrm{CaS}$ and $\mathrm{SrS}$, such as a precipitation method (using chloride precursors and sodium sulfide [285,286]) and an alkoxide method (using $\mathrm{H}_{2} \mathrm{~S}$ as sulfur source [285]). With both methods, particle sizes in the range from 15 to $25 \mathrm{~nm}$ 
could be obtained. Upon doping with $\mathrm{Eu}^{2+}$, the as-prepared particles are not luminescent and EPR (electron-paramagnetic resonance) shows the europium ions are not incorporated in the particles yet (at least not in their divalent state). After a thermal annealing at typically $700{ }^{\circ} \mathrm{C}$, luminescent nanoparticles are obtained, with emission and excitation spectra rather similar to the bulk counterparts [285,286]. Other methods using a reducing atmosphere at high temperature were proposed for the preparation of SrS:Eu,Dy and $\mathrm{SrS}: \mathrm{Cu}$ nanoparticles [205,287].

A solvothermal method was also reported to obtain doped sulfides, such as $\mathrm{CaS}: \mathrm{Pb}, \mathrm{CaS}: \mathrm{Ag}$ and CaS:Bi [288,289]. Chloride precursors, elemental sulfur, ethylenediamine and capping agents are heated to about 170 to $220{ }^{\circ} \mathrm{C}$ in a teflon-lined autoclave for several hours. Particles with a relatively broad size range are obtained, ranging from tens to hundreds of $\mathrm{nm}$. No thermal annealing is required to obtain luminescent particles. Modifications to this solvothermal synthesis using ethylenediamine as mentioned above, allowed the formation of nicely faceted, sub-micron to micron-sized $\mathrm{Ca}_{1-\mathrm{x}} \mathrm{Sr}_{\mathrm{x}} \mathrm{S}$ single crystals [155] [149,155]. Incorporation of dopant ions $\left(\mathrm{Eu}^{2+}\right.$ and $\left.\mathrm{Ce}^{3+}\right)$ is straightforward and leads to bright luminescence, without the need for a high-temperature annealing step. Hence, the temperature of the entire synthesis process is limited to $200{ }^{\circ} \mathrm{C}$, and no $\mathrm{H}_{2} \mathrm{~S}$ gas is used.

Whispering gallery modes (WGMs) were observed in $\mathrm{Eu}^{2+}$ and $\mathrm{Ce}^{3+}$-doped $\mathrm{CaS}$ and $\mathrm{SrS}$ particles, which were related to resonance modes in the equatorial planes of the octahedron shaped crystals [290]. A modification of this solvothermal method allowed the growth of oriented and textured CaS:Eu and SrS:Eu thin films, which showed bright photoluminescence, with emission properties in line with bulk phosphors, and AC electroluminescence when electrically contacted [291].

Recently, CaS:Eu nanowires with a high aspect ratio and diameter between 50 and $150 \mathrm{~nm}$ were prepared using a (molten) $\mathrm{B}_{2} \mathrm{O}_{3}$ matrix [164]. Unlike most of the nano-sized doped sulfides mentioned in this section, the $\mathrm{Eu}^{2+}$ emission spectrum deviates from the bulk phosphor, with a blue-shift of about $30 \mathrm{~nm}$.

\section{Conclusions}

In this Review, we attempted to give an account of the rich history of sulfides for a wide range of luminescence applications. Without any doubt, the sulfides possess specific properties which made them especially suited as powder electroluminescent phosphor (based on $\mathrm{ZnS}: \mathrm{Cu}$ ) or as thin film electroluminescent material, where one should highlight the yellow-orange-emitting ZnS:Mn and the blue $\mathrm{BaAl}_{2} \mathrm{~S}_{4}: \mathrm{Eu}$ phosphor. However, the future looks rather dim for these lighting and display techniques, due to the advent of superior techniques, like organic LEDs and liquid crystal displays. It is interesting to note that both in powder and thin film EL, the amount of research and development has always been relatively small, compared to the effort put into other techniques. Nevertheless, as thin film electroluminescence has some intrinsic advantages, it might still have a future as a full-color display technique in demanding environments.

The future of sulfide phosphors could be situated in the field of color conversion for white LEDs. Upon doping with $\mathrm{Eu}^{2+}$ and $\mathrm{Ce}^{3+}$, the emission can be tuned from deep blue to saturated red by appropriately choosing the host composition. In general, the emission and excitation bands are sufficiently broad, allowing both a good color rendering and efficient pumping by the LED. Two major criteria should however be systematically evaluated, namely the quantum efficiency of 
photoluminescence and the thermal quenching behavior (both in terms of intensity reduction and spectral shift). Even if 'ideal' host-dopant combinations are found, the preparation conditions and the long term stability of sulfides will largely determine whether they are to be incorporated in LEDs after all. Fine tuning of synthesis conditions and the application of protective coatings are two major research tracks to be considered.

$\mathrm{CdS}$ and $\mathrm{PbS}$ quantum dots have already shown unique abilities and future potential as luminescent material for a wide range of photonic applications, both in the visible and the near-infrared. However, from environmental point of view, the toxicity of both $\mathrm{Pb}$ and $\mathrm{Cd}$ remains a serious issue, hampering their large scale application. Doped semiconductor nanoparticles (based on sulfides) have probably not shown their full potential yet, as the incorporation of the dopants into the nanoparticles appears to be non-trivial.

\section{Acknowledgements}

PFS and IM are post-doctoral researchers for the Fund for Scientific Research - Flanders (FWOVlaanderen). This research was carried out under the Interuniversity attraction poles programme IAP/VI-17 (INANOMAT) financed by the Belgian State, Federal science policy office.

\section{References and Notes}

1. Yen, W.M.; Weber, M.J. Inorganic Phosphors: Compositions, Preparation and Optical Properties; CRC Press: Boca Raton, FL, USA, 2004.

2. Yen, W.M.; Shionoya, S.; Yamamoto, H. Phosphor Handbook, 2nd ed.; CRC Press: Boca Raton, FL, USA, 2007.

3. Harvey, E.N. A History of Luminescence From the Earliest Times Until 1900; American Philosophical Society: Philadelphia, PA, USA, 1957.

4. Leverenz, H.W. An Introduction to Luminescence of Solids; Wiley: New York, NY, USA, 1950.

5. Sidot, T. Recherches sur la crystallisation de quelque sulphures métalliques et sur les propriétés de la blende hexagonale. Comptes Rend. Ac. Sci. 1866, 62, 999-1001.

6. Wiedemann, E. Uber Fluorescenz und Phosphorescenz. Ann. der Physik 1888, 34, 446-449.

7. Zheludev, N. The life and times of the LED - a 100-year history. Nat. Photonics 2007, 1, 189-192.

8. Destriau, G. Recherches sur les scintillations des sulfures de zinc aux rayons. J. Chim. Phys. 1936, 33, 587-625.

9. Chadha, S.S. Powder electroluminescence. In Solid State Luminescence Theory, Materials and Devices; Kitai, A., Ed.; Chapman \& Hall: London, UK, 1993; pp. 159-227.

10. Mission Evaluation Team NASA manned spacecraft center. Apollo 11 Mission Report; National Aeronautics and Space Administration: Washington D.C., USA, 1971.

11. Thornton, W.A. Electroluminescence in zinc sulfide. Phys. Rev. 1956, 102, 38-46.

12. Piper, W.W.; Williams, F.E. Theory of Electroluminescence. Phys. Rev. 1955, 98, 1809-1813.

13. Vecht, A.; Werring, N.J.; Smith, P.J.F. High-efficiency DC electroluminescence in ZnS:Mn,Cu. J. Phys. D-Appl. Phys. 1968, 1, 134. 
14. Cusano, D.A. Cathodo-, photo-, and D.C.-Electroluminescence in Zinc Sulphide Layers. In Luminescence of Organic and Inorganic Materials; Kallman, H.P., Spruch, G.M., Eds.; John Wiley \& Sons: New York, NY, USA, 1962; pp. 494-522.

15. Fisher, A.G. Electroluminescence in II-VI Compounds. In Luminescence in Inorganic Solids; Goldberg, P., Ed.; Academic Press: New York, NY, USA, 1966; pp. 541-602.

16. Curie, D. Luminescence in Solids; Methuen: London, UK, 1963.

17. Morehead, F.F. Electroluminescence. In Physics and Chemistry of II-VI Compounds; Aven, M., Prener, J.S., Eds.; North-Holland: Amsterdam, The Netherlands, 1967; pp. 611-656.

18. Cusano, D.A. Thin film studies and electro-optical effects. In Physics and Chemistry of II-VI Compounds; Aven, M., Prener, J.S., Eds.; North-Holland: Amsterdam, The Netherlands, 1967; pp. 707-766.

19. Vecht, A. Methods of activating and recrystallizing thin films of II-VI compounds. In Physics of Thin Films; Hass, G., Thun, R.E., Eds.; Academic Press: New York, NY, USA, 1966; Volume 3, pp. 165-210.

20. Ivey, H.F. Electroluminescence and Related Effects (Advances in Electronics and Electron Physics. Supplement); Academic Press: New York, NY, USA, 1963.

21. Henish, H.K. Electroluminescence; Pergamon Press: Oxford, UK, 1962.

22. Chen, F.; Xiang, Y. AC Powder Electroluminescence. In Luminescent Materials and Applications; Kitai, A., Ed.; Wiley: Chichester, UK, 2008; pp. 249-268.

23. Chen, F.; Kitai, A.H.; Xiang, Y.W. Temperature-Dependent Degradation of AC Powder EL. $J$. Electrochem. Soc. 2009, 156, H585-H587.

24. Warkentin, M.; Bridges, F.; Carter, S.A.; Anderson, M. Electroluminescence materials ZnS : $\mathrm{Cu}, \mathrm{Cl}$ and $\mathrm{ZnS}: \mathrm{Cu}, \mathrm{Mn}, \mathrm{Cl}$ studied by EXAFS spectroscopy. Phys. Rev. B 2007, 75, 075301.

25. Bredol, M.; Dieckhoff, H.S. Materials for Powder-Based AC-Electroluminescence. Materials 2010, 3, 1353-1374.

26. Blasse, G.; Grabmaier, B.C. Luminescent Materials; Springer: Berlin, Germany, 1994.

27. Inaho, S.; Hase, T. Phosphors for cathode-ray tubes. In Phosphor Handbook; 2nd ed.; Yen, W.M., Shionoya, S.,Yamamoto, H., Eds.; CRC Press: Boca Raton, FL, USA, 2007.

28. Morimoto, K.; Itoh, S. Phosphor for vacuum fluorescent displays and field emission displays. In Phosphor Handbook; 2nd ed.; Yen, W.M., Shionoya, S.,Yamamoto, H., Eds.; CRC Press: Boca Raton, FL, USA, 2007; pp. 667-685.

29. Vlasenko, N.A.; Popkov, Y.A. Study of electroluminescence of a sublimated ZnS-Mn phosphor. Opt. Spektroskop. 1960, 8, 81-88.

30. Russ, M.J.; Kennedy, D.I. The effects of double insulating layers on the electroluminescence of evaporated ZnS:Mn films. J. Electrochem. Soc. 1967, 114, 1066-1071.

31. Mach, R.; Mueller, G.O. Physics and technology of thin-film electroluminescent displays. Semicond. Sci. Technol. 1991, 6, 305-323.

32. Mach, R.; Mueller, G.O. Mechanisms of thin-film color electroluminescence. SPIE Proc. Ser. 1993, 1910, 48-64.

33. Mach, R.; Muller, G.O. Physical concepts of high-field, thin-film electro-luminescence devices. Phys. Status Solidi A - Appl. Res. 1982, 69, 11-66. 
34. Rack, P.D.; Holloway, P.H. The structure, device physics, and material properties of thin film electroluminescent displays. Mater. Sci. Eng. R-Rep. 1998, 21, 171-219.

35. Inoguchi, T.; Takeda, M.; Kakihara, Y.; Nakata, Y.; Yoshida, M. Stable High Luminance Thin Film Electroluminescent Panels, In SID Symposium Digest of Technical Papers, San Diego, CA, USA, May 1974; pp. 84-85.

36. Wauters, D.; Poelman, D.; Van Meirhaeghe, R.L.; Cardon, F. Optical characterisation of SrS : $\mathrm{Cu}$ and $\mathrm{SrS}: \mathrm{Cu}, \mathrm{Ag} \mathrm{EL}$ devices. J. Lumines. 2000, 91, 1-6.

37. Inuzuka, H.; Yamauchi, T.; Hattori, Y.; Katayama, M.; Itou, N. EL displays for automotive applications. J. Soc. Inf. Disp. 2001, 9, 197-243.

38. Tuenge, R.; Goodman, J.; Koyama, R.; Ping, K.; Vetanen, W. A QVGA AMEL microdisplay with improved color performance. In Proceedings of the 21st Int. Display Research Conf. and 8th International Display Workshops, Nagoya, Japan, October 2001; pp. 1071-1074.

39. Laakso, C.; Khormaei, R.; King, C.; Harkonen, G.; Pakkala, A.; Pitkanen, T.; Surma-aho, M.; Törnqvist, R. A 9 inch diagonal, compact, multicolor TFEL display. In Conference Record of the 1991 International Display Research Conference, San Diego, CA, USA, October 1991; pp. 43-44.

40. Smet, P.F.; Poelman, D.; Van Meirhaeghe, R.L. Blue electroluminescence from multilayered BaS : Eu/Al2S3 thin films. J. Appl. Phys. 2004, 95, 184-190.

41. Tanaka, S.; Mikami, Y.; Deguchi, H.; Kobayashi, H. White-light emitting thin-film electroluminescent devices with $\mathrm{SrS}: \mathrm{Ce}, \mathrm{Cl} / \mathrm{ZnS}: \mathrm{Mn}$ double phosphor layers. Jpn. J. Appl. Phys. Part 2 - Lett. 1986, 25, L225-L227.

42. Chase, E.W.; Hepplewhite, R.T.; Krupka, D.C.; Kahng, D. Electroluminescence of ZnS Lumocen devices containing rare-earth and transition-metal fluorides. J. Appl. Phys. 1969, 40, 2512.

43. Kobayashi, H.; Tanaka, S.; Shanker, V.; Shiiki, M.; Kunou, T.; Mita, J.; Sasakura, H. Multicolor electroluminescent $\mathrm{ZnS}$ thin-films doped with rare-earth fluorides. Phys. Status Solidi A - Appl. Res. 1985, 88, 713-720.

44. Suyama, T.; Sawara, N.; Okamoto, K.; Hamakawa, Y. Multi-coloring of thin-film electroluminescent device. Jpn. J. Appl. Phys. 1982, 21, 383-387.

45. Vandenbossche, J.; Neyts, K.A.; Devisschere, P.; Corlatan, D.; Pauwels, H.; Vercaemst, R.; Fiermans, L.; Poelman, D.; Vanmeirhaeghe, R.L.; Laflere, W.H.; Cardon, F. Xps Study of TbF3 and TbOF Centers in ZnS. Phys. Status Solidi A - Appl. Res. 1994, 146, K67-K70.

46. Okamoto, K.; Hamakawa, Y. Bright green electroluminescence in thin-film ZnS-TbF . Appl. Phys. Lett. 1979, 35, 508-511.

47. Tohda, T.; Fujita, Y.; Matsuoka, T.; Abe, A. New efficient phosphor material ZnS:Sm,P for red electroluminescent devices. Appl. Phys. Lett. 1986, 48, 95-96.

48. Kuk, V.K.; Kynev, K.D. Luminescence of ZnS:Dy,Cu, ZnS:Pr,Cu and ZnS:Ho,Cu phosphors depending on the activator and coactivator concentration. J. Mater. Sci. Lett. 1989, 8, 711-715.

49. Okamoto, K.; Yoshimi, T.; Miura, S. TbOF complex centers in ZnS thin-film electroluminescent devices. Appl. Phys. Lett. 1988, 53, 678-680.

50. Ono, Y.A. Electroluminescent Displays; World Scientific Publishing: Singapore, 1995. 
51. Electroluminescence II. In Semiconductors and Semimetals; Mueller, G., Ed.; Academic Press: New York, NY, USA, 2000; Volume 65, Chapter 2-4.

52. Inoguchi, T.; Mito, S. Electroluminescence. In Topics in Applied Physics; Pankove, J.I., Ed.; Springer-Verlag: Berlin, Germany, 1977; Volume 17.

53. Mueller, G.O.; Mach, R.; Halden, E.; Fitting, H.J. Direct evidence of ballistic acceleration of electrons in $\mathrm{ZnS}$, In Proceedings of the 20th International Conference on the Physics of Semiconductors, Thessaloniki, Greece, August 1990; pp. 2510-2513.

54. Benalloul, P.; Barthou, C.; Benoit, J. $\mathrm{SrGa}_{2} \mathrm{~S}_{4}$ : RE phosphors for full colour electroluminescent displays. J. Alloy. Compd. 1998, 275, 709-715.

55. Barthou, C.; Jabbarov, R.B.; Benalloul, P.; Chartier, C.; Musayeva, N.N.; Tagiev, B.G.; Tagiev, O.B. Radiative properties of the blue $\mathrm{BaAl}_{2} \mathrm{~S}_{4}: \mathrm{Eu}^{2+}$ phosphor. J. Electrochem. Soc. 2006, 153, G253-G258.

56. Shanker, V.; Tanaka, S.; Shiiki, M.; Deguchi, H.; Kobayashi, H.; Sasakura, H. Electroluminescence in thin-film CaS:Ce. Appl. Phys. Lett. 1984, 45, 960-961.

57. Barrow, W.A.; Coovert, R.E.; King, C.N. Strontium sulphide: the host for a new high-efficiency thin-film EL blue phosphor. In SID Symposium Digest of Technical Papers, San Francisco, CA, USA, June 1984; pp. 249-250.

58. Tanaka, S.; Shanker, V.; Shiiki, M.; Deguchi, H.; Kobayashi, H. Multicolor Electroluminescence in Alkaline-Earth Sulfide Thin-Film Devices. In SID Symposium Digest of Technical Papers, Orlando, FL, USA, May 1985; pp. 255-258.

59. Kane, J.; Harty, W.E.; Ling, M.; Yocom, P.N. New electroluminescent phosphors based on strontium sulfide, In Conference Record of the 1985 International Display Research Conference, San Diego, CA, USA, October 1985; pp. 163-166.

60. Van Haecke, J.E.; Smet, P.F.; Poelman, D. The influence of source powder composition on the electroluminescence of $\mathrm{Ca}_{1-\mathrm{x}} \mathrm{Sr}_{\mathrm{x}} \mathrm{S}: \mathrm{Eu}$ thin films. Spectroc. Acta Pt. B-Atom. Spectr. 2004, 59, 1759-1764.

61. Van Haecke, J.E.; Smet, P.F.; Poelman, D. The formation of $\mathrm{Eu}^{2+}$ clusters in saturated red $\mathrm{Ca}_{0.5} \mathrm{Sr}_{0.5} \mathrm{~S}:$ Eu electroluminescent devices. J. Electrochem. Soc. 2005, 152, H225-H228.

62. Poelman, D.; Vercaemst, R.; VanMeirhaeghe, R.L.; Laflere, W.H.; Cardon, F. Influence of the growth conditions on the properties of CaS:Eu electroluminescent thin films. J. Lumines. 1997, $75,175-181$.

63. Yoshioka, T.; Sano, Y.; Nunomura, K.; Tani, C. Characteristics of red electroluminescent devices using $\mathrm{CaS}_{1-\mathrm{x}} \mathrm{Se}_{\mathrm{x}}$ :Eu phosphor layers, In SID Symposium Digest of Technical Papers, Baltimore, MD, USA, May 1989; pp. 313-316.

64. Poelman, D.; Vanmeirhaeghe, R.L.; Laflere, W.H.; Cardon, F. The Influence of Se Coevaporation on the Electroluminescent Properties of SrS:Ce Thin-Films. J. Lumines. 1992, 52, 259-264.

65. Poelman, D.; Vercaemst, R.; Vanmeirhaeghe, R.L.; Laflere, W.H.; Cardon, F. The Influence of Se-Coevaporation on the Emission Spectra of CaS:Eu and SrS:Ce Thin-Film Electroluminescent Devices. J. Lumines. 1995, 65, 7-10.

66. Poelman, D.; Wauters, D.; Van Meirhaeghe, R.L.; Cardon, F. Photoluminescence of SrS : Cu,Ag and $\mathrm{SrS}_{1-\mathrm{x}} \mathrm{Se}_{\mathrm{x}}: \mathrm{Cu}, \mathrm{Ag}$ thin films. Solid State Commun. 2000, 113, 405-410. 
67. Schecter, A.; Shanske, W.; Stenzler, A.; Quintilian, H.; Steinberg, H. Acute hydrogen selenide inhalation. Chest 1980, 77, 554-555.

68. Leppänen, M.; Härkönen, G.; Pakkala, A.; Soininen, E.; Törnqvist, R. Broadband Double Layer Phosphor for an Inverted Filtered RGB Electroluminescent Display, In Proceedings of the 13th International Display Research Conference, Strasbourg, France, August 31 - September 3 1993; pp. 229-232.

69. Poelman, D.; Vercaemst, R.; Vanmeirhaeghe, R.L.; Laflere, W.H.; Cardon, F. Effect of Moisture on Performance of SrS:Ce Thin-Film Electroluminescent Devices. Jpn. J. Appl. Phys. Part 1 1993, 32, 3477-3480.

70. Wauters, D.; Poelman, D.; Van Meirhaeghe, R.L.; Cardon, F. Effects of rapid thermal annealing on electron beam evaporated $\mathrm{SrS}$ : Ce thin film electroluminescent devices made in $\mathrm{H}_{2} \mathrm{~S}$ ambient. J. Cryst. Growth 1999, 204, 97-107.

71. Chartier, C.; Barthou, C.; Benalloul, P.; Chenot, S.; Frigerio, J.M. Structural and luminescent properties of green emitting $\mathrm{SrGa}_{2} \mathrm{~S}_{4}: \mathrm{Eu}$ thin films prepared by RF-sputtering. J. Cryst. Growth 2003, 256, 305-316.

72. Leskela, T.; Vasama, K.; Harkonen, G.; Sarkio, P.; Lounasmaa, M. Potential cerium precursors for blue colour in thin film electroluminescent devices grown by atomic layer epitaxy. Adv. Mater. Opt. Electron. 1996, 6, 169-174.

73. Sun Jin, Y.; Yong Shin, K.; Jung-Sook, K.; Sang-Hee Ko, P.; Kyoung-Ik, C.; Dong-Sung, M. High-luminance blue-emitting $\mathrm{CaS}: \mathrm{Pb}$ electroluminescent devices fabricated using atomic layer deposition. In SID Symposium Digest of Technical Papers, San Jose, CA, USA, May 1999; pp. 1142-1145.

74. Nakano, F.; Uekura, N.; Nakanishi, Y.; Hatanaka, Y.; Shimaoka, G. Preparation of $\mathrm{CaGa}_{2} \mathrm{~S}_{4}: \mathrm{Ce}$ thin films for blue emitting thin-film EL device. Appl. Surf. Sci. 1997, 121, 160-162.

75. Benalloul, P.; Barthou, C.; Benoit, J.; Eichenauer, L.; Zeinert, A. IIa- $\mathrm{III}_{2}-\mathrm{S}_{4}$ Ternary Compounds - New Host Matrices for Full-Color Thin-Film Electroluminescence Displays. Appl. Phys. Lett. 1993, 63, 1954-1956.

76. Smet, P.; Wauters, D.; Poelman, D.; Van Meirhaeghe, R.L. Influence of sintering on photoluminescent emission of $\mathrm{SrS}: \mathrm{Cu}, \mathrm{Ag}$ powders and e-beam evaporated phosphor layers. Solid State Commun. 2001, 118, 59-62.

77. Sun, S.S.; Dickey, E.; Kane, J.; Yocom, P.N. A bright and efficient new blue TFEL phosphor. In Proceedings of the 17th Int. Display Research Conference, Toronto, Canada, September 1997; pp. 301-304.

78. Krupka, D.C.; Mahoney, D.M. Electroluminescence and photoluminescence of thin-films of ZnS doped with rare-earth metals. J. Appl. Phys. 1972, 43, 2314-2320.

79. Mikami, A.; Ogura, T.; Tanaka, K.; Taniguchi, K.; Yoshida, M.; Nakajima, S. Tb-F emission centers in ZnS:Tb,F thin-film electroluminescent devices. J. Appl. Phys. 1987, 61, 3028-3034.

80. Vercaemst, R.; Poelman, D.; Vanmeirhaeghe, R.L.; Fiermans, L.; Laflere, W.H.; Cardon, F. An Xps Study of the Dopants Valence States and the Composition of $\mathrm{CaS}_{1-\mathrm{x}} \mathrm{Se}_{\mathrm{x}} \mathrm{Eu}$ and $\mathrm{SrS}_{1-\mathrm{x}} \mathrm{Se}_{\mathrm{x}} \mathrm{Ce}$ Thin-Film Electroluminescent Devices. J. Lumines. 1995, 63, 19-30.

81. Poelman, D.; VanMeirhaeghe, R.L.; Vermeersch, B.A.; Cardon, F. Possibilities and limitations of blue electroluminescence in $\mathrm{CaS}: \mathrm{Pb}^{2+}$ thin films. J. Phys. D-Appl. Phys. 1997, 30, 465-467. 
82. Versluys, J.; Poelman, D.; Wauters, D.; Van Meirhaeghe, R.L. Photoluminescent and structural properties of $\mathrm{CaS}: \mathrm{Pb}$ electron beam deposited thin films. J. Phys.-Condes. Matter 2001, 13, 5709-5716.

83. Yun, S.J.; Kim, Y.S.; Park, S.H.K. Fabrication of $\mathrm{CaS}: \mathrm{Pb}$ blue phosphor by incorporating dimeric $\mathrm{Pb}^{2+}$ luminescent centers. Appl. Phys. Lett. 2001, 78, 721-723.

84. Nykanen, E.; Lehto, S.; Leskela, M.; Niinisto, L.; Soininen, P. Blue electroluminescence in $\mathrm{Pb}^{2+}$ doped $\mathrm{CaS}$ and $\mathrm{SrS}$ thin films. In Proceedings of the 6th International Workshop on Electroluminescence, El Paso, TX, USA, May 1992; pp. 199-204.

85. Smet, P.F.; Van Gheluwe, J.; Poelman, D.; Van Meirhaeghe, R.L. Photoluminescence of electron beam evaporated CaS : Bi thin films. J. Lumines. 2003, 104, 145-150.

86. Miura, N.; Kawanishi, M.; Matsumoto, H.; Nakano, R. High-luminance blue-emitting $\mathrm{BaAl}_{2} \mathrm{~S}_{4}$ : $\mathrm{Eu}$ thin-film electroluminescent devices. Jpn. J. Appl. Phys. Part 2 - Lett. 1999, 38, L1291-L1292.

87. Miura, N.; Kawanishi, M.; Matsumoto, H.; Nakano, R. Blue-emitting $\mathrm{BaAl}_{2} \mathrm{~S}_{4}$ : Eu thin-film electroiluminescent devices prepared by two targets pulse electron beam evaporation. IEICE Trans. Electron. 2000, E83C, 1618-1621.

88. Tanaka, I.; Inoue, Y.; Tanaka, K.; Izumi, Y.; Okamoto, S.; Kawanishi, M.; Miura, N.; Matsumoto, H.; Nakano, R. Crystallographic and luminescent characterizations of blue-emitting $\mathrm{BaAl}_{2} \mathrm{~S}_{4}$ : Eu electroluminescent thin films. J. Lumines. 2002, 96, 69-74.

89. Smet, P.F.; Van Haecke, J.E.; Van Meirhaeghe, R.L.; Poelman, D. Crystallographic and luminescent properties of orthorhombic $\mathrm{BaAl}_{2} \mathrm{~S}_{4}:$ Eu powder and thin films. J. Appl. Phys. 2005, 98, 043512.

90. Barrow, W.A.; Coovert, R.E.; Dickey, E.; King, C.N.; Laakso, C.; Sun, S.-S.; Tuenge, R.T.; Wentross, W.; Kane, J. A New Class of Blue TFEL Phosphors with Applications to a VGA FullColor Display. In SID Symposium Digest of Technical Papers, Seattle, WA, USA, May 1993; pp. 761-764.

91. Benalloul, P.; Barthou, C.; Fouassier, C.; Georgobiani, A.N.; Lepnev, L.S.; Emirov, Y.N.; Gruzintsev, A.N.; Tagiev, B.G.; Tagiev, O.B.; Jabbarov, R.B. Luminescence of $\mathrm{Eu}^{2+}$ in calcium thiogallate. J. Electrochem. Soc. 2003, 150, G62-G65.

92. Djazovski, O.; Mikami, T.; Ohmi, K.; Tanaka, S.; Kobayashi, H. Microstructural characterization and photoluminescence of $\mathrm{SrGa}_{2} \mathrm{~S}_{4}: \mathrm{Ce}^{3+}$ thin films grown by deposition from binary vapors. IEICE Trans. Electron. 1997, E80C, 1101-1108.

93. Djazovski, O.N.; Mikami, T.; Ohmi, K.; Tanaka, S.; Kobayashi, H. Luminescence and energy transfer in thin films of $\mathrm{SrGa}_{2} \mathrm{~S}_{4}$ :Ce. J. Electrochem. Soc. 1999, 146, 1215-1221.

94. Eichenauer, L.; Jarofke, B.; Mertins, H.C.; Dreyhsig, J.; Busse, W.; Gumlich, H.E.; Benalloul, P.; Barthou, C.; Benoit, J.; Fouassier, C.; Garcia, A. Optical characterization of europium and cerium in strontium thiogallate thin films and powders. Phys. Status Solidi A - Appl. Res. 1996, 153, 515-527.

95. Chartier, C.; Barthou, C.; Benalloul, P.; Frigerio, J.M. Photoluminescence of $\mathrm{Eu}^{2+}$ in $\mathrm{SrGa}_{2} \mathrm{~S}_{4}$. J. Lumines. 2005, 111, 147-158. 
96. Wauters, D.; Poelman, D.; Van Meirhaeghe, R.L.; Cardon, F. Photoluminescent, electroluminescent and structural properties of $\mathrm{CaS}: \mathrm{Cu}$ and $\mathrm{CaS}: \mathrm{Cu}, \mathrm{Ag}$ thin films. J. Phys.Condes. Matter 2000, 12, 3901-3909.

97. Lethi, K.T.; Garcia, A.; Guillen, F.; Fouassier, C. Investigation of the $\mathrm{MS}-\mathrm{Al}_{2} \mathrm{~S}_{3}$ systems (M = $\mathrm{Ca}, \mathrm{Sr}, \mathrm{Ba}$ ) and luminescence properties of europium-doped thioaluminates. Mater. Sci. Eng. BSolid State Mater. Adv. Technol. 1992, 14, 393-397.

98. Xin, Y.; Hunt, T.; Acchione, J. Multi-Source Deposition of $\mathrm{BaAl}_{2} \mathrm{~S}_{4}$ Blue Phosphors. In SID Symposium Digest of Technical Papers, Seattle, WA, USA, May 2004; pp. 1138-1141.

99. Kawanishi, M.; Miura, N.; Matsumoto, H.; Nakano, R. Preparation of Efficient Blue Emitting $\mathrm{BaAl}_{2} \mathrm{~S}_{4}$ :Eu Thin Films without High Temperature Annealing. In Proceedings of the 21st International Display Research Conference in conjunction with the 8th International Display Workshops, Nagoya, Japan, October 2001; pp. 1075-1078.

100. Wu, X. Recent Development in Hybrid Inorganic Electroluminescent Devices. In Proceedings of the 11th International Workshop on Inorganic and Organic Electroluminescence \& 2002 International Conference on the Science and Technology of Emissive Displays, Gent, Belgium, September 2002; pp. 293-297.

101. Guo, C.; Tang, Q.; Huang, D.; Zhang, C.; Su, Q. Influence of co-doping different rare earth ions on $\mathrm{CaGa}_{2} \mathrm{~S}_{4}: \mathrm{Eu}^{2+}, \mathrm{RE}^{3+}(\mathrm{RE}=\mathrm{Ln})$ phosphors. J. Phys. Chem. Solids 2007, 68, 217-223.

102. Stiles, J.A.R.; Kamkar, M. Polymorphic barium thioaluminate electroluminescent phosphor materials. J. Appl. Phys. 2006, 100, 074508.

103. Eisenmann, B.; Jakowski, M.; Schafer, H. The structures of $\mathrm{BaGa}_{2} \mathrm{~S}_{4}$ and $\mathrm{BaAl}_{2} \mathrm{~S}_{4}$. Mater. Res. Bull. 1982, 17, 1169-1175.

104. Xin, Y.; Xu, Y.; Acchione, J. Development of bright and stable $\mathrm{BaAl}_{2} \mathrm{~S}_{4}$ :Eu blue phosphor. In Proceedings of the 12th International Workshop on Inorganic and Organic Electroluminescence \& 2004 International Conference on the Science and Technology of Emissive Displays, Toronto, Canada, September 2004; pp. 84-87.

105. Inoue, Y.; Tanaka, I.; Tanaka, K.; Izumi, Y.; Okamoto, S.; Kawanishi, M.; Barada, D.; Miura, N.; Matsumoto, H.; Nakano, R. Atomic composition and structural properties of blue emitting $\mathrm{BaAl}_{2} \mathrm{~S}_{4}$ : Eu electroluminescent thin films. Jpn. J. Appl. Phys. Part 1 2001, 40, 2451-2455.

106. Smet, P.F.; Van Haecke, J.E.; Van Meirhaeghe, R.L.; Poelman, D. An X-ray photoelectron spectroscopy study of $\mathrm{BaAl}_{2} \mathrm{~S}_{4}$ thin films. J. Electron Spectrosc. Relat. Phenom. 2005, 148, 91-95.

107. Smet, P.F.; Van Haecke, J.E.; Kitai, A.; Poelman, D. Annealing study on $\mathrm{BaAl}_{2} \mathrm{~S}_{4}$ :Eu EL devices prepared by multi-layered deposition. In Proceedings of the 13th International Workshop on Inorganic and Organic Electroluminescence \& 2006 International Conference on the Science and Technology of Emissive Displays, Jeju, Korea, September 2006; pp. 249-251.

108. Heikenfeld, J.C.; Steckl, A.J. Inorganic EL displays at the crossroads. Inf. Disp. 2003, 19, 20-25.

109. Poelman, D.; Vanmeirhaeghe, R.L.; Laflere, W.H.; Cardon, F. Spectral Shifts in Thin-Film Electroluminescent Devices - an Interference Effect. J. Phys. D-Appl. Phys. 1992, 25, 1010-1013.

110. Neyts, K. Microcavity effects and the outcoupling of light in displays and lighting applications based on thin emitting films. Appl. Surf. Sci. 2005, 244, 517-523. 
111. Minami, T.; Miyata, T.; Takata, S.; Fukuda, I. High-luminance green Zn2SiO4:Mn thin-film electroluminescent devices using an insulating BaTiO3 ceramic sheet. Jpn. J. Appl. Phys. Part 2 - Lett. 1991, 30, L117-L119.

112. Minami, T.; Kuroi, Y.; Takata, S. Preparation of $\mathrm{ZnGa2O4:Mn} \mathrm{phosphor} \mathrm{thin} \mathrm{films} \mathrm{as} \mathrm{emitting}$ layers for electroluminescent devices. J. Vac. Sci. Technol. A 1996, 14, 1736-1740.

113. Wu, X.; Carkner, D.; Hamada, H.; Yoshida, I.; Kutsukake, M.; Dantani, K. Large-screen Flat Panel Displays based on Thick-Dielectric Electroluminescent (TDEL) Technology. In SID Symposium Digest of Technical Papers, Seattle, WA, USA, May 2004; pp. 1146-1149.

114. Cho, Y.J.; Hirakawa, T.; Sakiyama, K.; Okamoto, H.; Hamakawa, Y. EL/PL hybrid device enhanced by UV emission from $\mathrm{ZnF}_{2}: \mathrm{Gd}$ thin film electroluminescence. J. Korean. Phys. Soc. 1997, 30, S65-S68.

115. Senda, T.; Cho, Y.J.; Hirakawa, T.; Okamoto, H.; Takakura, H.; Hamakawa, Y. Development of full-color display combined with ultraviolet-electroluminescence/photoluminescence multilayered thin films. Jpn. J. Appl. Phys. Part 1 2000, 39, 4716-4720.

116. Miura, N.; Sasaki, T.; Matsumoto, H.; Nakano, R. Strong ultraviolet-emitting ZnF 2 :Gd thin-film electroluminescent device. Jpn. J. Appl. Phys. Part 2 - Lett. 1991, 30, L1815-L1816.

117. Hamada, H.; Yoshida, I.; Carkner, D.; Wu, X.; Kutsukake, M.; Oda, K., A 34-inch Flat-Panel TV Fabricated by Combining Inorganic EL and Color-Conversion Technologies. Information and Media Technologies 2009, 4, 136-140.

118. Gao, Q.Z.; Mita, J.; Tsuruoka, T.; Kobayashi, M.; Kawamura, K. High luminance white EL devices using SrS:Ce,Eu,K films deposited in a H2 atmosphere. J. Cryst. Growth 1992, 117, 983-986.

119. Tanaka, S.; Mikami, Y.; Deguchi, H.; Kobayashi, H. White Light Emitting Thin-Film Electroluminescent Devices with SrS:Ce,Cl/ZnS:Mn Double Phosphor Layers Jpn. J. Appl. Phys. 1986, 25, L225-L227.

120. Hamada, H.; Yoshida, I.; Carkner, D.; Wu, X.W.; Kutsukake, M.; Oda, K. Inorganic EL devices with high-performance blue phosphor and application to 34 -in. flat-panel televisions. J. Soc. Inf. Disp. 2008, 16, 1183-1188.

121. Cho, Y.H.; Park, D.H.; Ahn, B.T. Low-temperature synthesis of Eu-doped cubic phase $\mathrm{BaAl}_{2} \mathrm{~S}_{4}$ blue phosphor using liquid-phase reaction. J. Electrochem. Soc. 2008, 155, J41-J44.

122. Cho, Y.H.; Chalapathy, R.B.V.; Park, D.H.; Ahn, B.T. Low Temperature Synthesis of Eu-Doped Cubic Phase $\mathrm{BaAl}_{2} \mathrm{~S}_{4}$ Blue Phosphor Using $\mathrm{H}_{3} \mathrm{BO}_{3}$ or $\mathrm{B}_{2} \mathrm{O}_{3}$ Flux. J. Electrochem. Soc. 2010, 157, J45-J49.

123. Petrykin, V.; Kakihana, M. Synthesis of $\mathrm{BaAl}_{2} \mathrm{~S}_{4}$ : Eu phosphor using $\mathrm{BaS}$ : Eu precursor prepared by the polymerizable complex method. J. Ceram. Soc. Jpn. 2007, 115, 615-618.

124. Petrykin, V.; Kakihana, M. Synthesis of $\mathrm{BaAl}_{2} \mathrm{~S}_{4}: \mathrm{Eu}^{2+}$ Electroluminescent Material by the Polymerizable Complex Method Combined with $\mathrm{CS}_{2}$ Sulfurization. J. Am. Ceram. Soc. 2009, 92, S27-S31.

125. Peter, M.; Westcott, M.; Pugliese, V. Optical band gap measurement of $\mathrm{BaAl}_{2} \mathrm{~S}_{4}$ :Eu thin films. In Proceedings of the 12th International Workshop on Inorganic and Organic Electroluminescence \& 2004 International Conference on the Science and Technology of Emissive Displays, Toronto, Canada, September 2004; pp. 351-354. 
126. Yu, R.J.; Wang, J.; Zhang, X.M.; Yuan, H.B.; Zhang, J.H.; Su, Q. Eu ${ }^{2+}$-doped thioaluminates: New candidates for white LEDs. Chem. Lett. 2008, 37, 410-411.

127. Dorenbos, P. Energy of the first $4 \mathrm{f}(7)->4 \mathrm{f}(6) 5 \mathrm{~d}$ transition of $\mathrm{Eu}^{2+}$ in inorganic compounds. $J$. Lumines. 2003, 104, 239-260.

128. Samura, Y.; Usui, S.; Ohmi, K.; Kobayashi, H. Ce ${ }^{3+}$ doped alkaline-earth thiosilicate blue EL phosphors. In Proceedings of the 12th International Workshop on Inorganic and Organic Electroluminescence \& 2004 International Conference on the Science and Technology of Emissive Displays, Toronto, Canada, September 2004; pp. 132-135.

129. Smet, P.F.; Korthout, K.; Van Haecke, J.E.; Poelman, D. Using rare earth doped thiosilicate phosphors in while light emitting LEDs: Towards low colour temperature and high colour rendering. Mater. Sci. Eng. B-Solid State Mater. Adv. Technol. 2008, 146, 264-268.

130. Ohashi, T.; Ohmi, K. Improvement in Luminescent Characteristics by Al Codoping in $\mathrm{Ba}_{2} \mathrm{SiS}_{4}$ :Ce Blue Phosphor for White LEDs. J. Light Vis. Env. 2008, 32, 139-142.

131. Miura, N. Color Phosphors for Inorganic Electroluminescent Devices. In SID Symposium Digest of Technical Papers, Seattle, WA, USA, May 2004; pp. 1142-1145.

132. Miura, N. Phosphor studies for color EL devices. In Proceedings of the 13th International Workshop on Inorganic and Organic Electroluminescence \& 2006 International Conference on the Science and Technology of Emissive Displays, Jeju, Korea, September 2006; pp. 240-242.

133. Kitai, A.; Xiang, Y.W.; Cox, B. Sphere-supported thin-film electroluminescence: A new platform technology for displays and lighting. J. Soc. Inf. Disp. 2005, 13, 493-500.

134. Schubert, E.F.; Kim, J.K. Solid-state light sources getting smart. Science 2005, 308, 1274-1278.

135. Mueller-Mach, R.; Mueller, G.; Krames, M.R.; Hoppe, H.A.; Stadler, F.; Schnick, W.; Juestel, T.; Schmidt, P. Highly efficient all-nitride phosphor-converted white light emitting diode. Phys. Status Solidi A-Appl. Mat. 2005, 202, 1727-1732.

136. Bachmann, V.; Ronda, C.; Meijerink, A. Temperature Quenching of Yellow Ce3+ Luminescence in YAG:Ce. Chem. Mat. 2009, 21, 2077-2084.

137. Bachmann, V.; Justel, T.; Meijerink, A.; Ronda, C.; Schmidt, P.J. Luminescence properties of $\mathrm{SrSi}_{2} \mathrm{O}_{2} \mathrm{~N}_{2}$ doped with divalent rare earth ions. J. Lumines. 2006, 121, 441-449.

138. Dorenbos, P. Light output and energy resolution of $\mathrm{Ce}^{3+}$-doped scintillators. Nucl. Instrum. Methods Phys. Res. Sect. A-Accel. Spectrom. Dect. Assoc. Equip. 2002, 486, 208-213.

139. Poort, S.H.M.; Meyerink, A.; Blasse, G. Lifetime measurements in Eu2+-doped host lattices. J. Phys. Chem. Solids 1997, 58, 1451-1456.

140. Dorenbos, P. Anomalous luminescence of Eu2+ and $\mathrm{Yb} 2+$ in inorganic compounds. J. Phys. Condes. Matter 2003, 15, 2645-2665.

141. Pandey, R.; Sivaraman, S. Spectroscopic properties of defects in alkaline-earth sulfides. J. Phys. Chem. Solids 1991, 52, 211-225.

142. Rennie, J.; Takeuchi, K.; Kaneko, Y.; Koda, T. Color centers in calcium sulfide and strontium sulfide single crystals. J. Lumines. 1991, 48-49, 787-791.

143. Gruzintsev, A.N.; Volkov, V.T.; Pronin, A.N. Investigation of luminescence centers of unactivated CaS films. J. Cryst. Growth 1992, 117, 975-978.

144. Kim, Y.S.; Yun, S.J. Photoluminescence properties of $\mathrm{Pb}^{2+}$ centres in $\mathrm{CaS}: \mathrm{Pb}$ thin films. $J$. Phys.-Condes. Matter 2004, 16, 569-579. 
145. Yamashita, N.; Harada, O.; Nakamura, K. Photoluminescence spectra of $\mathrm{Eu}^{2+}$ centers in $\mathrm{Ca}(\mathrm{S}, \mathrm{Se})$ :Eu and Sr(S,Se):Eu. Jpn. J. Appl. Phys. Part 1 1995, 34, 5539-5545.

146. Kasano, H.; Megumi, K.; Yamamoto, H. Cathodoluminescence of $\mathrm{Ca}_{1-\mathrm{x}} \mathrm{Mg}_{\mathrm{x}} \mathrm{S}: \mathrm{Eu}, \mathrm{Ca}_{1-\mathrm{x}} \mathrm{Mg}_{\mathrm{x}} \mathrm{S}$ :Ce. J. Electrochem. Soc. 1984, 131, 1953-1960.

147. Yamashita, N. Photoluminescence properties of $\mathrm{Cu}^{+}$centers in $\mathrm{MgS}, \mathrm{CaS}, \mathrm{SrS}$ and BaS. Jpn. J. Appl. Phys. Part 1 1991, 30, 3335-3340.

148. Yamashita, N.; Sasaki, Y.; Nakamura, K. Photoluminescence of $\mathrm{Sb}^{3+}$ centers in $\mathrm{SrS}$ and $\mathrm{SrSe}$. Jpn. J. Appl. Phys. Part 1 1992, 31, 2791-2797.

149. Van Haecke, J.E.; Smet, P.F.; De Keyser, K.; Poelman, D. Single crystal CaS : Eu and SrS : Eu luminescent particles obtained by solvothermal synthesis. J. Electrochem. Soc. 2007, 154, J278-J282.

150. Xia, Q.; Batentschuk, M.; Osvet, A.; Winnacker, A.; Schneider, J. Quantum yield of $\mathrm{Eu}^{2+}$ emission in $\left(\mathrm{Ca}_{1-\mathrm{x}} \mathrm{Sr}_{\mathrm{x}}\right) \mathrm{S}:$ Eu light emitting diode converter at 20-420 K. Radiat. Meas. 2010, in Press.

151. Okamoto, F.; Kato, K. Preparation and cathodoluminescence of CaS:Ce and $\mathrm{Ca}_{1-\mathrm{x}} \mathrm{Sr}_{\mathrm{x}} \mathrm{S}: \mathrm{Ce}$ phosphors. J. Electrochem. Soc. 1983, 130, 432-437.

152. Smet, P.F.; Van Haecke, J.E.; Loncke, F.; Vrielinck, H.; Callens, F.; Poelman, D. Anomalous photoluminescence in BaS : Eu. Phys. Rev. B 2006, 74, 035207.

153. Brower, D.T.; Lloyd, I.K. Investigation of the effect of host composition on the photoluminescent properties of $\mathrm{Sr}_{\mathrm{x}} \mathrm{Ba}_{1-\mathrm{x}} \mathrm{S}$ doped with $\mathrm{Eu}$ and Sm. J. Mater. Res. 1995, 10, 211-213.

154. Jia, D.D.; Wang, X.J. Alkali earth sulfide phosphors doped with $\mathrm{Eu}^{2+}$ and $\mathrm{Ce}^{3+}$ for LEDs. Opt. Mater. 2007, 30, 375-379.

155. Poelman, D.; Van Haecke, J.E.; Smet, P.F. Advances in sulfide phosphors for displays and lighting. J. Mater. Sci.-Mater. Electron. 2009, 20, 134-138.

156. Nazarov, M.; Yoon, C. Controlled peak wavelength shift of $\mathrm{Ca}_{1-\mathrm{x}} \mathrm{Sr}_{\mathrm{x}}\left(\mathrm{S}_{\mathrm{y}} \mathrm{Se}_{1-\mathrm{y}}\right)$ : $\mathrm{Eu}^{2+}$ phosphor for LED application. J. Solid State Chem. 2006, 179, 2529-2533.

157. Sung, H.J.; Cho, Y.S.; Huh, Y.D.; Do, Y.R. Preparation, characterization and photoluminescence properties of $\mathrm{Ca}_{1-\mathrm{x}} \mathrm{Sr}_{\mathrm{x}} \mathrm{S}$ : Eu red-emitting phosphors for a white LED. Bull. Korean Chem. Soc. 2007, 28, 1280-1284.

158. Kim, K.N.; Kim, J.M.; Choi, K.J.; Park, J.K.; Kim, C.H. Synthesis, characterization, and luminescent properties of CaS : Eu phosphor. J. Am. Ceram. Soc. 2006, 89, 3413-3416.

159. Dorenbos, P. Thermal quenching of $\mathrm{Eu}^{2+} 5 \mathrm{~d}-4 \mathrm{f}$ luminescence in inorganic compounds. J. Phys.Condes. Matter 2005, 17, 8103-8111.

160. Shin, H.H.; Kim, J.H.; Han, B.Y.; Yoo, J.S. Failure Analysis of a Phosphor-Converted White Light-Emitting Diode due to the CaS:Eu Phosphor. Jpn. J. Appl. Phys. 2008, 47, 3524-3526.

161. Avci, N.; Musschoot, J.; Smet, P.F.; Korthout, K.; Avci, A.; Detavernier, C.; Poelman, D. Microencapsulation of Moisture-Sensitive $\mathrm{CaS}: \mathrm{Eu}^{2+}$ Particles with Aluminum Oxide. $J$. Electrochem. Soc. 2009, 156, J333-J337.

162. Yoo, S.H.; Kim, C.K. Nanocomposite Encapsulation of CuS:Eu Light-Emitting Diode Phosphors for the Enhancement of the Stability Against Moisture. J. Electrochem. Soc. 2009, 156, J170-J173. 
163. Park, I.W.; Kim, J.H.; Yoo, J.S.; Shin, H.H.; Kim, C.K.; Choi, C.K. Longevity improvement of $\mathrm{CaS}$ : Eu phosphor using polymer binder coating for white LED application. J. Electrochem. Soc. 2008, 155, J132-J135.

164. Lin, J.; Huang, Y.; Bando, Y.; Tang, C.C.; Golberg, D. BN tubular layer-sheathed CaS:Eu ${ }^{2+}$ nanowires as stable red-light-emitting nanophosphors. Chem. Commun. 2009, 6631-6633.

165. Peters, T.E.; Baglio, J.A. Luminescence and structural properties of thiogallate phosphors: $\mathrm{Ce}^{+3}$ and $\mathrm{Eu}^{+2}$ activated phosphors. J. Electrochem. Soc. 1972, 119, 230-236.

166. Donohue, P.C.; Hanlon, J.E. Synthesis and photoluminescence of $\mathrm{MIIM}_{2} \mathrm{III}(\mathrm{S}, \mathrm{Se})_{4} . J$. Electrochem. Soc. 1974, 121, 137-142.

167. Davolos, M.R.; Garcia, A.; Fouassier, C.; Hagenmuller, P. Luminescence of Eu $^{2+}$ in strontium and barium thiogallates. J. Solid State Chem. 1989, 83, 316-323.

168. Avella, F.J. Cathodoluminescence of alkaline earth thiosilicate phosphors. J. Electrochem. Soc. 1971, 118, 1862-1863.

169. Sun, S.S.; Tuenge, R.T.; Kane, J.; Ling, M. Electroluminescence and photoluminescence of cerium-activated alkaline-earth thiogallate thin-films and devices. J. Electrochem. Soc. 1994, 141, 2877-2883.

170. Marceddu, M.; Anedda, A.; Corpino, R.; Georgobiani, A.N.; Ricci, P.C. Energy transfer in Ce and Eu co-doped barium thiogallate: A photoluminescence characterization. Mater. Sci. Eng. BSolid State Mater. Adv. Technol. 2008, 146, 216-219.

171. Jabbarov, R.B.; Chartier, C.; Tagiev, B.G.; Tagiev, O.B.; Musayeva, N.N.; Barthou, C.; Benalloul, P. Radiative properties of $\mathrm{Eu}^{2+}$ in $\mathrm{BaGa}_{2} \mathrm{~S}_{4}$. J. Phys. Chem. Solids 2005, 66, 1049-1056.

172. Georgobiani, A.N.; Tagiev, B.G.; Tagiev, O.B.; Abushov, S.A.; Kazymova, F.A.; Gashimova, T.S.; Xu, X.R. Temperature effect on the photoluminescence intensity and $\mathrm{Eu}^{2+}$ excited state lifetime in $\mathrm{EuGa}_{2} \mathrm{~S}_{4}$ and $\mathrm{EuGa}_{2} \mathrm{~S}_{4}: \mathrm{Er}^{3+}$. Inorg. Mater. 2009, 45, 116-122.

173. Kim, J.W.; Kim, Y.J. Synthesis and luminescent characterization of zinc thiogallate. J. Eur. Ceram. Soc. 2007, 27, 3667-3670.

174. Yu, R.J.; Wang, J.; Zhang, M.; Yuan, H.B.; Ding, W.J.; An, Y.; Su, Q. Luminescence properties of $\mathrm{Ca}_{1-\mathrm{x}} \mathrm{Sr}_{\mathrm{x}}\left(\mathrm{Ga}_{1-\mathrm{y}} \mathrm{Al}_{\mathrm{y}}\right)_{2} \mathrm{~S}_{4}: \mathrm{Eu}^{2+}$ and their potential application for white LEDs. J. Electrochem. Soc. 2008, 155, J290-J292.

175. Zhang, X.M.; Wang, J.; Wu, H.; Zhang, J.H.; Su, Q. One-step synthesis and double emission $\left(\mathrm{Ca}_{(1+\mathrm{x}-\mathrm{y})} \mathrm{Eu}_{\mathrm{y}}\right) \mathrm{Ga}_{2} \mathrm{~S}_{4+\mathrm{x}}$ phosphor for white LEDs. Mater. Lett. 2009, 63, 340-342.

176. Nazarov, M.; Noh, D.Y.; Byeon, C.C.; Kim, H. Efficient multiphase green phosphor based on strontium thiogallate. J. Appl. Phys. 2009, 105, 073518.

177. Jabbarov, R.; Musayeva, N.; Scholz, F.; Wunderer, T.; Turkin, A.N.; Shirokov, S.S.; Yunovich, A.E. Preparation and optical properties of $\mathrm{Eu}^{2+}$ doped $\mathrm{CaGa}_{2} \mathrm{~S}_{4}-\mathrm{CaS}$ composite bicolor phosphor for white LED. Phys. Status Solidi A-Appl. Mat. 2009, 206, 287-292.

178. Do, Y.R.; Ko, K.Y.; Na, S.H.; Huh, Y.D. Luminescence properties of potential $\mathrm{Sr}_{1-\mathrm{x}} \mathrm{Ca}_{\mathrm{x}} \mathrm{Ga}_{2} \mathrm{~S}_{4}: \mathrm{Eu}$ green- and greenish-yellow-emitting phosphors for white LED. J. Electrochem. Soc. 2006, 153, H142-H146. 
179. Zhang, J.; Takahashi, M.; Tokuda, Y.; Yoko, T. Preparation of Eu-doped $\mathrm{CaGa}_{2} \mathrm{~S}_{4}-\mathrm{CaS}$ composite bicolor phosphor for white light emitting diode. J. Ceram. Soc. Jpn. 2004, 112, 511513.

180. Benalloul, P.; Barthou, C.; Benoit, J.; Georgobiani, A.; Lepnev, L.; Gruzintsev, A.; Tagiev, B.; Tagiev, O.; Dzhabborrov, R. Luminescence of $\mathrm{Eu}^{2+}$ in $\mathrm{CaGa}_{2} \mathrm{~S}_{4}$ mono and polycrystals. Jpn. J. Appl. Phys. 2000, 39S1, 121-122.

181. Van Haecke, J.E.; Smet, P.F.; Poelman, D. Luminescent characterization of $\mathrm{CaAl}_{2} \mathrm{~S}_{4}: \mathrm{Eu}$ powder. J. Lumines. 2007, 126, 508-514.

182. Yu, R.J.; Wang, J.; Zhang, J.H.; Yuan, H.B.; Su, Q. Luminescence properties of Eu2+- and Ce3+-doped CaAl2S4 and application in white LEDs. J. Solid State Chem. 2008, 181, 658-663.

183. Kawanishi, M.; Ono, Y.; Nakagawa, R.; Miura, N.; Matsumoto, H.; Nakano, R. Possibility of RGB Emission by $\mathrm{Eu}^{2+}$ ion doped $\mathrm{IIa}^{2} \mathrm{IIIb}_{2}-\mathrm{S}_{4}$ phosphors for Full Color Inorganic Electroluminescent Displays. In Proceedings of the 11th International Workshop on Inorganic and Organic Electroluminescence \& 2002 International Conference on the Science and Technology of Emissive Displays, Gent, Belgium, September 2002; pp. 239-242.

184. Kim, M.Y.; Baik, S.J.; Kim, W.T.; Jin, M.S.; Kim, H.G.; Choe, S.H.; Yoon, C.S. Optical properties of undoped and $\mathrm{Co}^{2+}-, \mathrm{Ho}^{3+}-, \mathrm{Er}^{3+}-$, and $\mathrm{Tm}^{3+}$-doped $\mathrm{CaGa}_{2} \mathrm{~S}_{4}, \mathrm{CaGa}_{2} \mathrm{Se}_{4}, \mathrm{CaIn}_{2} \mathrm{~S}_{4}$, and $\mathrm{CaIn}_{2} \mathrm{Se}_{4}$ single crystals. J. Korean. Phys. Soc. 2003, 43, 128-134.

185. Olivierfourcade, J.; Ribes, M.; Philippot, E.; Merle, P.; Maurin, M. Emission characteristics of alkaline thiosilicates and alkaline-earth thiosilicates. Mater. Res. Bull. 1975, 10, 975-982.

186. Smet, P.F.; Avci, N.; Loos, B.; Van Haecke, J.E.; Poelman, D. Structure and photoluminescence of (Ca, Eu) 2SiS4 powders. J. Phys.-Condes. Matter 2007, 19, 246223.

187. Smet, P.F.; Avci, N.; Poelman, D. Red Persistent Luminescence in $\mathrm{Ca}_{2} \mathrm{SiS}_{4}$ :Eu,Nd. $J$. Electrochem. Soc. 2009, 156, H243-H248.

188. Parmentier, A.; Smet, P.F.; Bertram, F.; Christen, J.; Poelman, D. Structure and luminescence of (Ca,Sr) ${ }_{2} \mathrm{SiS}_{4}: \mathrm{Eu}^{2+}$ phosphors. J. Phys. D-Appl. Phys. 2010, 43, 085401.

189. Johrendt, D.; Pocha, R. Europium thiosilicate at 100 K. Acta Crystallogr. Sect. E.-Struct Rep. Online 2001, 57, i57-i59.

190. Nishimura, M.; Nanai, Y.; Bohda, T.; Okuno, T. Yellow Photoluminescence of Europium Thiosilicate on Silicon Substrate. Jpn. J. Appl. Phys. 2009, 48.

191. Tanaka, K.; Okamoto, S. Green electroluminescence of $\mathrm{EuGa}_{2} \mathrm{~S}_{4}$ thin films. Appl. Phys. Lett. 2003, 83, 647-649.

192. Chen, W.; Zhang, X.H.; Huang, Y.N. Luminescence enhancement of EuS nanoclusters in zeolite. Appl. Phys. Lett. 2000, 76, 2328-2330.

193. Yamada, M.; Naitou, T.; Izuno, K.; Tamaki, H.; Murazaki, Y.; Kameshima, M.; Mukai, T. Redenhanced white-light-emitting diode using a new red phosphor. Jpn. J. Appl. Phys. Part 2 - Lett. 2003, 42, L20-L23.

194. Xie, R.J.; Hirosaki, N.; Suehiro, T.; Xu, F.F.; Mitomo, M. A simple, efficient synthetic route to $\mathrm{Sr}_{2} \mathrm{Si}_{5} \mathrm{~N}_{8}: \mathrm{Eu}^{2+}$-based red phosphors for white light-emitting diodes. Chem. Mat. 2006, 18, 5578-5583. 
195. Hirosaki, N.; Xie, R.J.; Kimoto, K.; Sekiguchi, T.; Yamamoto, Y.; Suehiro, T.; Mitomo, M. Characterization and properties of green-emitting beta-SiAlON : $\mathrm{Eu}^{2+}$ powder phosphors for white light-emitting diodes. Appl. Phys. Lett. 2005, 86.

196. Xie, R.J.; Hirosaki, N.; Mitomo, M.; Takahashi, K.; Sakuma, K. Highly efficient white-lightemitting diodes fabricated with short-wavelength yellow oxynitride phosphors. Appl. Phys. Lett. 2006, 88, 101104.

197. Clabau, F.; Rocquefelte, X.; Jobic, S.; Deniard, P.; Whangbo, M.H.; Garcia, A.; Le Mercier, T. On the phosphorescence mechanism in $\mathrm{SrAl}_{2} \mathrm{O}_{4}: \mathrm{Eu}^{2+}$ and its codoped derivatives. Solid State Sci. 2007, 9, 608-612.

198. Jia, W.Y.; Yuan, H.B.; Lu, L.Z.; Liu, H.M.; Yen, W.M. Crystal growth and characterization of $\mathrm{Eu}^{2+}, \mathrm{Dy}^{3+}: \mathrm{SrAl}_{2} \mathrm{O}_{4}$ and $\mathrm{Eu}^{2+}, \mathrm{Nd}^{3+}: \mathrm{CaAl}_{2} \mathrm{O}_{4}$ by the LHPG method. J. Cryst. Growth 1999, 200, 179-184.

199. Aitasalo, T.; Hassinen, J.; Holsa, J.; Laamanen, T.; Lastusaari, M.; Malkamaki, M.; Niittykoski, J.; Novak, P. Synchrotron radiation investigations of the $\mathrm{Sr}_{2} \mathrm{MgSi}_{2} \mathrm{O}_{7}: \mathrm{Eu}^{2+}, \mathrm{R}^{3+}$ persistent luminescence materials. J. Rare Earths 2009, 27, 529-538.

200. Van den Eeckhout, K.; Smet, P.F.; Poelman, D. Persistent luminescence in $\mathrm{Eu}^{2+}$ doped compounds: a review. Materials 2010, 3, 2536-2566.

201. Poelman, D.; Avci, N.; Smet, P.F. Measured luminance and visual appearance of multi-color persistent phosphors. Opt. Express 2009, 17, 358-364.

202. Rea, M.S.; Bullough, J.D. Making the move to a unified system of photometry. Lighting Res. Technol. 2007, 39, 393-403.

203. Van den Eeckhout, K.; Smet, P.F.; Poelman, D. Persistent luminescence in rare-earth codoped $\mathrm{Ca}_{2} \mathrm{Si}_{5} \mathrm{~N}_{8}: \mathrm{Eu}^{2+}$. J. Lumines. 2009, 129, 1140-1143.

204. Hu, Y.S.; Zhuang, W.D.; Ye, H.Q.; Zhang, S.S.; Fang, Y.; Huang, X.W. Preparation and luminescent properties of $\left(\mathrm{Ca}_{1-\mathrm{x}} \mathrm{Sr}_{\mathrm{x}}\right) \mathrm{S}: \mathrm{Eu}^{2+}$ red-emitting phosphor for white LED. J. Lumines. 2005, 111, 139-145.

205. Duan, X.X.; Huang, S.H.; You, F.T.; Kang, K. Hydrothermal preparation and persistence characteristics of nanosized phosphor SrS: $\mathrm{Eu}^{2+}, \mathrm{Dy}^{3+}$. J. Rare Earths 2009, 27, 43-46.

206. Fang, M.; Wang, H.Q.; Tan, X.L.; Cheng, B.C.; Zhang, L.D.; Xiao, Z.D. One-dimensional hollow SrS nanostructure with red long-lasting phosphorescence. J. Alloy. Compd. 2008, 457, 413-416.

207. Jia, D.D.; Zhu, J.; Wu, B.Q. Influence of co-doping with Cl- on the luminescence of $\mathrm{CaS}: \mathrm{Eu}^{2+}$. J. Electrochem. Soc. 2000, 147, 3948-3952.

208. Jia, D.D. Enhancement of long-persistence by Ce co-doping in $\mathrm{CaS}: \mathrm{Eu}^{2+}, \mathrm{Tm}^{3+}$ red phosphor. $J$. Electrochem. Soc. 2006, 153, H198-H201.

209. Jia, D.D.; Jia, W.Y.; Evans, D.R.; Dennis, W.M.; Liu, H.M.; Zhu, J.; Yen, W.M. Trapping processes in $\mathrm{CaS}: \mathrm{Eu}^{2+}, \mathrm{Tm}^{3+}$. J. Appl. Phys. 2000, 88, 3402-3407.

210. Tamura, Y.; Shibukawa, A. Optical studies of CaS:Eu,Sm infrared stimulable phosphors. Jpn. J. Appl. Phys. Part 1 1993, 32, 3187-3196.

211. Weidner, M.; Osvet, A.; Schierning, G.; Batentschuka, M.; Winnackera, A. Influence of dopant compounds on the storage mechanism of $\mathrm{CaS}: \mathrm{Eu}^{2+}, \mathrm{Sm}^{3+}$. J. Appl. Phys. 2006, 100, 5. 
212. He, Z.Y.; Wang, Y.S.; Sun, L.; Xu, X.R. Optical absorption studies on the trapping states of CaS : Eu,Sm. J. Phys.-Condes. Matter 2001, 13, 3665-3675.

213. Wu, J.P.; Newman, D.; Viney, I.V.F. Study on relationship of luminescence in CaS : Eu,Sm and dopants concentration. J. Lumines. 2002, 99, 237-245.

214. Jia, D.D.; Zhu, J.; Wu, B.Q. Improvement of persistent phosphorescence of $\mathrm{Ca}_{0.9} \mathrm{Sr}_{0.1} \mathrm{~S}: \mathrm{Bi}^{3+}$ by codoping $\mathrm{Tm}^{3+}$. J. Lumines. 2000, 91, 59-65.

215. Hidaka, C.; Shiino, M.; Takizawa, T. Role of rare earth elements as co-activators on both PL and afterglow of CaGa2S4:Eu. In Physica Status Solidi C - Current Topics in Solid State Physics, Vol 6, No 5; Sadewasser, S., AbouRas, D., Lake, B., Schock, H.W., Eds.; Wiley-V C H Verlag Gmbh: Weinheim, 2009; Volume 6, pp. 1166-1169.

216. Brus, L.E. Electron Electron and Electron-Hole Interactions in Small Semiconductor Crystallites - the Size Dependence of the Lowest Excited Electronic State. J. Chem. Phys. 1984, 80, 4403-4409.

217. Yu, W.W.; Peng, X.G. Formation of high-quality CdS and other II-VI semiconductor nanocrystals in noncoordinating solvents: Tunable reactivity of monomers. Angew. Chem.-Int. Edit. 2002, 41, 2368-2371.

218. Peng, Z.A.; Peng, X.G. Formation of high-quality CdTe, CdSe, and CdS nanocrystals using CdO as precursor. J. Am. Chem. Soc. 2001, 123, 183-184.

219. Reiss, P.; Protiere, M.; Li, L. Core/Shell Semiconductor Nanocrystals. Small 2009, 5, 154-168.

220. Michalet, X.; Pinaud, F.F.; Bentolila, L.A.; Tsay, J.M.; Doose, S.; Li, J.J.; Sundaresan, G.; Wu, A.M.; Gambhir, S.S.; Weiss, S. Quantum dots for live cells, in vivo imaging, and diagnostics. Science 2005, 307, 538-544.

221. Gill, R.; Zayats, M.; Willner, I. Semiconductor quantum dots for bioanalysis. Angew. Chem.-Int. Edit. 2008, 47, 7602-7625.

222. Tan, Z.N.; Zhang, F.; Zhu, T.; Xu, J.; Wang, A.Y.; Dixon, D.; Li, L.S.; Zhang, Q.; Mohney, S.E.; Ruzyllo, J. Bright and color-saturated emission from blue light-emitting diodes based on solution-processed colloidal nanocrystal quantum dots. Nano Lett. 2007, 7, 3803-3807.

223. Bourdakos, K.N.; Dissanayake, D.M.N.M.; Lutz, T.; Silva, S.R.P.; Curry, R.J. Highly efficient near-infrared hybrid organic-inorganic nanocrystal electroluminescence device. Appl. Phys. Lett. 2008, 92, 153311.

224. Anikeeva, P.O.; Halpert, J.E.; Bawendi, M.G.; Bulovic, V. Quantum Dot Light-Emitting Devices with Electroluminescence Tunable over the Entire Visible Spectrum. Nano Lett. 2009, 9, 2532-2536.

225. Rogach, A.L.; Gaponik, N.; Lupton, J.M.; Bertoni, C.; Gallardo, D.E.; Dunn, S.; Pira, N.L.; Paderi, M.; Repetto, P.; Romanov, S.G.; O'Dwyer, C.; Torres, C.M.S.; Eychmuller, A. Lightemitting diodes with semiconductor nanocrystals. Angew. Chem.-Int. Edit. 2008, 47, 6538-6549.

226. Eisler, H.J.; Sundar, V.C.; Bawendi, M.G.; Walsh, M.; Smith, H.I.; Klimov, V. Color-selective semiconductor nanocrystal laser. Appl. Phys. Lett. 2002, 80, 4614-4616.

227. Hoogland, S.; Sukhovatkin, V.; Howard, I.; Cauchi, S.; Levina, L.; Sargent, E.H. A solutionprocessed $1.53 \mathrm{mu} \mathrm{m}$ quantum dot laser with temperature-invariant emission wavelength. Opt. Express 2006, 14, 3273-3281. 
228. Chan, Y.; Steckel, J.S.; Snee, P.T.; Caruge, J.M.; Hodgkiss, J.M.; Nocera, D.G.; Bawendi, M.G. Blue semiconductor nanocrystal laser. Appl. Phys. Lett. 2005, 86, 073102.

229. Bera, D.; Qian, L.; Tseng, T.-K.; Holloway, P.H. Quantum Dots and Their Multimodal Applications: A Review. Materials 2010, 3, 2260-2345.

230. Efros, A.L.; Efros, A.L. Interband Absorption of Light in a Semiconductor Sphere. Soviet Physics Semiconductors-Ussr 1982, 16, 772-775.

231. Brus, L. Electronic Wave-Functions in Semiconductor Clusters - Experiment and Theory. $J$. Phys. Chem. 1986, 90, 2555-2560.

232. Henglein, A. Small-Particle Research - Physicochemical Properties of Extremely Small Colloidal Metal and Semiconductor Particles. Chem. Rev. 1989, 89, 1861-1873.

233. Rossetti, R.; Hull, R.; Gibson, J.M.; Brus, L.E. Excited Electronic States and Optical-Spectra of Zns and Cds Crystallites in the Almost-Equal-to-15 to 50-a Size Range - Evolution from Molecular to Bulk Semiconducting Properties. J. Chem. Phys. 1985, 82, 552-559.

234. Rossetti, R.; Hull, R.; Gibson, J.M.; Brus, L.E. Hybrid Electronic-Properties between the Molecular and Solid-State Limits - Lead Sulfide and Silver-Halide Crystallites. J. Chem. Phys. 1985, 83, 1406-1410.

235. Wang, Y.; Herron, N. Quantum Size Effects on the Exciton Energy of CdS Clusters. Phys. Rev. $B$ 1990, 42, 7253-7255.

236. Wang, Y.; Suna, A.; Mahler, W.; Kasowski, R. Pbs in Polymers - from Molecules to Bulk Solids. J. Chem. Phys. 1987, 87, 7315-7322.

237. Ekimov, A.I.; Efros, A.L.; Onushchenko, A.A. Quantum Size Effect in Semiconductor Microcrystals. Solid State Commun. 1985, 56, 921-924.

238. Kang, I.; Wise, F.W. Electronic structure and optical properties of $\mathrm{PbS}$ and $\mathrm{PbSe}$ quantum dots. J. Opt. Soc. Am. B-Opt. Phys. 1997, 14, 1632-1646.

239. Potter, B.G.; Simmons, J.H. Quantum Size Effects in Optical-Properties of Cds-Glass Composites. Phys. Rev. B 1988, 37, 10838-10845.

240. Wise, F.W. Lead salt quantum dots: The limit of strong quantum confinement. Accounts Chem. Res. 2000, 33, 773-780.

241. Murray, C.B.; Norris, D.J.; Bawendi, M.G. Synthesis and Characterization of Nearly Monodisperse CdE $(\mathrm{E}=\mathrm{S}, \mathrm{Se}, \mathrm{Te})$ Semiconductor Nanocrystallites. J. Am. Chem. Soc. 1993, 115, 8706-8715.

242. Adachi, S. Optical Properties of Crystalline and Amorphous Semiconductors; Kluwer Academic: Boston, MA, USA, 1999.

243. Cao, Y.C.; Wang, J.H. One-pot synthesis of high-quality zinc-blende CdS nanocrystals. J. Am. Chem. Soc. 2004, 126, 14336-14337.

244. Steckel, J.S.; Zimmer, J.P.; Coe-Sullivan, S.; Stott, N.E.; Bulovic, V.; Bawendi, M.G. Blue luminescence from $(\mathrm{CdS}) \mathrm{ZnS}$ core-shell nanocrystals. Angew. Chem.-Int. Edit. 2004, 43, 2154-2158.

245. Protiere, M.; Reiss, P. Facile synthesis of monodisperse $\mathrm{ZnS}$ capped CdS nanocrystals exhibiting efficient blue emission. Nanoscale Res. Lett. 2006, 1, 62-67. 
246. Acar, H.Y.; Kas, R.; Yurtsever, E.; Ozen, C.; Lieberwirth, I. Emergence of 2MPA as an Effective Coating for Highly Stable and Luminescent Quantum Dots. J. Phys. Chem. C 2009, 113, 10005-10012.

247. Cademartiri, L.; Bertolotti, J.; Sapienza, R.; Wiersma, D.S.; von Freymann, G.; Ozin, G.A. Multigram scale, solventless, and diffusion-controlled route to highly monodisperse $\mathrm{PbS}$ nanocrystals. J. Phys. Chem. B 2006, 110, 671-673.

248. Hyun, B.R.; Chen, H.Y.; Rey, D.A.; Wise, F.W.; Batt, C.A. Near-infrared fluorescence imaging with water-soluble lead salt quantum dots. J. Phys. Chem. B 2007, 111, 5726-5730.

249. Luther, J.M.; Law, M.; Beard, M.C.; Song, Q.; Reese, M.O.; Ellingson, R.J.; Nozik, A.J. Schottky Solar Cells Based on Colloidal Nanocrystal Films. Nano Lett. 2008, 8, 3488-3492.

250. McDonald, S.A.; Konstantatos, G.; Zhang, S.G.; Cyr, P.W.; Klem, E.J.D.; Levina, L.; Sargent, E.H. Solution-processed $\mathrm{PbS}$ quantum dot infrared photodetectors and photovoltaics. Nat. Mater. 2005, 4, 138-U114.

251. Sargent, E.H. Infrared photovoltaics made by solution processing. Nat. Photonics 2009, 3, 325-331.

252. Nozik, A.J. Exciton multiplication and relaxation dynamics in quantum dots: Applications to ultrahigh-efficiency solar photon conversion. Inorg. Chem. 2005, 44, 6893-6899.

253. Rauch, T.; Boberl, M.; Tedde, S.F.; Furst, J.; Kovalenko, M.V.; Hesser, G.N.; Lemmer, U.; Heiss, W.; Hayden, O. Near-infrared imaging with quantum-dot-sensitized organic photodiodes. Nat. Photonics 2009, 3, 332-336.

254. Moreels, I.; De Geyter, B.; Van Thourhout, D.; Hens, Z. Transmission of a quantum-dot-siliconon-insulator hybrid notch filter. J. Opt. Soc. Am. B-Opt. Phys. 2009, 26, 1243-1247.

255. Hines, M.A.; Scholes, G.D. Colloidal $\mathrm{PbS}$ nanocrystals with size-tunable near-infrared emission: Observation of post-synthesis self-narrowing of the particle size distribution. Adv. Mater. 2003, 15, 1844-1849.

256. Joo, J.; Na, H.B.; Yu, T.; Yu, J.H.; Kim, Y.W.; Wu, F.X.; Zhang, J.Z.; Hyeon, T. Generalized and facile synthesis of semiconducting metal sulfide nanocrystals. J. Am. Chem. Soc. 2003, 125, 11100-11105.

257. Lin, W.; Fritz, K.; Guerin, G.; Bardajee, G.R.; Hinds, S.; Sukhovatkin, V.; Sargent, E.H.; Scholes, G.D.; Winnik, M.A. Highly luminescent lead sulfide nanocrystals in organic solvents and water through ligand exchange with poly(acrylic acid). Langmuir 2008, 24, 8215-8219.

258. Warner, J.H.; Thomsen, E.; Watt, A.R.; Heckenberg, N.R.; Rubinutein-Dunlop, H. Timeresolved photoluminescence spectroscopy of ligand-capped PbS nanocrystals. Nanotechnology 2005, 16, 175-179.

259. Oron, D.; Aharoni, A.; de Mello Donega, C.; van Rijssel, J.; Meijerink, A.; Banin, U. Universal Role of Discrete Acoustic Phonons in the Low-Temperature Optical Emission of Colloidal Quantum Dots. Phys. Rev. Lett. 2009, 102, 177402.

260. Darugar, Q.; Qian, W.; El-Sayed, M.A. Observation of optical gain in solutions of CdS quantum dots at room temperature in the blue region. Appl. Phys. Lett. 2006, 88, 261108.

261. van Driel, A.F.; Allan, G.; Delerue, C.; Lodahl, P.; Vos, W.L.; Vanmaekelbergh, D. Frequencydependent spontaneous emission rate from CdSe and CdTe nanocrystals: Influence of dark states. Phys. Rev. Lett. 2005, 95, 236804. 
262. Moreels, I.; Lambert, K.; Smeets, D.; De Muynck, D.; Nollet, T.; Martins, J.C.; Vanhaecke, F.; Vantomme, A.; Delerue, C.; Allan, G.; Hens, Z. Size-Dependent Optical Properties of Colloidal PbS Quantum Dots. ACS Nano 2009, 3, 3023-3030.

263. Klimov, V.I.; Mikhailovsky, A.A.; Xu, S.; Malko, A.; Hollingsworth, J.A.; Leatherdale, C.A.; Eisler, H.J.; Bawendi, M.G. Optical gain and stimulated emission in nanocrystal quantum dots. Science 2000, 290, 314-317.

264. Malko, A.V.; Mikhailovsky, A.A.; Petruska, M.A.; Hollingsworth, J.A.; Htoon, H.; Bawendi, M.G.; Klimov, V.I. From amplified spontaneous emission to microring lasing using nanocrystal quantum dot solids. Appl. Phys. Lett. 2002, 81, 1303-1305.

265. Chen, G.; Rapaport, R.; Fuchs, D.T.; Lucas, L.; Lovinger, A.J.; Vilan, S.; Aharoni, A.; Banin, U. Optical gain from InAs nanocrystal quantum dots in a polymer matrix. Appl. Phys. Lett. 2005, $87,251108$.

266. Schaller, R.D.; Petruska, M.A.; Klimov, V.I. Tunable near-infrared optical gain and amplified spontaneous emission using PbSe nanocrystals. J. Phys. Chem. B 2003, 107, 13765-13768.

267. Sukhovatkin, V.; Musikhin, S.; Gorelikov, I.; Cauchi, S.; Bakueva, L.; Kumacheva, E.; Sargent, E.H. Room-temperature amplified spontaneous emission at $1300 \mathrm{~nm}$ in solution-processed $\mathrm{PbS}$ quantum-dot films. Opt. Lett. 2005, 30, 171-173.

268. Bakueva, L.; Musikhin, S.; Hines, M.A.; Chang, T.W.F.; Tzolov, M.; Scholes, G.D.; Sargent, E.H. Size-tunable infrared (1000-1600 nm) electroluminescence from $\mathrm{PbS}$ quantum-dot nanocrystals in a semiconducting polymer. Appl. Phys. Lett. 2003, 82, 2895-2897.

269. Coe, S.; Woo, W.K.; Bawendi, M.; Bulovic, V. Electroluminescence from single monolayers of nanocrystals in molecular organic devices. Nature 2002, 420, 800-803.

270. Konstantatos, G.; Huang, C.J.; Levina, L.; Lu, Z.H.; Sargent, E.H. Efficient infrared electroluminescent devices using solution-processed colloidal quantum dots. Adv. Funct. Mater. 2005, 15, 1865-1869.

271. Hamaguchi, S.; Yamamoto, T.; Kobayashi, M. Synthesis of Ternary Compound Sulfide Nanoparticles. Jpn. J. Appl. Phys. 2009, 48, 04C131

272. Yang, H.S.; Santra, S.; Holloway, P.H. Syntheses and applications of Mn-doped II-VI semiconductor nanocrystals. J. Nanosci. Nanotechnol. 2005, 5, 1364-1375.

273. Bol, A.A.; Meijerink, A. Luminescence quantum efficiency of nanocrystalline $\mathrm{ZnS}: \mathrm{Mn}^{2+} .1$. Surface passivation and $\mathrm{Mn}^{2+}$ concentration. J. Phys. Chem. B 2001, 105, 10197-10202.

274. Bol, A.A.; Meijerink, A. Long-lived $\mathrm{Mn}^{2+}$ emission in nanocrystalline $\mathrm{ZnS}: \mathrm{Mn}^{2+}$. Phys. Rev. $B$ 1998, 58, 15997-16000.

275. Bhargava, R.N.; Gallagher, D.; Hong, X.; Nurmikko, A. Optical properties of manganese doped nanocrystals of ZnS. Phys. Rev. Lett. 1994, 72, 416-419.

276. Quan, Z.W.; Wang, Z.L.; Yang, P.P.; Lin, J.; Fang, J.Y. Synthesis and characterization of highquality $\mathrm{ZnS}, \mathrm{ZnS}: \mathrm{Mn}^{2+}$, and $\mathrm{ZnS}: \mathrm{Mn}^{2+} / \mathrm{ZnS}$ (core/shell) luminescent nanocrystals. Inorg. Chem. 2007, 46, 1354-1360.

277. Chen, W.; Zhang, J.Z.; Joly, A.G. Optical properties and potential applications of doped semiconductor nanoparticles. J. Nanosci. Nanotechnol. 2004, 4, 919-947.

278. Biswas, S.; Kar, S. Fabrication of $\mathrm{ZnS}$ nanoparticles and nanorods with cubic and hexagonal crystal structures: a simple solvothermal approach. Nanotechnology 2008, 19, 045710. 
279. Chen, W.; Malm, J.O.; Zwiller, V.; Huang, Y.N.; Liu, S.M.; Wallenberg, R.; Bovin, J.O.; Samuelson, L. Energy structure and fluorescence of $\mathrm{Eu}^{2+}$ in $\mathrm{ZnS}: \mathrm{Eu}$ nanoparticles. Phys. Rev. $B$ 2000, 61, 11021-11024.

280. Cheng, B.C.; Wang, Z.G. Synthesis and optical properties of europium-doped ZnS: Long-lasting phosphorescence from aligned nanowires. Adv. Funct. Mater. 2005, 15, 1883-1890.

281. Sun, L.D.; Yan, C.H.; Liu, C.H.; Liao, C.S.; Li, D.; Yu, J.Q. Study of the optical properties of $\mathrm{Eu}^{3+}$-doped ZnS nanocrystals. J. Alloy. Compd. 1998, 275, 234-237.

282. Bol, A.A.; van Beek, R.; Meijerink, A. On the incorporation of trivalent rare earth ions in II-VI semiconductor nanocrystals. Chem. Mat. 2002, 14, 1121-1126.

283. Wood, V.; Halpert, J.E.; Panzer, M.J.; Bawendi, M.G.; Bulovic, V. Alternating Current Driven Electroluminescence from ZnSe/ZnS:Mn/ZnS Nanocrystals. Nano Lett. 2009, 9, 2367-2371.

284. Toyama, T.; Hama, T.; Adachi, D.; Nakashizu, Y.; Okamoto, H. An electroluminescence device for printable electronics using coprecipitated ZnS:Mn nanocrystal ink. Nanotechnology 2009, 20, 055203.

285. Sawada, N.; Chen, Y.; Isobe, T. Low-temperature synthesis and photoluminescence of IIA-VIB nano-phosphors doped with rare earth ions. J. Alloy. Compd. 2006, 408, 824-827.

286. Sun, B.Q.; Yi, G.S.; Chen, D.P.; Zhou, Y.X.; Cheng, J. Synthesis and characterization of strongly fluorescent europium-doped calcium sulfide nanoparticles. J. Mater. Chem. 2002, 12, 1194-1198.

287. Anila, E.I.; Aravind, A.; Jayaraj, M.K. The photoluminescence of SrS : Cu nanophosphor. Nanotechnology 2008, 19, 145604.

288. Wang, C.R.; Tang, K.B.; Yang, Q.; An, C.H.; Hai, B.; Shen, G.Z.; Qian, Y.T. Blue-light emission of nanocrystalline $\mathrm{CaS}$ and $\mathrm{SrS}$ synthesized via a solvothermal route. Chem. Phys. Lett. 2002, 351, 385-390.

289. Wang, C.R.; Tang, K.B.; Yang, Q.; Qian, Y.T. Preparation and photoluminescence of CaS : Bi, $\mathrm{CaS}: \mathrm{Ag}, \mathrm{CaS}: \mathrm{Pb}$, and $\mathrm{Sr}_{1-\mathrm{x}} \mathrm{Ca}_{\mathrm{x}} \mathrm{S}$ nanocrystallites. J. Electrochem. Soc. 2003, 150, G163-G166.

290. Korthout, K.; Smet, P.F.; Poelman, D. Whispering gallery modes in micron-sized SrS:Eu octahedrons. Appl. Phys. Lett. 2009, 94, 051104.

291. Smet, P.F.; Poelman, D. Templated growth of textured and luminescent CaS:Eu thin films by a low-temperature solvothermal process. J. Phys. D-Appl. Phys. 2009, 42, 095306.

(C) 2010 by the authors; licensee MDPI, Basel, Switzerland. This article is an open-access article distributed under the terms and conditions of the Creative Commons Attribution license (http://creativecommons.org/licenses/by/3.0/). 